\title{
Citrulline : a serological parameter for monitoring epithelial small bowel cancer treatment induced injury
}

Citation for published version (APA):

Lutgens, L. C. H. W. (2005). Citrulline : a serological parameter for monitoring epithelial small bowel cancer treatment induced injury. [Doctoral Thesis, Maastricht University]. Maastricht University. https://doi.org/10.26481/dis.20051202ll

Document status and date:

Published: 01/01/2005

DOI:

10.26481/dis.20051202Il

Document Version:

Publisher's PDF, also known as Version of record

\section{Please check the document version of this publication:}

- A submitted manuscript is the version of the article upon submission and before peer-review. There can be important differences between the submitted version and the official published version of record.

People interested in the research are advised to contact the author for the final version of the publication, or visit the DOI to the publisher's website.

- The final author version and the galley proof are versions of the publication after peer review.

- The final published version features the final layout of the paper including the volume, issue and page numbers.

Link to publication

\footnotetext{
General rights rights.

- You may freely distribute the URL identifying the publication in the public portal. please follow below link for the End User Agreement:

www.umlib.nl/taverne-license

Take down policy

If you believe that this document breaches copyright please contact us at:

repository@maastrichtuniversity.nl

providing details and we will investigate your claim.
}

Copyright and moral rights for the publications made accessible in the public portal are retained by the authors and/or other copyright owners and it is a condition of accessing publications that users recognise and abide by the legal requirements associated with these

- Users may download and print one copy of any publication from the public portal for the purpose of private study or research.

- You may not further distribute the material or use it for any profit-making activity or commercial gain

If the publication is distributed under the terms of Article $25 \mathrm{fa}$ of the Dutch Copyright Act, indicated by the "Taverne" license above, 



\section{CITRULLINE}

a serological parameter for monitoring epithelial small bowel cancer treatment induced injury

Ludy Lutgens 
Cover design: my princess, Romy.

The work presented in chapter 9 was supported by a grant from the European Society of Parenteral and Enteral Nutrtion.

Financial support for the publication of this thesis was provided by Nucletron

BSD Medical 


\section{CITRULLINE}

a serological parameter for monitoring epithelial small bowel cancer treatment induced injury

\section{PROEFSCHRIFT}

ter verkrijging van de graad van doctor aan de Universiteit Maastricht, op gezag van de Rector Magnificus,

Prof.mr. G.P.M.F. Mols

volgens het besluit van het College van Decanen, in het openbaar te verdedigen

op vrijdag 2 december 2005 om 14.00 uur

door

\section{Ludy Lutgens}




\section{PROMOTORES:}

Prof. dr. Ph. Lambin

Prof. dr. M.F. von Meyenfeldt

\section{CO-PROMOTORES:}

Dr. N.E.P. Deutz

Prof. dr. B.G. Wouters

\section{BEOORDELINGSCOMMISSIE:}

Prof. dr. P.B. Soeters (voorzitter)

Prof. dr. M. Hauer-Jensen (University of Arkansas, USA)

Prof. dr. F.C.S. Ramaekers

Prof. dr. H.C. Schouten

Dr. M.C. Vozenin-Brotons (Institut Gustave-Roussy, France) 
"The Road goes ever on and on Down from the door where it began.

Now far ahead the Road has gone, And I must follow, if I can, Pursuing it with eager feet, Until it joins some larger way Where many paths and errands meet. And whither then? I cannot say."

J.R.R. Tolkien

\author{
For \\ Yvonne \\ Maurice \& Romy
}





\section{Contents}

Introduction

Chapter $I$ Small bowel and radiation: A dangerous liaison I0

$\begin{array}{lll}\text { Chapter } 2 \quad \text { Small bowel epithelium } & 14\end{array}$

$\begin{array}{ll}\text { Chapter 3 Hypothesis } & 27\end{array}$

Chapter $4 \quad$ Pilot studies $\quad 30$

$\begin{array}{ll}\text { References } & 35\end{array}$

Chapter 5 Citrulline: A physiological marker enabling quantitation 49 and monitoring of epithelial radiation-induced small bowel damage. Int J Radiat Oncol Biol Phys 2003; 57: 1067-1074.

Chapter 6 Keratinocyte growth factor ameliorates acute graft-versushost disease in a novel nonmyeloablative haploidentical transplantation model.

Bone Marnow Transplant 2005. (in press)

Chapter 7 Citrulline: A potentially simple quantitative marker of intestinal epithelial damage following myeloablative therapy Bone Marrow Tramsplant 2004 Aug; 34 (3): 193-196.

Chapter 8 Monitoring myelo-ablative therapy induced small bowel toxicity by serum citrulline concentration: a comparison with sugar permeability tests.

Cancer 2005; 103:191-199.

Chapter 9 Plasma citrulline concentration: A surrogate endpoint for radiation-induced mucosal atrophy of the small bowel. A leasibility study in 23 patients. Int J Radiat Oncol Biol Phys 2004; 60 (1):275-85. 
Chapter 10 General discussion and future directions

List of abbreviations

Summary

Samenvatting

135

Dankwoord / Acknowledgement

138

Curriculum Vitae

141 


\section{Introduction}

Research begins with defining valid and representative endpoints. The small bowel has been a topic in radiation research for many decades. The clinical relevance of cancer treatment induced small bowel injury ${ }^{1.2}$ and the use of small bowel tissue as a unique biological model ${ }^{3}$ are important reasons for this long lasting and ongoing interest. 


\section{Chapter 1}

SMALL BOWEL AND RADIATION:

A DANGEROUS LIAISON 
lonizing radiation is used in about half of all cancer patients, often with curative intent. An. increased use of multiple treatment modalities is characteristic for current developments in curative cancer treatment. This strategy has yielded superior treatment results in a variety of solid tumors albeit treatment related acute toxicity is increased as well." ${ }^{4}$ Moreover, treatment related morbidity is an important limiting factor for innovative cancer treatments. In case of radiation treatment for pelvic and/or abdominal cancers the small bowel is an important dose-limiting organ with regard to both early and late treatment related morbidity. The required tumoricidal doses are generally much higher than the tolerance dose of this radiosensitive organ.

Clinical symptoms of acute radiation enteritis inchde anorexia, nausea, vomiting, abdominal cramps and diarhea. These symptoms may occur immediately following the start of treatment, although more usually, radiation sequellae become manifest during the 2nd or 3rd week of fractionated treatment and lasting 2-6 weeks following treatment. Whereas very early symptoms are attributable to altered intestimal motor acitivity, mucosal injury is the prominent feature underlying symptoms later on during the course of treatment, although altered intestinal motor activity is another contributing factor throughout the treatment course and following treatment. ${ }^{810}$ The incidence of acute radiation-induced symptoms largely depends on the radiated volume of bowel and radiation dose. Approximately two thirds of patients receiving post-operative fractionated pelvic radiotherapy for endometrial cancer experienced treatment related symptoms of any grade, whereas toxicity related treatment interruption was necessary in $2 \%$ of patients. ${ }^{11}$ During consolidative fractionated whole abdominal radiotherapy following cytoreductive surgery and adjuvant chemotherapy about half of all patients experienced treatment related intestinal toxicity of any grade, with $23 \%$ graded mild, $26 \%$ graded moderate and $3 \%$ graded as severe diarbea (the latter including bloody stool or bowel obstruction). ${ }^{12}$ The lack of consistency in toxicity grading systems used precludes a more accurate estimate of the magnitude of this clinical problem.

A reliable estimate of the incidence of late small bowel injury is hampered by several factors. First, not all histological changes are clinically manifest. For example, subclinical injury may become manifest following stress-full situations such as surgery. ${ }^{13}$ Secondly, subtle symptoms and signs of chronic radiation enteropathy are frequently not reported and remain unknown unless specifically looked for. Thus a lactase deficiency and a consequential lactose malabsorption may be circumvented by the patient through a reduced intake of dairy products ${ }^{14}$ and may be objectivated by a reduced dietary calcium intake. ${ }^{15}$ Hence, several manifestations of radiation enteritis, considered to be self-limiting mucosal disorders, have been shown to be persistent functional changes in a considerable percentage of patients using investigative techniques. ${ }^{14-18}$ Thirdly, in most systems used for recording and assessing morbidity, the frequency of occurrence of maximal late damage is scored. ${ }^{19}$ In doing so, information about morbidity of a lower degree is lost, which nevertheless may severely influence the patients quality of life. Several risk factors for radiation enteropathy have been reported in the literature, mainly applying to late severe injuries. Treatment related factors are the total dose ${ }^{20,21}$, dose per fraction, ${ }^{22}$ volume of small bowel, ${ }^{20}$ 
treatment technique, ${ }^{22,} 23$ and previous abdominal or pelvic surgery. ${ }^{20,} 22,24$ Major constitutional factors are pre-existent pelvic inflammatory disease, diabetes mellitus, hypertension, pre-existent vascular disease, body habitus and age, $22,25,26$

Traditionally, acute and chronic radiation injury have been regardied as unrelated events which are characterized a different time course for clinical expression. ${ }^{27,28}$ Thus, epithelial radiation effects have been associated with acute radiation injury whereas stromal radiation effects such as fibrosis and vascular sclerosis have been associated with late radiation injury. ${ }^{29}$ Radiobiological ${ }^{28,30-37}$ and clinical data obtained more recently ${ }^{38-411}$ suggest an additional mechanism for late radiation injury that links radiation effects in both tissue compartments. An acute inflammatory stromal reaction, initiated by direct radiation effects on stromal elements, is sustained by an epithelial cell loss exposing stromal elements to detrimental luminal contents. Stromal fibrosis may thus result from an inappropriate stromal inflammatory response. This type of tissue injury which suggests a causal relationship between acute and late intestinal radiation injury has been termed consequential late radiation injury. $36^{42}$

The pathophysiology of clinical symptoms related to small bowel irradiation is complex with mucosal denudation being one of several events. ${ }^{43}$. ${ }^{45}$ ascular and connective tissue damage are considered main features of late, or delayed, bowel injury. ${ }^{29,46,47}$ The onset of clinical symptoms occurs after a variable latency period, usually 6 months to 5 years, sometimes even longer. ${ }^{46}$ Malabsorption, (intermittent) signs of partial or complete intestinal obstruction, intestinal perforation or -bleeding, and fistulas are all long-term clinical manifestations. The management of delayed radiation enteritis must be based on the exact nature of the injury, the clinical condition of the patient, and the status of the malignant disease. Severe late complications frequently require surgical management. The majority of patients have a wide-spread radiation enteropathy rather then a singlie discrete radiation injury ${ }^{48-50}$ which probably accounts for a relatively high surgical morbidity- and mortality rate and a substantial number of subsequent radiation related bowel complications. ${ }^{51.52}$ Galland et al. ${ }^{51}$ reported $39 \%$ (20/51) and Harling et al ${ }^{52} 23 \%(28 / 124)$ subsequent complications in patients treated for severe radiation enteritis (both small and large bowel injuries were included). Only 34\%-50\% of patients survive without further intestinal complications and RT enteritis was directly or indirectly the cause of death in $23 \%$ - $62 \%$ of patients. ${ }^{51,32}$ Letschert at al. ${ }^{20,53}$ reported incidences of $29 \%$ and $2 \%$ for chronic diarthea and malabsorbtion respectively, in patients treated for rectal carcinoma with postoperative radiation. Severe late injury occurs probably in less than $5 \%{ }^{20,38}$ of nonoperated patients and in between $5 \%$ and $40 \%$ of previously operated patients. ${ }^{20}$

In summary, delayed radiation enteritis is a serious side effect of radiotherapy, which seems to be difficult to control and incurable in a substantial number of patients. However, the incidence of so called "minor symptoms", which may severely influence the patients quality of life, is likely to be underestimated. Epithelial radiation injury is an important causal factor of acute morbidity and a potential contributing factor in delayed radiation 
enteropathy. Hence, strategies aimed at reducing epithelial radiation injury will have a major impact on abdominal and/or pelvic cancer treatment related morbidity, both qualitatively and quantitatively. Furthermore, as epithelial radiation injury to the intestine is increased with new treatment strategies, e.g. chemo-radiotherapy, monitoring of epithelial damage, both during the acute phase and with longer follow-up, will be an essential factor enabling proper determination of the therapeutic gain. 
Chapter 2

SMALL BOWEL EPITHELIUM 


\section{SMALL BOWEL STRUCTURE}

General features of organization can be distinguished throughout the gastrointestinal tract. The inner surface is lined with a mucous membrane, the mucosa, consisting of a superficial layer of epithelium and a supporting layer of loose connective tissue, the lamina propria. The small bowel mucosal morphology is in accordance with its specific function including transport, digestion and absorption of nutrients in addition to a barrier function. The lamina propria consists of connective tissue rich in blood capillaries. This is demarcated by the muscularis mucosae, a thin layer of smooth muscle. The peripheral layer of the intestinal wall consists of a thicker smooth muscle making up the musctularis externa, consisting of an inner circular and outer longitudinal layer with the sympathetic myenteric nerve plexus in between. The layer between the muscularis mucosae and muscularis externa is a layer of loose connective tissue, the submucosa, containing blood vessels, nerves and lymphatics. The external serosal coat consists of a layer of mesothelial cells resting on loose connective tissue. The serosal lining is continuous with the mesenterial leaves at their intestinal attachment.

\section{EPITHELIAL HOMEOSTASIS: PROLIFERATION AND APOPTOSIS}

The luminal surface of the small bowel is lined by a single collumnar epithelial cell layer and is fowled into deep cavities, the crypts of Lieberkuthn. Here, stem cells are located towards the crypt base with an adjacent proliferative zone apical from the stem cells. The epithelial surface is increased by finger-like projections, i.e. villi, covered with differentiated enterocytes. A hierarchical stem cell organization is proposed for the mouse small intestine with all epithelial cells originating from the stem cells in the crypts of Lieberkuihn. A total of 5 differentiated functional cells are derived from these stem cells, the majority being absorptive enterocytes, located along the villi. There is a continuous movement of differentiated cells towards the villus tip where they shed into the Jumen. This continuous cell loss must be replaced at an equal rate in order to maintain the absorptive capacity, i.e. luminal surface area, and epithelial integrity, i.c. barrier function. The villus transit time, the interval between entering the villus base and shedding from the villus tip, is between 2 and 3 days. This continuous process of cell production and cell loss, i.e. epithelial homeostasis, must be exactly balanced and hence, under extremely stringent control, as a decreased proliferation (or increased cell loss) rapidly results in loss of epithelial integrity. It is now generally accepted that control of cell death is equally important, if not more important, for the regulation of epithelial homeostasis than prolliferation. ${ }^{54}$ Apoptosis plays a dual role in the maintenance of epithelial homeostasis. "It has been recognized as an important mechanism for eliminating excess normal cells and (radiation) damaged cells. ${ }^{54,}$, so - 58 Apoptosis of undifferentiated crypt cells occurs at the stem cell zone at a rate of approximately $5-10 \% .{ }^{56,58.59}$ In contrast, on reaching the tip ${ }^{60.63}$ differentiated villus cells will undergo a form of apoptosis termed "anoikis", i.e. cell detachment-induced apoptosis." $\mathrm{Bcl}-2$ family members and $\mathrm{p} 53$ are genes involved in the regulation of apoptosis. ${ }^{54,65,66}$ 
Experiments in $p 53$ knockout mice have shown that spontaneous apoptosis is p53 independent. ${ }^{67}$ For the induction of enterocytic anoikis $\mathrm{p} 38$ is required with distinct isoforms being involved depending on the differentiation-state of the cells.

\section{SMALL INTESTINAL INTERMEDIARY METABOLISM}

The intestinal epithelium provides a barrier and a transport function with respect to luminal contents such as micro-organisms, digestive enzymes and macronutrients. ${ }^{68-70}$ In addition to absorbing food, the small bowel plays an important role in the intermediary metabolism of amino acids, particularly glutamine, citrulline and arginime ${ }^{71,72}$ and other macronutrients, ${ }^{73}$ thereby conditioning the availability of dietary amino acids to extra-intestinal organs. ${ }^{68}$ Moreover, the gut has become recognized as a central organ of metabolic activity during critical illness. Intestinal dysfunction resulting from intestinal disease or injury affects intermediary and inter-organ metabolism. ${ }^{74-76}$ Hence, any factor affecting the intestinal mucosal cell mass will have an impact on protein and amino acid metabolism. ${ }^{74,77-81}$

\section{Small imestinal substrates for oxidative metabolism}

The intestinal intermediary metabolism has been studied extensively. For a long time glucose has been regarded as the major energy source for the gut. ${ }^{82}$ In a large series of ex vivo experiments in rats Windmueller and Spaeth identified glutamine as the quantitatively most important arterial energy source ${ }^{83-86}$ for the rat jejunum in fasted animals. Measurements in different species consistently demonstrated a concentration dependent high rate of intestinal glutamine extraction from the blood. Thus, $25-33 \%$ of the total plasma glutamine is extracted by the small bowel in each single pass. ${ }^{83}$ Whereas the gut epithelial cell has access to substrates from 2 sources, i.e the arterial blood and the gut Jumen, glutamine appears to be the only amino acid extracted by the gut. ${ }^{83}$ Windmueller and Spaeth quantified the relative contribution of different substrates to the oxidative metabolism of the small intestine. They identified 6 arterial substrates accounting for the entire intestinal $\mathrm{CO}_{2}$ production. Glutamine was the single largest contributor $(35 \%)$ with the ketone bodies 3 hydroxybutyrate $(26 \%)$ and acetoacetate $(24 \%)$ being additional major energy sources whereas glucose $(7 \%)$, lactate $(5 \%)$ and un-esterified fatty acids $(3 \%)$ only accounted for $15 \%$ of the substrate used by the small intestine. ${ }^{84}$ Under fed conditions, dietary glutarnate, dietary glucose and arterial glutamine contribute to $36 \%, 6 \%$ and $15 \%$, respectively, of the $\mathrm{CO}_{2}$ production by portal drained viscera (i.e. small and large bowel, stomach, pancreas and spleen). Since the pioneering work of Windmueller and Spaeth during the 1970's it has been demonstrated by many research groups that amino acids are the major fuel for the small bowel epithelium, both under conditions of fasting and feeding, respectively. ${ }^{86,88-93}$ 


\section{Ghutamine or glutamate?}

Glutamine is the most abundant amino acid in plasma and plays a key role in whole body protein and amino acid metabolism. ${ }^{83}$, 94 Organs may be classified as glutamine producers and as glutamine consumers. ${ }^{95}$ Skeletal muscle is by far the most important producer and the small bowel the most important consumer. The gut epithelium has been identified as the predominant site of glutamine uptake and metabolism. ${ }^{83}$ Of all epithelial cellls, enterocytes are the major cells responsible for glutamine utilization. ${ }^{96,97}$

The mucosal glutamine pool of the small intestine is very low. ${ }^{83}$ The first step in enteral glutamine catabolism is the conversion to glutamate and ammonia by the mitochondrial enzyme glutaminase in a non-reversible reaction. ${ }^{98}$ In contrast to glutamine, glutamate is highly compartmentalized. It is one of the most concentrated intracellular and one of the least abundant amino acids in plasma. Whereas the luminal uptake is more rapid and more complete for glutamine, intestinal metabolism is more complete for glutamate. ${ }^{86,90}$

The intestinal uptake of glutamine from the blood varies with the availability of substrate in the lumen. However, the intestinal metabolism of plasma glutamine is sustained during competitive luminal substrate provision, even under conditions of luminal overloading with glutamate. ${ }^{83,86}$

These data suggest that glutamine provides the enterocyt with a large requirement of intracellular glutamate but also that both amino acids may have different functional roles.

\section{Metabolic fate of glutamine}

The metabolic fate of glutamine was studied extensively in animals ${ }^{83,}, 86_{2}, 92$ and has been confirmed in humans. ${ }^{89,99-104}$ The gut epithelial cell has access to glutamine from the arterial blood and the gut lumen, respectively. ${ }^{83}$ The metabolic fate of glutamine from both routes is nearly identical indicating a common metabolic pool ${ }^{86}$ Major glutamine carbon products are $\mathrm{CO}_{2}(55-65 \%)$, lactate $(8-16 \%)$, citrate $(2-7 \%)$, citrulline (4-6\%), proline (5$6 \%)$, alanine $(0.5-4 \%)$ and ornithine $(0.5-2 \%)$. Major glutamine nitrogen products are ammonia $(23-36 \%)$, alanine $(33-36 \%)$, citrulline $(10-34 \%)$ and proline $(7-10 \%)$.

\section{Citrulline, an endproduct of glutamine metabolism}

Of the metabolic products of glutamine, citrulline was identified as an endproduct of nitrogen metabolism in the rat intestine accounting for $27.6 \%$ of the metabolised glutamine. ${ }^{83}, 84,92$ Citrulline is an intermediate in the urea cycle. ${ }^{105,606}$ This cycle is comprised of 5 enzymes, being 2 mitochondrial (carbamoyl phosphate synthetase I (CPSI) and ornithine carbamoyltransferase (OCT)) and 3 cytosolic enzymes (arginino succinate synthethase (ASS), arginino succinate lyase (ASL) and arginase). Windmueller and Spaeth ${ }^{71}$ did not detect any urea-cycle intermediate following luminal administration of citrulline to the intestinal mucosal cells whereas $>97 \%$ of the radioacitivity was recovered in the intestinal venous blood by $85 \mathrm{~min}$. Based on these results they concluded that intestinal mucosal cells contain an incomplete urea cycle. However, others suggested a complete urea 
cycle in rodent enteroctyes. ${ }^{107 .} 108 \%$ Wu finally demonstrated urea synthesis in porcine enterocytes from ammonia, glutamine and arginine in a dose-dependent manner, thus providing the evidence that, in addition to periportal hepatocytes, ${ }^{105}$ small intestinal enterocytes ${ }^{97,109}$ contain a complete urea cycle. Whereas an activity was observed of all urea cycle enzymes, the activity of OCT was by far the highest of all (i.e. a factor 10-20). ${ }^{109}$ In contrast to hepatocytes in which CPSI and ASS are considered the regulating enzymes due to an exceedingly high arginase activity, in enterocytes the arginase activity seems to be the limiting factor for the urea synthesis. ${ }^{109}$ Taken the high rate of glutamine/glutamate metabolism $86,89,92,101$ and the relative abundant OCT activity ${ }^{109}$ in small intestinal enterocytes, the majority of citrulline produced from glutamine/glutamate ${ }^{71,97}$ will not be further metabolised in the urea cycle but instead released in the portal circulation. Thus only $5 \%$ of the glutamine-derived ammonia was converted to urea indicating the low capacity of urea synthesis from glutamine (or ammonia) in enterocytes. ${ }^{109}$ Hence, although the small intestinal mucosa contains a metabolically significant urea cycle, the liver is without doubt the major organ for urea synthesis in mammals. ${ }^{105}$. 110 Furthermore, citrulline can be effectively regarded as an endproduct of glutamine/glutamate metabolism of intestinal enterocytes as suggested by Windmueller and Spaeth ${ }^{71,8 . x}$ and confirmed in many studies since then, $74,77 \cdot 79,81,97,101,104,111 \times 114$

\section{Pathways for citrulline synthesis (Figure)}

The synthesis of citrulline from glutamine involves 5 mitochondrial enzymes, being phosphate-dependent glutaminase (PDG), pyrroline-5-carboxylate synthase (P5CS), ormithine aminotransferase (OAT), OCT and CPSI with P5CS being the key regulatory enzyme. ${ }^{97,115-117}$ P5CS is unique to small intestinal enterocytes. $115.118-120$ PDG converts. glutamine to glutamate and ammonia. Glutamate is then converted to pyrroline-5 carboxylate by P5CS. Pyrroline-5-carboxylate is then converted to ornithine by OAT. Glutamine derived ammonia plus $\mathrm{HCO}_{3}{ }^{\circ}$ are converted to carbamoyl phosphate by CPSI. Carbamoyl phosphate and ornithine are finally converted to citrulline by OCT. Pyrroline-5carboxylate is a common precursor of both ornithine and proline. For long, glutamine and glutamate have been considered the only precursor for pyrroline-5-carboxylate. Wu et al ${ }^{421}$ have demonstrated proline oxidase (PROOX) activity in porcine enterocytes with the synthesis of citrulline and arginine from proline being another important pathway for citrulline synthesis. This pathway involves 4 mitochondrial enzymes, being PROox, ${ }^{122}$ OAT OCT and PCSI. Proline is converted to pyrroline-5-carboxylate by PROox. ${ }^{123}$ The subsequent metabolic steps are identical as for the citrulline synthesis from glutamine, involving OAT, CPSI and OCT, respectively. As a consequence, glutamine-derived nitrogen intermediates such as glutamate and ammonia are necessary for the synthesis of citrulline from proline. "121 Based on the relative enzyme activities, ${ }^{97}$ 124 PROox and CPSI are suggested key regulatory enzymes in the citrulline synthesis from proline." Small intestinal PROOx activity is relatively high, i.e. 10- and 6-fold greater than the activity in the liver and the kidney of piglets, respectively. ${ }^{22}$ Furthermore, the total cell mass of small intestine is relatively large compared to the liver and kidneys, respectively, i.e $162 \%$ (liver) and $970 \%$ (kidneys) in 6 week old pigs. ${ }^{125}$ Hence, the small intestine may be a major site of proline degradation and subsequent synthesis of citrulline from proline. ${ }^{12 !}$ In contrast to glutamine, 
Figure: Pathways for citrulline synthesis in small intestinal enterocyte.

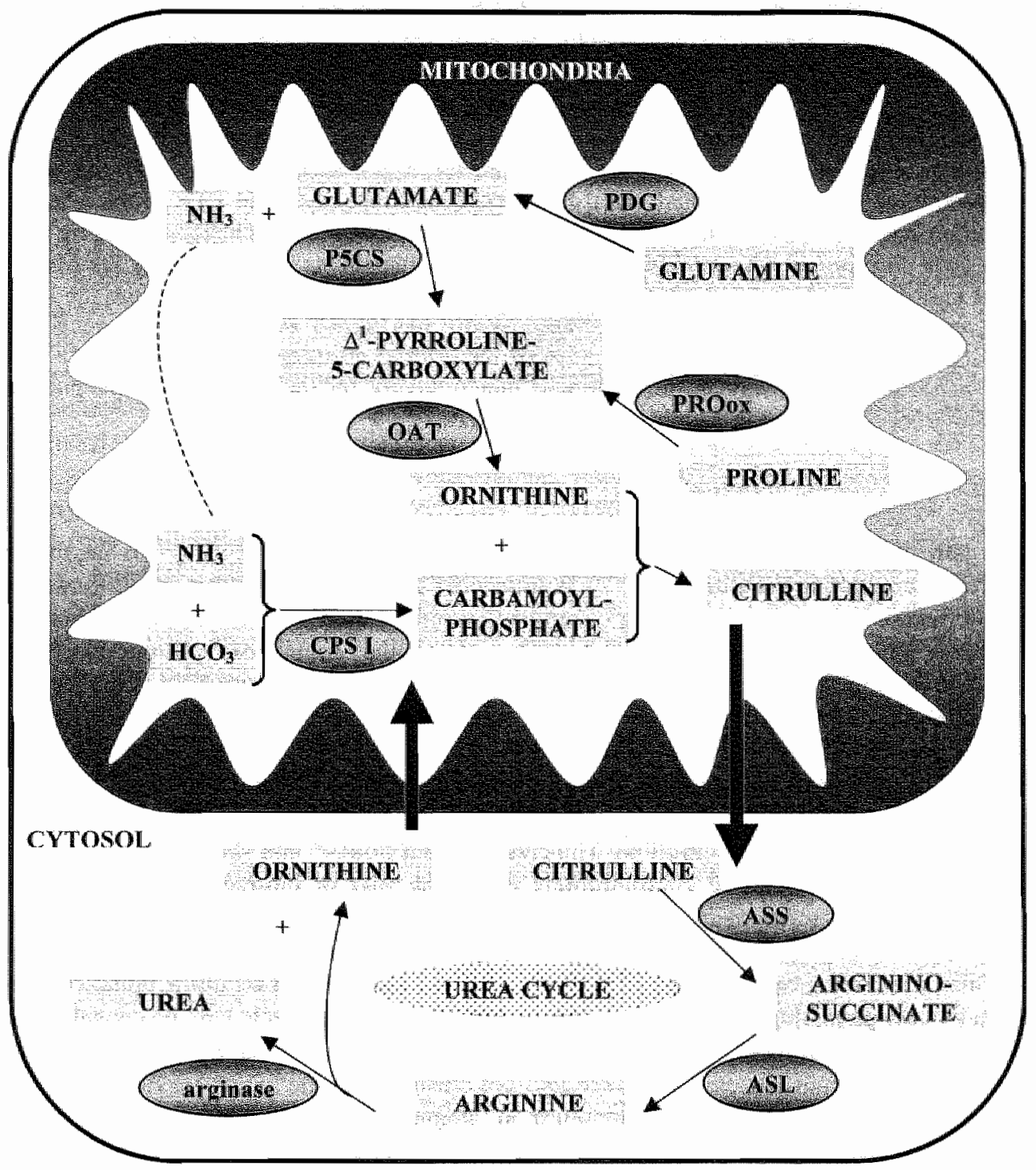

Figure: metabolic pathways involved in citrulline synthesis. $\mathrm{PDG}=$ phosphate dependent glutaminase; $\mathrm{P} 5 \mathrm{CS}=$ pytroline-5-carboxylate synthase; $\mathrm{OAT}=$ ornithine amino-transferase; CPSI = carbamoylphosphate synthetase I; OCT = ornithine carbamoyl-transferase; PROox = proline oxidase; $\mathrm{ASS}=$ argininosuccinate synthetase; $\mathrm{ASL}=$ argininosuccinate lyase. 
the luminal proline derived from the diet is the most important source of proline for citrulline synthesis: ${ }^{83}$. 121

\section{Metabolic fate of citrulline released into the portal wein}

Under physiologic conditions there is no appreciable uptake of citrulline by the liver." Labelled citrulline was supplied to the liver by a continuous portal infusion at a concentration 1.5 times the usual portal blood concentration. Less than $10 \%$ of the labelled citrilline had disappeared from the perfusate after about 40 passes clearly indicating that very little citrulline in the portal blood released by the intestine is metabolised by the liver. ${ }^{71}$ Thus citrulline produced and released by the small intestine simply passes through the liver and reaches the systemic circulation. Subsequently the kidney is the major consumer of circulating citrulline extracting about $35 \%$ of the arterial citrulline in each pass. ${ }^{71,} 77$ The relevance of this pathway is demonstrated quantitatively by the increase of the plasma citrulline level observed in patients with renal failure. ${ }^{126}$

\section{Source of circulating citrulline}

It is now generally accepted that the small intestinal absorptive epithelial cell is the major source of circulating citrulline. ${ }^{97,121,127}$ Windmueller and Spaeth investigated the existence of alternative sources for circulating citrulline. ${ }^{7 !}$ Within 5 min after exclusion of either the intestine alone or all portal drained viscera from the circulation, plasma citrulline concentration fell by only $27 \%$ and $20 \%$, respectively. Hence, more than $70 \%$ of the plasma citrulline concentration is sustained. Based on the high rate of citrulline uptake by the kidney accounting for $83 \%$ of the citrulline released by the small bowel, it can be estimated that clearance of citrulline from the plasma should be complete after $4.3 \mathrm{~min}$ in the rat in the absence of any input. ${ }^{71}$ These findings indicate the existence of extra-splanchnic production sites and/or storage sites of citrulline. The cerebrospinal fluid ${ }^{128}$ and skeletal muscle ${ }^{129}$ are known sites with citrulline concentrations exceeding that of plasma but could not be identified as citrulline releasing sites. ${ }^{71}$ Measurement of arteriovenous concentration differences across the hindquarter after complete removal of the portal drained viscera revealed a small net release of citrulline accounting for only $24 \%$ of citrulline uptake by the kidney under physiological conditions. Hence, whereas skeletal muscle may be considered a storage site for citrulline, it is not a substantial source for circulating citrulline under physiological circumstances. ${ }^{71}$ The liver does not release citrulline unless provided with unphysiologically high doses of ammonium in conjunction with high concentrations of ornithine or proline in the perfusate, indicating that all the citrulline formed from ornithine or proline is converted to arginine. "This is probably due to the efficient metabolic channelling of citrulline to ASS and the high activity of type I arginase in hepatocytes leading to a subsequent rapid hydrolysis of arginine into urea and ornithine. ${ }^{130}$ Hence, despite the results observed with the organ exclusion experiments performed by Windmuller and Spaeth, no other site but the intestine has been identified so far that releases significant amounts of citrulline under physiological conditions. The role of the small intestine as the major source for circulating citrulline is demonstrated by experiments 
in which the plasma citrulline concentration is reduced by means of small bowel turgeted interventions such as specific inhibitors of $\mathrm{OAT}{ }^{115}$ or $\mathrm{OCT}$, "111 yielding a similar decrease of plasma cirulline concentration as observed after small bowel resection. ${ }^{74,}$ 77, $111 ., 112$ Furthermore, strong lines of evidence have been obtained since then through clinical observations which are in agreement with this concept. ${ }^{7}, 81.100,113,114,132-134$

\section{Determinants of intestinal citrulline synthesis}

What are the known determinants of small intestinal citrulline synthesis and consequentially the plasma citrulline concentration? The activity of intestinal citrulline synthesizing enzymes changes as a function of the feeding regimen, i.e. during the suckling and (post)weaning period. ${ }^{97,109,121,124,130,135}$ Interestingly, Yamada et al. ${ }^{136}$ observed a peak P5CS activity during the suckling period in rat enterocytes whereas Wu et al ${ }^{97,124,135}$ observed increased P5CS activity during the post-weaning period in pig enterocytes. Weaninginduced changes in plasma cortisol levels are suggested to play a role in the difference observed between suckling and weaning animals, rather than developmental changes related

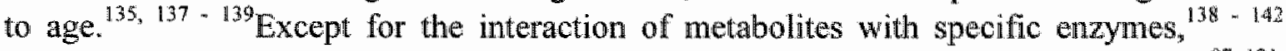
substrate availability is another determinant of the citrulline production by enterocytes. ${ }^{9 \%}, 121$, 141, 143 Similarly, several inborn errors may give rise to specific changes in citrullinemia. ${ }^{14}$ 147 Taken the central role of glutamine metabolism in the small intestinal citrulline synthesis, ${ }^{97,} 121$ any metabolic condition substantially influencing intestinal glutamine metabolism is likely to have a major impact on citrulline synthesis as well. In this respect cumulative data indicate an important role for glucose metabolism. ${ }^{141,142,} 148$ The major determinant, however, under steady state conditions for the rate of citrulline released into the portal and subsequently the systemic circulation is the actual number of functional enterocytes. This has been demonstrated amply in pre-clinical experiments ${ }^{74,77,111,112}$ and was repeatedly confimed by clinical data $78,81.413,114,134,149$ obtained after resection of a substantial length of small bowel. This was further demonstrated by clinical data on small bowel transplantation." ${ }^{132,133,150-153}$ In addition to a variation in citrulline synthesis, alterations in citrulline utilization will have an influence on the plasma citrulline concentration. ${ }^{71,118,126}$

\section{Citrulline as a marker for the functional epithelial cell mass}

Taken together, these data strongly indicate that, under steady state conditions, citrulline is a marker for the functional epithelial cell mass of small bowel. As such, plasma citrulline concentration has been proposed as a biological marker being indicative for the viability of small bowel transplants ${ }^{132,133,152}$ or the dependece on total parenteral nutrition. ${ }^{113}$ Of notice, the lower plasma citrulline level obserwed in short bowel patients was sustained up to one year after treatment ${ }^{113}$ emphasizing its strict dependence on the epithelial cell mass. In patients with villous atrophy-associated small bowel disease the plasma level of citrulline was discriminative for the degree of villous atrophy and could be used for monitoring treatment response. ${ }^{114}$ 


\section{RADIOBIOLOGY}

Small bowel epithelium: a target for acute and late radiation damage

Functionally, the small intestine is composed of two comparments: a functional epithelial (mucosa) and a supportive stromal compartment (submucosa ${ }_{y}$ muscularis and serosa). The cellular mechanism of small bowel radiation injury has been studied extensively in the laboratory. For long, epithelial and stromal radiation induced injury were considered separate pathophysiological processes. The development of acute epithelial effects is predictable on the basis of the hierarchical organization and cell kinetic properties of the target cells. Traditionally, the rapidly proliferating crypt cell is considered the target cell for acute mucosal radiation effects. ${ }^{65,}{ }^{154-156}$ More recently the radiation-induced apoptosis of the pericryptal endothelial cell has been suggested as an initiating event of crypt cell damage in epithelial radiation injury. ${ }^{157}$ This concept, although not generally accepted yet, ${ }^{158}, 159$ might have a significant impact in targeting radiation induced small bowel damage. Irrespective of this, the clonogenic crypt cell is a central target of intestinal epithelial radiation damage. Radiation will affect the proliferative clonogenic crypt cells whereas the differentiated functional cells are unaffected. This will result in an impairment or loss of cell production and eventually in the loss of functional cells. ${ }^{155}$ Thus, radiationinduced epithelial injury becomes manifest within days or weeks following single dose or fractionated radiation.

In contrast to the epithelial compartment, the target cells responsible for and the mechanisms underlying the development of stromal radiation injury are poorly understood. ${ }^{156}$ Until recently endothelial cells and fibroblasts were suggested as slowly proliferating target cells leading to vascular damage and fibrosis. ${ }^{156} \mathrm{~A}$ major role for the endothelial cell as (most) important target cell for vascular damage is proposed ${ }^{29,47,160}$ as it seems to be the most radiosensitive element of vascular walls. ${ }^{161 .}$ " 162 However, the differential response of endothelial cells at different sites in vivo and the fact that endothelial cells from different sites have similar radiation survival characteristics in vitro ${ }^{162.163}$ has lead to the hypothesis that, endothelial cell damage is clearly not the sole pathway. The fibroblast is another cell type associated with late radiation enteropathy. ${ }^{29}$ Recent experiments have focused on the role of transforming growth factor beta (TGF- $\beta$ ) in the development of radiation induced fibrosis ${ }^{27,164-169}$ and a role for cell-types other than fibroblasts with a key role for mast cells. ${ }^{27} .166 .170$ Stromal changes are supposed to progress gradually to clinically latent or manifest morphologic endpoints ${ }^{29}$ such as vascular sclerosis ${ }^{16}$ and fibrosis, ${ }^{37}$ typically months or years after radiation. ${ }^{171}$

During the last two decades an accumulating set of experimental data support an additional pathophysiologic mechanism in late radiation enteropathy, termed consequential radiation damage. In this concept stromal injury is the consequence of severe and sustained epithelial damage causing a disruption of the epithellial integrity. ${ }^{27,28,32,34-37,42,164,168,172-176}$ The experimental data on TGF- $\beta$ support the concept that epithelial injury associated late stromal injury is an additional mechamism for development of late radiation enteropathy. ${ }^{27 .}$ 164. 165. 169. 170 Furthermore, sustained morphologic and functional changes have been 
observed irrespective of concomitant stromal radiation damage. ${ }^{17 / 178}$ Hence, epithelial radiation injury should not be regarded as a separate, transient or self-limiting event but merely as a potential target for improwing the therapeutic natio in cancer treatment, both in the acute and late setting. 179

\section{Small bowel epithelium: a hierorchical tissue}

From the view of classical cellular radiobiology, the loss of clonogenic cells is the initiating event of radiation effects in both tumour and normal tissues. 1800 According to this concept, the level of clonogenic cell loss, or better, the level of surviving clonogenic cells directly determines the regenerative capacity of the tissue and its subsequent functional and/or structural integrity. Tissues are composed of different cell types with each cell type having specific kinetic properties and intrinsic radiosensitive properties. In addition, tissues can be classified according to their proliferative organisation, i.e. as a hierarchical or a flexible tissue with the small intestinal epithelium being a typical example of a hierarchical tissue. ${ }^{181}$ Whereas the dose-dependence of a radiation response is determined by the intrinsic radiosensitivity of target cells involved, the temporal expression of radiation effects is primarily determined by the type of proliferative organisation and the cell kinetic properties of the target cells involved. ${ }^{181,182}$

\section{Radiation effects on epithelial stem cell}

It is generally accepted that epithelial homeostasis is governed by intestinal stem cells located near the crypt base and that cell number is regulated by stem cell proliferation and apoptosis. ${ }^{54,65,183}$ Spontaneous apoptosis and radiation induced apoptosis occur at the stem cell position in the mouse small intestinal crypt. ${ }^{184,} 185$ Under steady state conditions a single crypt (small intestine in mice) contains 4-6 actual stem cells which are extremely sensitive to radiation induced DNA damage ${ }^{56}$ and unable to repair this damage. ${ }^{58}$ Radiation with doses up to 1 Gy induces an early apoptotic peak of stem cells within 6 h after radiation and plateaus at larger doses. ${ }^{38}$ This radiation induced apoptosis at the stem cell zone is 153 dependent. $6 \%$. 186 After larger radiation doses a second apoptotic peak is seen at about $24 \mathrm{~h}$ after radiation 187,188 which is $\mathrm{p} 53$ independent. ${ }^{18 \%}$ Interestingly, morphology of the apoptotic cells of the second peak suggested aberrant mitosis as a causal event. ${ }^{187}$ Reduced cell numbers in the crypts induces proliferation of additional crypt stem cells between $8-12 \mathrm{~h}$ with simultaneous changes in up-regulation of TGF- $\beta$, EGF and TGF- $\alpha$ in the villus and crypt cells, respectively, followed by the second apoptotic peak. ${ }^{188}$

\section{Radiation effects on epithelial functional cell}

A wide diversity of functional disorders has been observed following ionizing radiation such as changes in trans-epithelial transport processes, ${ }_{3}^{189.190}$ gut barrier function, ${ }^{191}$ motility dysfunction, ${ }^{192}, 193$ or the absorption of various nutrients such as carbohydrates, amino acids, proteins, vitamins and bile acid. ${ }^{14,194-201}$ Some of these functional changes have been 
correlated with the epithelial cell mass available for absorption ${ }^{198-201}$ suggesting a cellular basis in at least part of radiation induced functional disorders. However, several drawbacks should be taken into account for the use of functional endpoints both in pre-clinical and in clinical studies addressing radiation-induced small bowel injury. First, normal physiology of the crypt-villus unit is complex and the function of the constituting cell types is only partly understood. Multiple functional effects may result from radiation injury to a single cell type. For example, an altered secretion and absorption can be observed after irradiation for the same cell type albeit with a different time course. ${ }^{189,198,200,201}$ Secondly, similar functional changes may be related to different cel\| types and/or physiological processes. Thus similar secretory changes have been attributed to radiation effects on enteric neurons. ${ }^{202}$ Thirdly, the pathophysiology of clinical symptoms related to small bowel irradiation is complex with mucosal denudation being one of several functional events. $43-45$

\section{Radiation effects on small intestinal glutamine metabolism}

Detailed studies on radiation-induced changes of gut intermediary metabolism have not been reported. Scarce data come from groups who have focused on glutamine as a radioprotector for gut damage. However, these studies do not allow firm conclusions with regard to the effects of radiation on intestinal glutamine metabolism. For example, the time interval between radiation and assessment of metabolic endpoints differed widely. Souba et al. ${ }^{203}$ observed a decreased glutamine plasma level 4 days after whole abdominal single dose radiation. Klimberg et al. ${ }^{204}$ observed no radiation effect on intestinal glutamine extraction measured 8 days after irradiation. In contrast, Jensen et al. ${ }^{205}$ found a decreased glutamine extraction at 2 months following radiation.

\section{ENDPOINTS FOR EPITHELIAL RADIATION INJURY}

\section{Morphologic endpoints}

In rodents the kinetics of radiation-induced effects on small bowel epithelium have been well described. ${ }^{154}$ Radiation damage to the intestinal crypt cell compartment and consequential epithelial denudation is strictly dose dependent. ${ }^{57.155}$ Also in patients the radiation dose and the irradiated small bowel volume have been identifed as determinants for radiation-induced toxicity. ${ }^{20,206,207}$ The number of regenerated crypts per circumference assessed at $84 \mathrm{~h}$ after radiation is a validated endpoint. ${ }^{208}$ Although the assay is validated for an interval of $31 / 2-4$ days after radiation, it has been applied at longer intervals. ${ }^{177}$ Mucosal surface measurements, the number of villi per unit length and villus height, being surrogate endpoints for the number of functional epithelial cells, have proven to be valid endpoints for epithelial radiation injury. ${ }^{31,42}$ "The application of morphological endpoints such as crypt cell regeneration, ${ }^{208}$ apoptosis of target cells ${ }^{157.183}$ and mucosal surface measurements ${ }^{198}$ is hampered by the need for tissue sampling. As a consequence, such data are mainly derived from rodent studies. 


\section{Surrogate endpoints for epithelial damage.}

Epithelial cell loss is one of several pathophysiological mechanisms underlying clinical symptoms related to small bowel irradiation. ${ }^{10,43-45}$ Clinical symptoms are frequently used as a surrogate endpoint for radiation-induced gut damage during and following treatment. However, clinical symptoms correlate poorly with objective parameters of gut damage such as sugar permeability tests 209,210 and altered morphology." 211 Furthermore, except that toxicity grading systems are not used uniformly by investigators they are being adjusted on a regular basis.

Because of the limitations related to the assessment of morphological endpoints in patients, investigators have used several surrogate endpoints for measuring small bowel dysfunction. Such endpoints are the determination of gut barrier function through measuring absorption of test markers ${ }^{69,}{ }^{70}$ or tests for nutrient malabsorption, ${ }^{195,}, 212$ bile acid or vitamin $\mathrm{B} 12$ absorption. ${ }^{14,17,18,50,197}$ Allthough not as troublesome as taking mucosal biopsies, these tests are also impractical for monitoring purposes during and following radiation treatment. Moreover, these function tests are qualitative tests mainly suited for diagnostic purposes and the endpoints used do not address damage to target cells. Consequently, they lack a dose response relationship.

Diamine oxidase (DAO), a cytoplasmic enzyme found in almost all organs occurs in particularly high concentration in the epithelial cells of the small intestine. ${ }^{23-215}$ Following injury to intestinal epithelial cells DAO is released into the intestinal lumen and intercellular space where it is taken up by lymphatics and blood vessels. ${ }^{2 / 4}$ Circulating DAO is rapidly cleared by the liver. ${ }^{216}$ The plasma DAO activity has been suggested as a candidate marker for measuring ischemic small bowel injury. ${ }^{217}-219$ Ely et al. ${ }^{20}$ demonstrated a radiation dose-dependent decline of ileal tissue and plasma DAO activity in rats. Nadir values were observed at 3 days after radiation. At this time point a linear dose-response relationship was demonstrated for plasma and tissue DAO activity at a dose range of $0-6$ Gy and $2-8 \mathrm{~Gy}$, respectively. DeBell et al ${ }^{221}$ investigated the time course of tissue and plasma DAO activity changes following irradiation. They found that the decline of plasma DAO activity preceded the decline of jejunal tissue DAO activity. In addition, the calculated RBE values for both parameters were not the same. These data do not support a direct correlation between the changes of plasma DAO activity and intestinal tissue DAO activity as was in fact also the case for the observation made by Bounous et al. ${ }^{218}$ These authors observed a 7.5 and 1.4 fold increase in serum DAO activity 24 and 30 hours following the onset of symptoms in a patient with a lethal acute intestinal ischemia.

Overgaard et al. ${ }^{198}$ demonstrated a dose response relationship for jejunal glucose absorption in mice following single dose upper abdominal irradiation. Also a linear correlation was observed between radiation-induced changes in jejunal glucose absorption and the absorptive surface in mice following a single upper abdominal radiation dose of $10 \mathrm{~Gy}$. The glucose absorption did not correlate with jejunal crypt survival at 4 days after radiation. However, crypt cell survival data were obtained in a separate experiment using the same mouse strain. 
Kirichenko et al. ${ }^{201}$ used a nuclear scintigraphic technique to quantitate active enterocyte transport in mice. At $3 \frac{1}{2}$ days after single dose total body irradiation absorption of the isotope significantly correlated with a surrogate endpoint for the jejunal absorptive surface, i.e. the number of cells per villus. A strong correlation was observed between absorption and radiation dose at this time point. For the dose points used in these experiments, i.e. 4,6 , 8 and $12.5 \mathrm{~Gy}$, respectively, no correlation was seen between jejunal crypt regeneration, radiation dose and absorption. The results of both experiments 198,201 indicate a cellular basis for the absorptive function and, consequently, a correlation with the absorptive area. Also a dose-response relationship was observed for the intestinal absorption function. of notice, compared to crypt damage and crypt regeneration the dose-dependent changes of the absorptive surface occurred earlier and at lower doses. As a result, both endpoints correlate

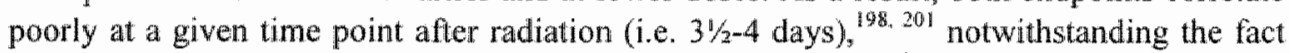
that crypt damage is the initiating event of mucosal atrophy. ${ }^{155}$ Both function tests were investigated for their applicability as a clinical assay for radiation-induced epithelial cell loss in the gut and indirectly for quantification of radiation damage to the target cell for epithelial small bowel damage. To date none of these assays has been introduced in clinical practice for routine use during and following fractionated treatment, mainly for practical reasons.

The small bowel is comprised of different cell types. Radiation-induced effects will be the resultant of different effects on these respective cell types with different untrinsic radiosensitivities and a different temporal expression of radiation damage due to differences in cell kinetic properties of the individual cell types. Whereas radiation-induced tissue damage is unlikely to be expressed or quantified by a single functional or morphological parameter, ${ }^{4+4}$ an assay measuring damage to relevant target cells involved in the initiation of tissue damage is of great importance for both experimental and clinical research. Such an assay provides an objective tool for measuring effects resulting from interventions aimed at reducing normal tissue toxicity. Ideally, such an assay must be tissue-specific, display a dose-response relationship and in case of the small intestinal epithelium also a volumeresponse relationship. In addition, the assay must be easily accessible in clinical practice and independent of experimental conditions such as concurrent medical conditions, medication and nutritional status. We have focused on the validation of citrulline as an assay for assessment of radiation-induced epithelial cell loss as an important initiating factor in the pathogenesis of acute and chronic intestinal radiation injury. 


\section{Chapter 3}

HYPOTHESIS 
Effectively, citrulline can be regarded as an endproduct of glutamine and/or proline metabolism of intestinal enterocytes. ${ }^{71,83,97,109,121}$ Several enzymes are involved in the synthesis of citrulline from glutamine and/or proline. ${ }^{97.109,121}$ Whereas OAT ${ }^{115,120}$ can be categorized as a ubiquitous enzyme, OCT, CPSI, PROOx are highly polarized and P5CS is extremely polarized. ${ }^{118}$ Thus high activities of $\mathrm{OCT}^{222} \mathrm{CPSI}^{222}$ and PROox ${ }^{120.122}$ are found in the small intestine and liver. PSCS activity is almost exclusively found in small intestinal enterocytes. ${ }^{15,11 \%, 120}$ This unique enzymatic profile, the unique role of the small intestine in whole body glutamine metabolism ${ }^{92,223}$ and the relatively high small bowel enterocyt cell mass ${ }^{125}$ make the small bowel epithelium the most important source of circulating citrulline. ${ }^{127}$. 130 Taken together these data indicate a high specificity for circulating citrulline, i.e. small intestinal enterocytes.

Thus under steady state conditions, citrulline can be considered a marker for the functional epithelial cell mass of small bowel, a concept amply demonstrated in experimental and clinical studies. $^{71,74,7774,81,97,100,101,104,111-115,131-134,152}$ As such, plasma citrulline concentration has been proposed as a biological marker for viable small bowel epithelium. $^{113,114,132,133,152}$ Crenn et al. ${ }^{114}$ have recently correlated plasma citrulline concentration with histologically graded villous atrophy in 42 patients with celiac and 10 patients with non-celiac villous atrophy disease. These authors identified a threshold value of $10 \mu \mathrm{mol} / \mathrm{L}$ ( $25 \%$ of the mean normal baseline value) to be predictive for severe and extensive villous atrophy and $20 \mu \mathrm{mol} / \mathrm{L}$ to be predictive for severe villous atrophy, whatever the extent. The plasma level of citrulline was thus indicative for the degree of villous atrophy. This finding is indicative for a possible volume effect.

Crenn et al. ${ }^{14}$ demonstrated the use of plasma citrulline for monitoring treatment response in patients with celiac disease, indicating the simplicity of the marker in clinical practice.

Taken together, plasma citrulline is a candidate marker for measuring radiation-induced epithelial small bowel damage. So lar the data indicate that this marker is tissue-specific i.e. unique for small intestinal epithelium. The marker corresponds with an important morpholocal endpoint, i.e. mucosal atrophy, and is easily accessible in clinical practice. A volume effect is suggested by the data provided by Crenn et al. ${ }^{114}$ However, experimental ${ }^{119}$ and clinical data ${ }^{101}$ suggest a non-homogenous distribution of citrulline production. Finally, since no data exist about the effects of small bowel radiation on intestinal citrulline production, the radiation dose-response relationship is not known. 
This thesis is focused on the validation of citrulline as an assay for assessment of radiation induced epithelial cell loss as a major radiation effect on small bowel.

We hypothesize that in response to small bowel radiation the plasma citrulline concentration:

1. Decreases as a result of epithelial cell loss.

2. Displays similar radiobiological characteristics as radiation-induced epithelial cell loss, i.e. a dose-response relationship and a volume-response relationship.

3. Displays a similar temporal relationship than epithellal cell loss.

4. Correlates with relevant morphologic endpoints of epithelial small bowel injury. 
Chapter 4

PILOT STUDIES 
During the nineties a collaborative research project was initiated with participation of associates from the Maastricht Radiation Therapy and Oncology (MAASTRO) department ". the department of Surgery at the Maastricht University ", the department of Radiobiology and Radiotherapy at the Catholic University of Leuven ", Brussels, Belgium, and the department of Pathology at the academic hospital Maastricht ${ }^{4}$, the Netherlands .

Specific expertise on clinical normal tissue radiation toxicity ${ }^{1}$, inter-organ metabolism ${ }^{2}$, experimental small intestinal radiation toxicity ${ }^{2}$ and digitised imaging techniques ${ }^{4}$ where thus joined and resulted in a collaborative project at the Maastricht University.

First an animal model was developed aimed to investigate radiation-induced intestinal damage, radiation induced changes in small bowel and inter-organ metabolism, the effects of metabolic intervention on radiation-induced damage. In a series of pilot experiments using a porcine and rodent animal model citrulline was identified as a candidate marker for quantification and monitoring of radiation effects on small intestinal epithelium. The results of the pilot studies will be briefly described in this chapter.

In a first pilot experiment we used a model that enables the measurement of inter-organ metabolism and the collection of jejunal biopsies in the conscious pig. ${ }^{224}$ Following a single dose whole abdominal radiation (WAR) of $6 \mathrm{~Gy}$, small bowel glutamine metabolism was measured between $8.00-8.30 \mathrm{a} . \mathrm{m}$. on day $1,3,5,8,10$ and 12 . The animals were fasted overnight before sampling. Two female pigs, aged 6 weeks, were used for these experiments. Mucosal biopsies were obtained on the same time points. Following radiation a rapid decrease of gut glutamine consumption to $16 \%$ of the pre-treatment level was observed on day 1 . Thereafter gut glutamine consumption rapidly increased to $148 \%$ of the pre-treatment level on day 5. On day 10 gut glutamine consumption was restored to the pretreatment value. Mucosal GLN content increased almost 4-fold at I day after RT and declined rapidly to control levels thereafter. In contrast, the temporal change of the plasma citrulline concentration was in accordance with the expected time course of epithelial atrophy following radiation, i.e. maximal mucosal atrophy at 3-5 days post-radiation. No difference was observed between simultaneously measured plasma citrulline concentrations in arterial (aorta) and venous blood (vena porta, vena hepatica and vena cava) (figure), indicating absence of citrulline uptake in the liver.

A similar experimental model developed for rodents ${ }^{225,226}$ was applied in male Wistatr rats in a second series of pilot experiments. The animals were housed individually in metabolic cages and randomly assigned to 1 of 7 groups ( $n=10$ animals per group). All animals, except for the control group, were subjected to a single WAR dose of $10 \mathrm{~Gy}$, or sham radiation (SHWAR) between $8.00-8.30 \mathrm{a}$.m. In a previous experiment this dose was found to induce diarrhea within 4-5 days after WAR without lethality during a post-radiation period of 14 days. Small intestinal metabolism was measured at $6 \mathrm{~h}, 12 \mathrm{~h}$ or $24 \mathrm{~h}$ after WAR or SHWAR. The control group was subjected to metabolic experiments at 9.00 a.m. Studies were performed in the post-absorptive state with the rats being fasted for $12 \mathrm{~h}$ prior to metabolic experiments. Following anesthesia a laparotomy was performed and the abdominal aorta, the v.cava, a tertiary branch of the mesenteric vein and the portal vein 
were cannulated using a 25-gauge needle fixed to a silastic tubing, connected to a $1 \mathrm{~mL}$ syringe. For flow measurements, the indicator dilution method with para-aminohippuric acid (PAH) was used. A primed constant infusion of PAH was conducted in the mesenteric vein using a peristaltic pump. The priming dose was $0.15 \mathrm{~mL} / 100 \mathrm{~g}$ body weight (bw) ( 50 $\mathrm{mmol} / \mathrm{L})$, and the infusion was $0.75 \mathrm{~mL} \cdot 100 \mathrm{~g} \mathrm{bw} \cdot \mathrm{h}^{-1}(5 \mathrm{mmol} / \mathrm{L})$. Plasma flow across the PDV was calculated using $\mathrm{PAH}$ in the indicator dilution method. ${ }^{225,}{ }^{227}$ Substrate fluxes were calculated by multiplying the venous-arterial concentration differences with the mean portal plasma flow of the group and are expressed in nmol $100 \mathrm{~g} \mathrm{bw}^{-1} \cdot \min ^{-1}$. A positive flux indicates net release; a negative flux indicates net uptake.

Figure 1: Plasma citrulline concentration $(\mu \mathrm{mol} / \mathrm{L})$ simultaneously measured at 4 different sample sites in a pig-model ${ }^{224}$ following a single dose of 6 Gy whole abdominal radiation (WAR). Data are means \pm SEM in 2 animals.

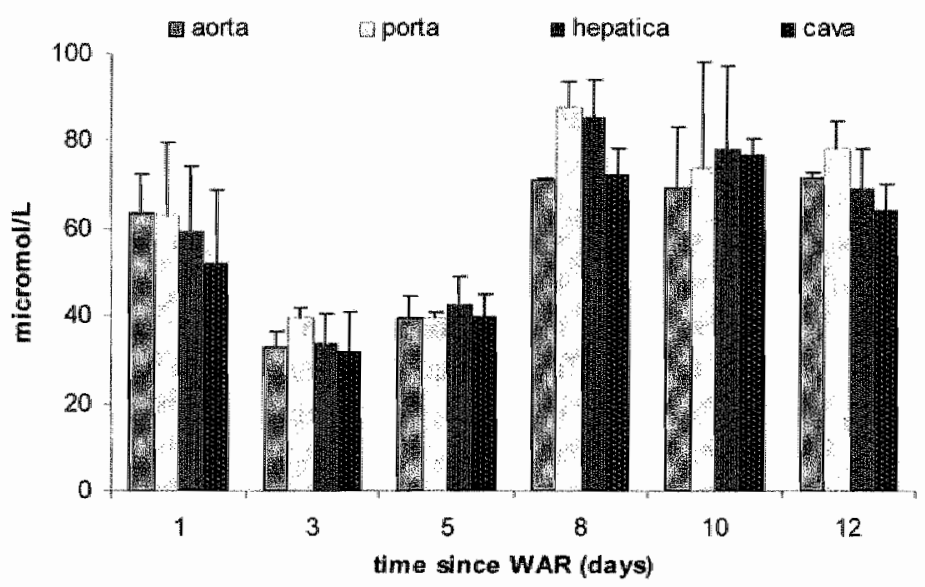

Nineteen animals were lost during the experimental procedure for metabolic experiments. Thus 7, 8, 8, 8, 5, 10 and 5 animals were available for analysis in the control group, the $6 \mathrm{~h}$, $12 \mathrm{~h}$ and $24 \mathrm{~h} \mathrm{SHAM}$ groups and $6 \mathrm{~h}, 12 \mathrm{~h}$, and $24 \mathrm{~h}$ WAR groups, respectively. No substantial effect of the experimental procedure was observed at any time point on the arterial substrate levels or PDV substrate fluxes (data not shown). The arterial glucose level significantly increased after WAR $(p<0.001)$ at all 3 timepoints $(p=0.032 ; p=0.001$ and $p=0.008$, respectively). The arterial citrulline concentration progressively decreased after WAR and was significantly decreased at $24 \mathrm{~h}$ after WAR $(p=0.002)$. None of the other anino acid levels were affected by WAR, including glutamine. Intestinal blood flow as measured by the plasma flow across the portal drained viscera (PDV) increased more than 2-fold at $12 \mathrm{~h}$ after radiation. PDV substrate fluxes are summarized in the table. Of all substrates analyzed, only the PDV glutamine and citrulline flux were significantly affected by WAR. A 
significant time effect was observed for glutamine $(p=0.003)$ and citrulline $(p=0.003)$. PDV glutamine uptake and citmulline release were both significantly enhanced at I2h after WAR $(p=0.008$ and $p=0.047$, respectively).

This study showed that shortly after radiation, gut glutamine requirements are increased. Enhanced gui glutamine metabolism strongly correlates with a simultaneous citrulline release from the gut and decreased arterial citrulline concentration, indicating that plasma citnulline and possibly citrulline turnover could be used as parameter of gut metabolism and hence, functional intestinal epithelium, after abdominal radiation.

Table: Gut substrate flux in nmol/100g bw/min $\pm \mathrm{SEM}$

\begin{tabular}{|c|c|c|c|c|c|c|}
\hline & & oh & $6 \mathrm{~h}$ & $12 \mathrm{~h}$ & $24 \mathrm{~h}$ & ANOVA \\
\hline \multirow[t]{2}{*}{ Arterial CTT } & SHAM & $70 \pm 3$ & $64 \pm 3$ & $62 \pm 2$ & $60 \pm 2$ & $P=0.050^{\circ}$ \\
\hline & WAR & & $70 \pm 5$ & $56 \pm 3$ & $39 \pm 6$ & $\mathrm{P}=0.00 \mathrm{t}^{2}$ \\
\hline \multirow[t]{2}{*}{ Arierial GLN } & SHAM & $647 \pm 20$ & $588 \pm 30$ & $585 \div 39$ & $679 \pm 43$ & $\mathrm{p}=\mathrm{ns}$ \\
\hline & WAR & & $567 \pm 56$ & $624 \pm 21$ & $625 \pm 40$ & \\
\hline \multirow[t]{2}{*}{ PDVCIT } & SHAM & $31 \pm 5$ & $13 \pm 2$ & $32 \pm 4$ & $30 \pm 16$ & \\
\hline & WAR & & $25 \pm 3$ & $65 \pm 13$ & $36 \pm 5$ & $P=0.007^{3}$ \\
\hline \multirow[t]{2}{*}{$P D V G L N$} & SHAM & $-150 \pm 44$ & $-65 \pm 10$ & $-150 \pm 47$ & $-201 \pm 101$ & \\
\hline & WAR & & $-110 \pm 39$ & $-426 \pm 70$ & $-222 \pm 43$ & $P=0.003^{3}$ \\
\hline
\end{tabular}

${ }^{3}$ simple factorial ANOVA and bonferroni post-hoc testing. "6 vs $12 \mathrm{hr} ;{ }^{2} 12 \mathrm{ws} 24 \mathrm{hr},{ }^{3}=12 \mathrm{hr}$ 
Figure 2: Portal drained viscera substrate flux as a function of time (h) and experimenta] group. Values are mean $\pm \mathrm{SEM}$. Data are expressed in nmol $\cdot 100 \mathrm{~g} b w^{-1} \cdot \mathrm{min}^{-1}$. Positive flux indicates net release, negative flux indicates net uptake.

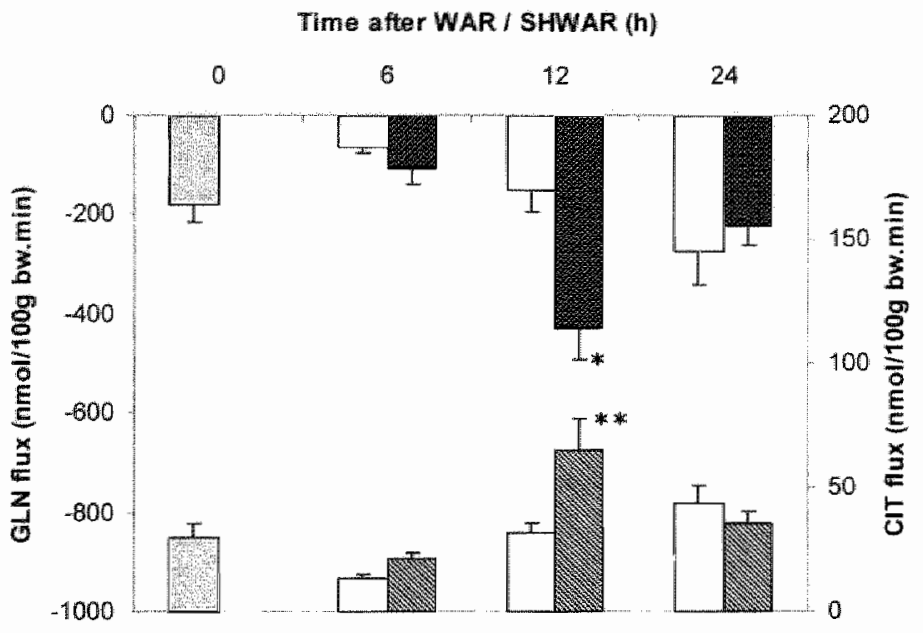

Legend: radiation GLN ( radiation CIT ( $)$ ); sham-radiation ( $\square$ ) or control (圆).

Abbreviations: WAR $=$ whole abdominal radiation. SHWAR = sham WAR. Test-statistics: One-way ANOVA, Tukey's post-hoc test: * $\mathrm{p}=0.008 ;{ }^{* *} \mathrm{p}=0.047$. 


\section{References}

1. Keefe DM, Gibson RJ, Hauer Jensen M. Gastrointestinal mucositis. Sem Oncol Nurs $2004: 20: 38-47$.

2. Elting LS, Cooksley C, Chambers M, Cantor SB, Manzullo E, Rubenstein EB. The burdens of cancer therapy. Clinical and economic outcomes of chemotherapyinduced mucositis. Cancer 2003; $98: 1531-1539$.

3. Potten CS. Radiation, the ideal cytotoxic agent for studying the cell biology of lissues such as the small intestine. Radiat Res 2004;161:123-136.

4. Han SC, Kim DH, Higgins SA, Carcangiu ML, Kacinski BM. Chemoradiation as primary or adjuvant treatment for locally advanced carcinoma of the vulva. Int $J$ Radiat Oncol Bioll Phys 2000;47:1235-1244.

5. Pahlman L, Hohenberger W, Gunther K, Fietka R, Metzger U. Is radiochemotherapy necessary in the treatment of rectal cancer? Eur J Cancer 1990 $1998 ; 34: 438-448$.

6. Green IA, Kirwan JM, Tierney JF, Symonds P, Fresco L, Collingwood M, Williams CJ. Survival and recurrence after concomitant chemotherapy and radiotherapy for cancer of the uterine cervix: a systematic review and meta-analysis. Lancet $2001 ; 358: 781-786$.

7. Thomas PR, Lindblad AS. Adjuvant postoperative radiotherapy and chemotherapy in rectal carcinoma: a review of the Gastrointestinal Tumor Study Group experience. Radiother Oncol 1988;13:245-252.

8. Erickson BA, Otterson MF, Moulder JE, Sarna SK. Altered motility causes the early gastrointestinal toxicity of irradiation. Int J Radiat Oncol Biol Phys 1994;28:905-912.

9. Fraser R, Frisby C, Schirmer M, Blackshaw A, Langman I, Yeoh E, Rowland R, Horowitz M. Effects of fractionated abdominal irradiation on small intestinal motility--studies in a novel in vitro animal model. Acta Oncol 1997;36:705-710.

10. Otterson MF, Sarna SK, Moulder JE. Effects of fractionated doses of ionizing radiation on small intestinal motor activity. Gastroenterology 1988;95:1249-1257.

11. Creutzberg CL, van Putten WL, Koper PC, Lybeert ML, Jobsen JJ, Warlam Rodenhuis $\mathrm{CC}_{\text {, }}$ De Winter $K \mathrm{~A}_{\text {, Lutgens }} \mathrm{LC}$, van den $\mathrm{Bergh} \mathrm{AC}$, van de Steen Banasik $\mathbb{E}$, Beerman $H$, van $\mathbb{L}$ ent $\mathbb{M}$. Surgery and postoperative radiotherapy versus surgery alone for patients with stage-1 endometrial carcinoma: multicentre randomised trial. PORTEC Study Group. Post Operative Radiation Therapy in Endometrial Carcinoma. Lancet 2000;355:1404-1411.

12. Sorbe B. Consolidation treatment of advanced (FIGO stage III) ovarian carcinoma in complete surgical remission after induction chemotherapy: a randomized, controlled, clinical trial comparing whole abdominal radiotherapy, chemotherapy, and no further treatment. Int J Gynecol Cancer 2003:13:278-286.

13. Galland RB, Spencer J. Spontaneous postoperative perforation of previously asymptomatic irradiated bowel. Br J Surg 1985:72:285.

14. Yeoh E, Horowitz M, Russo A, Muecke T, Ahmad A Robb T, Chatterton B. A retrospective study of the effects of pelvic irradiation for carcinoma of the cervix on gastrointestinal function. Int J Radiat Oncol Biol Phys $1993 ; 26: 229-237$. 
15. Yeoh EK, Horowitz M, Russo A, Muecke T, Robb T, Chatterton BE. Gastrointestinal function in chronic radiation enteritis-effects of loperamide-N-oxide. Gut $1993 ; 34: 476-482$.

16. Yeoh E, Razali M, OBrien PC. Radiation therapy for early stage seminoma of the testis. Analysis of survival and gastrointestinal toxicity in patients treated with modern megavoltage techniques over 10 years. Australas Radiol 1993;37:367-369.

17. Yeoh E, Horowitz M, Russo A, Muecke T, Robb T, Maddox A, Chatterton B. Effect of pelvic irradiation on gastrointestinal function: a prospective longitudinal study. Am J Med 1993;95:397-406.

18. Yeoh $E$, Horowitz $M$, Russo $A$, Muecke $T$, Robb $T$, Chatterton B. The effects of abdominal irradiation for seminoma of the testis on gastrointestinal function. $J$ Gastroenterol Hepatol 1995; 10:125-130.

19. Pedersen D, Bentzen SM, Overgaard J. Early and late radiotherapeutic morbidity in 442 consecutive patients with locally advanced carcinoma of the uterine cervix. Int $J$ Radiat Oncol Biol Phys 1994;29:941-952.

20. Letschert JG, Lebesque JV, Aleman BM, Bosset JF, Horiot JC, Bartelink H, Cionini L, Hamers JP, Leer JW, van Glabbeke M. The volume effect in radiation-related late small bowel complications: results of a clinical study of the EORTC Radiotherapy Cooperative Group in patients treated for rectal carcinoma. Radiother Oncol $1994 ; 32: 116-123$.

21. Hamberger AD, Unal A, Gershenson DM, Fletcher GH. Analysis of the severe complications of irradiation of carcinoma of the cervix: whole pelvis irradiation and intracavitary radium. Int I Radiat Oncol Biol Plhys 1983;9:367-371.

22. Lanciano RM, Martz K, Montana GS, Hanks GE. Influence of age, prior abdomina] surgery, fraction size, and dose on complications after radiation therapy for squamous cell cancer of the uterine cervix. A patterns of care study. Cancer $1992 ; 69: 2124-2130$.

23. Hanks GE, Herring DF, Kramer S. Patterns of care outcome studies. Results of the national practice in cancer of the cerwix. Cancer 1983;51:959-967.

24. Unal A, Hamberger AD, Seski JC, Fletcher GH. An analysis of the severe complications of irradiation of carcinoma of the uterine cervix: treatment with intracavilary radium and parametrial irradiation. Int $J$ Radiat Oncol Biol Phys 1981;7:999-1004.

25. Potish RA. Importance of predisposing factors in the development of enteric damage. Am J Clin Oncol 1982;5:189-194.

26. Perez CA, Breaux S, Bedwinek JM, Madoc Jones H, Camel HM, Purdy JA, Walz BJ. Radiation therapy alone in the treatment of carcinoma of the uterine cervix. II. Analysis of complications. Cancer $₫ 984 ; 54: 235-246$.

27. Richter $K K$, Langberg CW, Sung CC, Hauer-Jensen M. Increased transforming growth factor beta (TGF meta) immunoreactivity is independently associated with chronic injury in both consequential and primary radiation enteropathy. Int J Radiat Oncol Biol Phys 1997;39:187-195.

28. Hauer-Jensen M, Sauer T, Berstad T, Nygaard K. Influence of pancreatic secretion on late radiation enteropathy in the rat. Acta Radiol Oncol 1985;24:555-560.

29. Hauer-Jensen M. Late radiation injury of the small intestine. Clinical, pathophysiologic and radiobiologic aspects. A review. Acta Oncol 1990;29:401 -415. 
30. Trott KR. Chronic damage after radiation therapy: challenge to radiation biology. Int J Radiat Oncol Biol Phys 1984;10:907-913.

31. Hauer Jensen M, Poulakos L, Osborne JW. Effects of accelerated fractionation on radiation injury of the small intestine: a new rat model. Int J Radiat Oncol Biol Phys $1988 ; 14: 1205-1212$.

32. Hauer-Jensen $M$, Poulakos L, Osborne JW. Intestinal complications following accelerated fractionated $x$-irradiation. An experimental study in the rat. Acta Oncol 1990;29:229-234.

33. Followill DS, Kester D, Travis EL. Histological changes in mouse colon after singleand split-dose irradiation. Radiat Res 1993;136:280-288.

34. Langberg CW, Sauer T, Reitan JB, Hauer-Jensen M. Tolerance of rat small intestine to localized single dose and fractionated irradiation. Acta Oncol 1992;31:781-787.

35. Langberg CW, Waldron JA, Baker ML, Hauer-Jensen M. Significance of overall treatment time for the development of radiation-induced intestinal complications. An experimental study in the rat. Cancer 1994;73:2663-2668.

36. Langberg CW, Sauer T, Reitan JB, Hauer-Jensen M. Relationship between intestinal fibrosis and histopathologic and morphometric changes in consequential and late radiation enteropathy. Acta Oncol 1996;35:81-87.

37. Followill DS, Travis EL. Differential expression of collagen types I and III in consequential and primary fibrosis in irradiated mouse colon. Radiat Res 1995; 144: 318-328.

38. Bourne RG, Kearsley JH, Grove WD, Roberts SJ. The relationship between early and late gastrointestinal complications of radiation therapy for carcinoma of the cervix. Int I Radiat Oncol Biol Phys 1983;9:1445-1450.

39. Wang CJ, Leung SW, Chen HC, Sun LM, Fang FM, Huang EY, Hsiung CY, Changchien $\mathrm{CC}$. The correlation of acute toxicity and late rectal injury in radiotherapy for cervical carcinoma: evidence suggestive of consequential late effect (CQLE). Int J Radiat Oncol Biol Phys 1998;40:85-91.

40. Weiss E, Hirnle P, Amold Bofinger H, Hess CF, Bamberg M. Therapeutic outcome and relation of acute and late side effects in the adjuvant radiotherapy of endometrial carcinoma stage I and II. Radiother Oncol 1999:53:37-44.

41. Creutzberg $\mathrm{CL}_{\text {, van }}$ Putten WL, Koper $\mathrm{PC}$, Lybeert ML, Jobsen JJ, Warlam Rodenhuis $\mathrm{CC}$, De Winter KA, Lutgens $\mathrm{LC}$, van den Bergh $\mathrm{AC}$, van der Steen Banasik $E$, Beerman $H$, van Lent $M$. The morbidity of treatment for patients with Stage I endometrial cancer: results from a randomized trial. Int J Radiat Oncol Biol Phys 2001;51:1246-1255.

42. Hauer-Jensen M, Sauer T, Devik F, Nygaard K. Effects of dose fractionation on late roentgen radiation damage of rat small intestine. Acta Radiol Oncol 1983;22:38 . 384.

43. Thomson AB, Keelan M, Thiesen A, Clandinin MT, Ropeleski M, Wild GE. Small bowel review: diseases of the small intestine. Dig Dis Sci 2001;46:2555-2566.

44. Griffiths NM. The example of gastrointestinal damage induced by ionising radiation: are there accessible markers? Cell Mol Biol (Noisy le Grand) 2001;47:427-435.

45. MacNaughton WK. Review article: new insights into the pathogenesis of radiationinduced intestinal dysfunction. Aliment Pharmacol Ther 2000;14:523-528. 
46. Berthrong $M$, Fajardo LF. Radiation injury in surgical pathology. Part Il. Alimentary tract. Am I Surg Pathol 1981;5:153-178.

47. Trott KR, Breiter N, Spiethoff A. Experimental studies on the pathogenesis of the chronic radiation ulcer of the large bowel in rats. Int $J$ Radiat Oncol Biol Phys $1986 ; 12: 1637-1643$.

48. Sher ME, Bauer J. Radiation-induced enteropathy. Am J Gastroenterol 1990;85:121128 .

49. Smith DH, DeCosse JJ. Radiation damage to the small intestine. World J Surg $1986 ; 10: 189-194$.

50. Yeoh EK, Horowitz M. Radiation enteritis. Surg Gynecol Obstet 1987;165:373-379.

51. Galland RB, Spencer J. Natural history and surgical management of radiation enteritis. Brit J Surg 1987;74:742-747.

52. Harling $\mathrm{H}_{3}$ Balslev $\mathrm{I}$. Long-term prognosis of patients with severe radiation enteritis. Am J Surg 1988;155:517-519.

53. Letschert JG, Lebesque JV, de Boer RW, Hart AA, Bartelink H. Dose-volume correlation in radiation-related late small-bowel complications: a chinical study. Radiother Oncol 1990;18:307-320.

54. Potten CS, Wilson JW, Booth C. Regulation and significance of apoptosis in the stem cells of the gastrointestinal epithelium. Stem Cells 1997;15:82-93.

55. Potten CS. Epithelial cell growth and differentiation. II. Intestinall apoptosis. Am J Physiol 1997:273:0253-257.

56. Potten CS. Extreme sensitivity of some intestinal crypt cells to $X$ and gamma irradiation. Nature 1977;269:518-521.

57. Potten CS. Structure, function and proliferative organisation of mammalian gut. In: Potten CS, Hendry JH, editors. Radiation and Gut. Amsterdam: Elsevier; 1995. pp. 131 .

58. Hendry JH, Potten CS, Chadwick C, Bianchi M. Cell death (apoptosis) in the mouse small intestine after low doses: effects of dose-rate, $14.7 \mathrm{MeV}$ neutrons, and 600 $\mathrm{MeV}$ (maximum energy) neutrons. Int J Radiat Biol Relat Stud Phys Chem Med $1982 ; 42: 611-620$.

59. Potten CS. The significance of spontaneous and induced apoptosis in the gastrointestinal tract of mice. Cancer Metastasis Rev 1992;11:179-195.

60. Hall PA, Coates PJ, Ansari B, Hopwood D. Regulation of cell number in the mammalian gastrointestinal tract: the importance of apoptosis. J Cell Sci 1994; 107 : 3569-3577.

61. Mayhew TM, Myklebust R, Whybrow A, Jenkins R. Epithelial integrity, cell death and cell loss in mammalian small intestine. Histol Histopathol 1999; 14:257-267.

62. Grossmann J, Walther $\mathrm{K}$, Artinger M, Kiessling $\mathrm{S}$, Scholmerich J. Apoptotic signaling during initiation of detachment-induced apoptosis ("anoikis") of primary human intestinal epithelial cells. Cell Growth Differ 2001;12:147-155.

63. Vachon PH, Hamois C, Grenier A, Dufour $\mathrm{G}$, Bouchard V, Han J, Landry J, Beaulieu JF, Vezina A, Dydensborg AB, Gauthier $R$, Cote A, Drolet JF, Lareau $F$. Differentiation state-selective roles of 38 isoforms in human intestinal epithelial cell anoikis. Gastroenterology 2002;123:1980-1991.

64. Frisch SM, Francis H. Disruption of epithelial cell-matrix interactions induces apoptosis. J Cell Biol 1994; 124:619-626. 
65. Potten CS, Booth C, Pritchard DM. The intestinal epithelial stem cell: the mucosal govemor. Int I Exp Pathol 1997;78:219-243.

66. Fouquet S, Lugo Martinez VH, Faussat AM, Renaud F, Cardot P, Chambaz J, Pincon Raymond $\mathrm{M}$, Thenet $\mathrm{S}$. Early loss of E-cadherin from cell-cell contacts is involved in the onset of Anoikis in enterocytes. J Biol Chem 2004;279:43061-43069.

67. Merritt AJ, Potten CS, Kemp CJ, Hickman JA, Balmain A, Lane DP, Hall PA. The role of p53 in spontaneous and radiation-induced apoptosis in the gastrointestinal tract of normal and p53-deficient mice. Cancer Res 1994;54:614-617.

68. Wu G. Intestinal mucosal amino acid catabolism. J Nutr 1998;128:1249-1252.

69. Travis S, Menzies I. Intestinal permeability: functional assessment and significance. Clin Sci 1979 1992;82:471-488.

70. Bjarnason 1, MacPherson A, Hollander D. Intestinal permeability: an overview. Gastroenterology 1995;108:1566-1581.

71. Windmueller $\mathrm{HG}_{\text {, }}$ Spaeth AE. Source and fate of circulating citrulline. Am J Physiol 1981;241:E473-480.

72. Windmueller HG, Spaeth AE. Respiratory fuels and nitrogen metabolism in vivo in small intestine of fed rats. Quantitative importance of glutamine, glutamate, and aspartate. J Biol Chem 1980;255:107-112.

73. Soeters PB, Hulsewe KW, Deutz NEP, Luiking Y, Dejong CH. Gastrointestinal disease. In: Cynober LA, editor. Metabolic and therapeutic aspects of amino acids in clinical nutrition. 2nd ed: CRC press; 2004. pp. 405-418.

74. Wakabayashi Y, Yamada E, Yoshida T, Takahashi N. Effect of intestinal resection and arginine-free diet on rat physiology. Am J Physiol 1995;269:G3॥ 3-318.

75. Sido B, Hack V, Hochlehnert A, Lipps H, Herfarth C, Droge W. Impairment of intestinal glutathione synthesis in patients with inflammatory bowel disease. Gut $1998: 42: 485-492$.

76. Buchman AL, Scolapio J, Fryer J. AGA technical review on short bowel syndrome and intestinal transplantation. Gastroenterology 2003;124:1111-1134.

77. Dejong $\mathrm{CH}$, Welters CF, Deutz NE, Heineman E, Soeters PB. Renal arginine metabolism in fasted rats with subacute short bowel syndrome. Clin Sci 1998; 95: 409-418.

78. Osowska S, Moinard C, Loi C, Neveux N, Cynober L. Citrulline increases arginine pools and restores nitrogen balance after massive intestinal resection. Gui 2004;53:1781-1786.

79. Yamada E, Wakabayashi Y, Saito A, Yoda K, Tanaka Y, Miyazaki M. Hyperammonaemia caused by essential aminoacid supplements in patient with short bowel. Lancet 1993;341:1542-1543.

80. Grazer RE, Sutton JM, Friedstrom S, McBarron FD. Hyperammonemic encephalopathy due to essential amino acid hyperalimentation. Arch Intern Med 1984; 144:2278-2279.

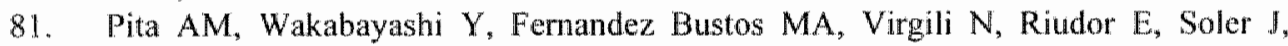
Farriol M. Plasma urea-cycle-related amino acids, ammonium levels, and urinary orotic acid excretion in short-bowel patients managed with an oral diet. Clin Nutr 2003;22:93-98.

82. Anderson JW. Glucose metabolism in jejunal mucosa of fed, fasted, and streptozotocin-diabetic rats. Am J Physiol 1974; 226: 226-229. 
83. Windmueller HG, Spaeth AE. Uptake and metabolism of plasma glutamine by the small intestine. J Biol Chem 1974;249:5070-5079.

84. Windmueller $H G$, Spaeth $A E$. Identification of ketone bodies and glutamine as the major respiratory fuels in vivo for postabsorptive rat small intestine. $J$ Biol Chem $1978 ; 253: 69-76$.

85. Windmueller $\mathrm{HG}$, Spaeth AE. Vascular perfusion of rat small intestine: metabolic studies with isolated and in situ preparations. Fed Proc 1977;36:177-181.

86. Windmueller $\mathrm{HG}_{3}$ Spaeth AE. Intestinal metabolism of glutamine and glutamate from the lumen as compared to glutamine from blood. Arch Biochem Biophys $1975 ; 171: 662-672$.

87. Reeds PJ, Burrin DG, Stoll B, Jahoor F. Intestinal glutamate metabolism. I Nutr $2000 ; 130: 978 s-982 s$.

88. Windmueller $\mathrm{HG}$, Spaeth AE. Metabolism of absorbed aspartate, asparagine, and arginine by rat small intestine in vivo. Arch Biochem Biophys 1976;175:670-676.

89. Battezzati A, Brillon DJ, Matthews DE. Oxidation of glutamic acid by the splanchnic bed in humans. Am J Physiol 1995;269:E269-276.

90. Reeds PJ, Burrin DG, Jahoor F, Wykes L, Henry J, Frazer EM. Enteral glutamate is almost completely metabolized in first pass by the gastrointestinal tract of infant pigs. Am J Physiol 1996;270:E413-418.

91. Stoll B, Burrin DG, Henry J, Yu H, Jahoor F, Reeds PJ. Substrate oxidation by the portall drained viscera of fed piglets. Am J Physiol 1999;277:E168-175.

92. Windmueller HG. Glutamine utilization by the small intestine. Adv Enzymol Relat Areas Mol Biol 1982;53:201-237.

93. Wu G, Knabe DA, Yan W, Flynn NE. Glutamine and glucose metabolism in enterocytes of the neonatal pig. Am I Physiol 1995; 268: R334-342.

94. Alteheld B, Stehle P, Furst P. Measurement of amino acid concentrations in biological fluids and tissues using reversed-phase HPLC-based methods. In: Cynober $\mathrm{L}$, editor. Metabolic and therapeutic aspects of amino acids in clinical nutrition. 2 nd ed: CRC Press; 2004. pp. 29-44.

95. Oehler R, Roth E. Regulative capacity of glutamine. Curr Opin Clin Nutr Metab Care $2003 ; 6: 277-282$

96. Watford M, Lund P, Krebs HA. Isolation and metabolic characteristics of rat and chicken enterocytes. Biochem J 1979;178:589-596.

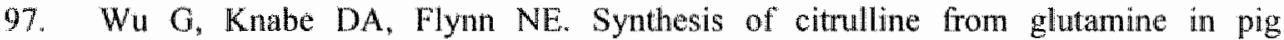
enterocytes. Biochem J 1994;299:115-121.

98. Pinkus LM, Windmueller HG. Phosphate-dependent glutaminase of small intestine: localization and role in intestinal glutamine metabolism. Arch Biochem Biophys $1977: 182: 506-517$

99. Castillo L, Chapman TE, Sanchez M, Yu YM, Burke IF, Ajani AM, Vogt J, Young VR. Plasme arginine and citrulline kinetics in adults given adequate and arginine-free diets. Proc Natl Acad Sci U SA 1993;90:7749-7753.

100. Castillo L, Sanchez M, Vogt J, Chapman TE, DeRojas Walker TC, Tannenbaum SR, Ajami AM, Young VR. Plasma arginine, citrulline, and ornithine kinetics in adults, with observations on nitric oxide synthesis. Am J Physiol 1995;268:E360-367. 
101. van der Hulst RR, von Meyenfeldt MF, Deutz NE, Soeters PB. Glutamine extraction by the gut is reduced in depleted gastrointestinal cancer. Ann Surg $1997 ; 225: 112$ 121.

102. Matthews DE, Marano MA, Campbell RG. Splanchnic bed utilization of glutamine and glutamic acid in humans. Am J Physiol 1993;264:E848-854.

103. Darmaun D, Matthews DE, Bier DM. Glutamine and glutamate kinetics in humans. Am J Pysiol 1986;251:E1 17-126.

104. Dechelotte $\mathrm{P}$, Darmaun $\mathrm{D}$, Rongier $\mathrm{M}$, Hecketsweiler $\mathrm{B}$, Rigal $\mathrm{O}$, Desjeux JF. Absorption and metabolic effects of enterally administered glutamine in humans. Am J Physiol 1991;260:G677-682.

105. Meijer Al. Ureagenesis and ammoniagenesis: an update. In: Cynober L, editor. Metabolic and therapeutic aspects of amino acids in clinical nutrition. 2 nd ed: CRC press; 2004. pp. 111-122.

106. Coomes MW. Amino acid metabolism. In: Devlin TM, editor. Textbook of Biochemistry with clinical correlations. 5th ed. New York: Wiley-Liss; 2002. pp. $779-823$.

107. Raijman L. Citrulline synthesis in rat tissues and liver content of carbamoyl phosphate and ornithine. Biochem J 1974;138:225-232.

108. Hurwitz $R$, Kretchmer $N$. Development of arginine-synthesizing enzymes in mouse intestine. Am J Physiol 1986;251:G103-110.

109. Wu G. Urea synthesis in enterocytes of developing pigs. Biochem J 1995;312:717 723.

11. Meijer AJ, Lamers WH, Chamuleau RA. Nitrogen metabolism and ornithine cycle function. Physiol Rev 1990;70:701-748.

111. Wakabayashi Y, Yamada E, Yoshida T, Takahashi H. Arginine becomes an essential amino acid after massive resection of rat small intestine. J Biol Chem 1994; 269 : 32667-32671.

1. 12. Chen K, Nezu R, Sando K, Haque SM, liboshi Y, Masunari A, Yoshida $H$, Kamata $\mathrm{S}$, Takagi $\mathrm{Y}, \mathrm{Okada} \mathrm{A}$. Influence of glutamine-supplemented parenteral nutrition on intestinal amino acid metabolism in rats after small bowel resection. Surg Today $1996 ; 26: 618-623$.

113. Crenn P, Coudray Lucas C, Thuillier F, Cynober L, Messing B. Postabsorptive plasma citrullime concentration is a marker of absorptive enterocyte mass and intestinal failure in humans. Gastroenterology 2000;119:1496-1505.

114. Crenn $\mathbb{P}$, Vahedi $K$, Lavergne Slove A, Cynober L, Matuchansky C, Messing B. Plasma citrulline: A marker of enterocyte mass in villous atrophy-associated small bowel disease. Gastroenterology 2003;124:1210-1219.

115. Flynn NE, Wu G. An important role for endogenous synthesis of arginine in maintaining arginine homeostasis in neonatal pigs. Am J Physiol 1996;271:R1 1491155.

116. Wakabayashi $Y$, Jones ME. Pyrroline-5-carboxylate synthesis from glutamate by rat intestinal mucosa. I Biol Chem 1983;258:38:65-3872.

117. Kramer JJ, Henslee JG, Wakabayashi Y, Jones ME. Delta 1-pyrroline-5-carboxylate synthase from rat intestinal mucosa. Methods Enzymol 1985;113:113-120. 
118. Wakabayashi $Y$. The glumate crossway. In: Cynober LA, editor. Metabolic and therapeutic aspects of amino acids in clinical nutriton. 2nd ed: CRC press: 2004, pp. $135-152$.

119. Wakabayashi $Y$, Yamada E, Hasegawa T, Yamada R. Enzymological evidence for the indispensability of small intestine in the synthesis of arginine from glutamate. 1 . Pyrroline-5-carboxylate synthase. Arch Biochem Biophys 1991;291:1-8.

120. Wu G, Davis PK, Flynn NE, Knabe DA, Davidson JT. Endogenous synthesis of arginine plays an important role in maintaining arginine homeostasis in postweaning growing pigs. J Nutr 1997; $127: 2342-2349$.

121. Wu G. Synthesis of citrulline and arginine from proline in enterocytes of postnatal pigs. Am J Physiol 1997;272:G1382-1390.

122. Samuels SE, Aarts HL, Ball RO. Effect of dietary proline on proline metabolism in the neonatal pig. I Nutr 1989;119:1900-1906.

123. Adams $\mathbb{E}$, Frank $\mathbb{L}$. Metabolism of proline and the hydroxyprolines. Annu Rev Biochem 1980;49:1005-1061.

124. Wu $G$, Knabe DA. Arginine synthesis in enterocytes of neonatal pigs. Am I Physiol 1995;269:R621-629.

125. Schoknecht PA. Pond WG. Short-term ingestion of a high protein diet increases liver and kidney mass and protein accretion but not cellularity in young pigs. Proc Soc Exp Biol Med 1993;203:251-254.

126. Tizianello A, De Ferrari $G$, Garibotto $G$, Gurreri $G$, Robaudo $C$. Renal metabolism of amino acids and ammonia in subjects with normal renal function and in patients with chronic renal insufficiency. J Clin Invest 1980;65:1162-1173.

127. Wu G, Morris SM, Ir. Arginine metabolism: nitric oxide and beyond. Biochem $J$ $1998 ; 336: 1-17$.

128. Shih VE. Congenital hyperammonemic syndromes. Clin Perinatol 1976;3:3-14.

129. Chan W, Wang $M$, Kopple JD, Swendseid ME. Citrulline levels and urea cycle enzymes in uremic rats. J Nutr 1974;104:678-683.

130. Wu G, Morris SM, Jr. Arginine metabolism in mammals. In; Cynober LA, editor. Metabolic and therapentic aspects of amino acids in clinical nutrition. 2 nd ed: CRC press; 2004. pp. 153-167.

131. Hoogemraad N, Totino N, Elmer H, Wraight C, Alewood P, Johns RB. Inhibition of intestinal citrulline synthesis causes severe growth retardation in rats. Am J Physiol $1985: 249: \mathrm{G} 792-799$.

132. Gondolesi GE, Kaufman SS, Sansaricq C, Magid MS, Raymond K, Iledan LP, Tao Y, Florman SS, LeLeiko NS, Fishbein TM. Defining normal plasma citrulline in intestinal transplant recipients. Am J Transplant 2004;4:414-418.

133. Pappas PA, G Tzakis A, Gaynor JJ, Carreno MR, Ruiz P, Huijing F, Kleiner G, Rabier D, Kato T, Levi DM, Nishida $S$, Gelman B, Thompson JF, Mittal $N$, Saudubray IM. An analysis of the association between serum citrulline and acute rejection among 26 recipients of intestinal transplant. Am J Transplant 2004;4:11241. 132.

134. Crenn P, Coudray Lucas C, Cynober L, Messing B. Post-absorptive plasma citrulline concentration: a marker of intestinal failure in humans. Transplant Proc 1998; 30: 2528 . 
135. Wu G, Meininger $\mathrm{CJ}$, Kelly $\mathrm{K}$, Watford M; Morris SM, Jr. A cortisol surge mediates the enhanced expression of pig intestimal pyrroline-5-carboxylate synthase during weaning. J Nutr 2000;130:1914-1919.

136. Yamada $E$, Wakabayashi $Y$. Development of pyrroline-5-carboxylate synthase and N-acetylglutamate synthase and their changes in lactation and aging. Arch Biochem Biophys 1991;291:15-23.

137. Dugan $M E$, Knabe DA, Wu $\mathrm{G}$. The induction of citrulline synthesis from glutamine in enterocytes of weaned pigs is not due primarily to age or change in diet. I Nutr $1995 ; 125: 2388-2393$.

138. Flynn NE, Wu G. Enhanced metabolism of arginine and glutamine in enterocyles of cortisol-treated pigs. Am I Physiol 1997;272:0447-480.

139. Flynn NE, Wu G. Glucocorticoids play an important role in mediating the enlanced metabolism of arginine and glutamine in enterocytes of postweaning pigs. I Nutr 1997; 127:732-737.

140. Flymn NE, Meininger CJ, Kelly K, Ing NH, Morris SM, Ir, Wu G. Glucocorticoids mediate the enhanced expression of intestinal type II arginase and argininosuccinate lyase in postweaning pigs. J Nutr 1999;129:799-803.

141. Wu G. An important role for pentose cycle in the synthesis of citrulline and protine from glutamine in porcine enterocytes. Arch Biochem Biophys 1996:336:224-230.

142. Dillon EL, Knabe DA, Wu G. Lactate inhibits citrulline and arginine synthesis from proline in pig enterocytes. Am J Physiol 1999;276:G1079-1086.

143. Houdijk AP, van Leeuwen PA, Teerlink T, Flinkerbusch EL, Boermeester MA, Sauerwein HP, Wesdorp RI. Glutamine-enriched enteral diet increases renal arginine production. JPEN 1994;18:422-426.

144. Carpenter TO, Levy HL, Holtrop ME, Shih VE, Anast CS. Lysinuric protein intolerance presenting as childhood osteoporosis. Clinical and skeletal response to citrulline therapy. NEJM 1985;312:290-294.

145. Rajantie J, Simell $O$, Rapola J, Perheentupa J. Lysinuric protein intolerance: a twoyear trial of dietary supplementation therapy with citrulline and lysine. J Pediatr $1980 ; 97: 927-932$.

146. Kawamoto S, Strong RW, Kerlin P, Lynch SV, Steadman C, Kobayashi K,

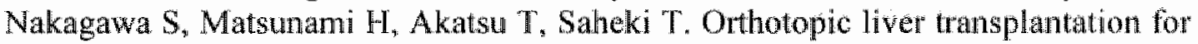
adult-onsei type II citrullinaemia. Clin Transplant 1997;11:453-458.

147. Fletcher JM, Couper R, Moore D, Coxon R, Dorney S. Liver transplantation for citrullinaemia improves intellectual function. I Inherit Metab Dis 1999;22:581-586.

148. Mithieux G. New data and concepts on glutamine and glucose metabolism in the gut. Curr Opin Clin Nutr Metab Care 2001;4:267-271.

149. Cremn $P$, Thuillier $F$, Rakatoambinina $B$, Rongier $M$, Darmaun $D$, Messing $B$. Duodenal vs. gastric administration of labeled leucine for the study of splanchnic metabolism in humans. J Appl Physiol 2000;89:573-580.

150. Pappas PA, Saudubray IM, Tzakis AG, Rabier D, Carreno MR, Gomez Marin O, Huijing F, Gelman B, Levi DM, Nery JR, Kato T, Mittal N, Nishida S, Thompson JF, Ruiz P. Serum citrulline and rejection in small bovel transplantation: a preliminary report. Transplantation 2001;72:1212-1216.

151. Pappas PA, Saudubray JM, Tzakis AG, Rabier D, Carreno MR, Gomez Marin O, Huijing F, Gelman B, Levi DM, Nery JR, Kato T, Mittal N, Nishida S, Thompson 
JF, Ruiz P. Serum citrulline as a marker of acute cellular rejection for intestinal transplantation. Transplant Proc 2002;34:915-917.

152. Pappas PA, Tzakis AG, Saudubray JM, Gaynor JJ, Carreno MR, Huijing F, Kleiner

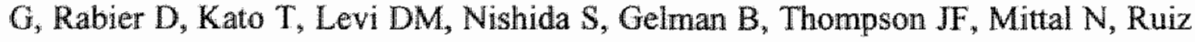
$P$. Trends in serum citrulline and acute rejection among recipients of small bowel transplants. Transplant Proc 2004;36:345-347.

153. Gondolesi G, Fishbein T, Chehade M, Tschemia A, Magid M, Kaufman S, Raymond $K$, Sansaricq $C$, LeLeiko N. Serum citrulline is a potential marker for rejection of intestinal allografts. Transplant Proc 2002;34:918-920.

154. Potten CS, Hendry JH. Radiation and gut:: Elsevier Science B.V. Amsterdam.; 1995.

155. Potten CS. Effects of radiation on murine gastrointestinal cell proliferation. In: Potten CS, Hendry H, editors. Radiation and gut. Amsterdam: Elsevier Science B.V.; 1995. $\mathrm{pp}_{.} 61-84$.

156. Osborne JW. Early and late radiation effects (external irradiation) on the gut. In: Potten CS, Hendry JH, editors. Radiation and gut. Amsterdam: Elsevier; 1995. pp. 145-209.

157. Paris $F$, Fuks Z, Kang A, Capodieci P, Juan G, Ehleiter D, Haimovitz Friedman A, Cordon Cardo C, Kolesnick R. Endothelial apoptosis as the primary lesion initiating intestinal radiation damage in mice. Science $2001 ; 293: 293-297$.

158. Suit $\mathrm{HD}$, Withers $\mathrm{HR}$. Endothelial cells and radiation gastrointestinal syndirome. Science $2001 ; 294: 1411$.

159. Hendry JH, Booth C, Potten CS. Endothelial cells and radiation gastrointestinal syndrome. Science 2001; $294: 1411$.

160. Hopewell JW, Calvo W, Campling, Reinhold HS, Rezvani M, Yeung TK. Effects of radiation on the microvasculature. Implications for normal-tissue damage. In: Vaeth JM, Meyer JL, editors. Radiation tolerance of normal tissues. Vol 23. Basel: Karger; 1989. p. 85.

161. Fajardo LF, Berthrong M. Vascular lesions following radiation. Pathol Annu 1988; 23 Pt 1:297-330.

162. Fischer Dzoga $K$, Dimitrievich GS, Griem ML. Radiosensitivity of vascular tissue. II. Differential radiosensitivity of aortic cells in vitro. Radiat Res $1984 ; 99: 536-546$.

163. Penhaligon M, Laverick M. Radiation response of endothelial cells in vitro. $\mathrm{Br} J$ Radiol 1985; 58:913-914.

164. Richter KK, Langberg CW, Sung CC, Hauer-Jensen M. Association of transforming growth factor beta (TGF-beta) immunoreactivity with specific histopathologic lesions in subacute and chronic experimental radiation enteropathy. Radiother Oncol 1996; 39:243-251.

165. Hauer-Jensen M, Richter KK, Wang J, Abe E, Sung CC, Hardin JW. Changes in transforming growth factor betal gene expression and immunoreactivity levels during development of chronic radiation enteropathy. Radiat Res 1998;150:673-680.

166. Wang $J_{3}$ Zheng $H$, Sung $C C$, Richter KK, Hauer Jensen M. Cellular sources of transforming growth factor-beta isoforms in early and chronic radiation enteropathy. Am J Pathol 1998; 153:1531-1540.

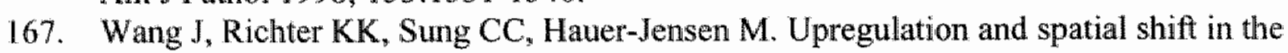
localization of the mannose 6-phosphate/insulin-like growth factor II receptor during radiation enteropathy development in the rat. Radiother Oncol 1999;50:205-213. 
168. Wang J, Zheng H, Sung CC, Hauer-Jensen M. The synthetic somatostatin analogue, octreotide, ameliorates acute and delayed intestinal radiation injury. Int d Radiat Oncol Biol Phys 1999; 45:1289-1296.

169. Langberg CW, Hauer-Jensen M, Sung CC, Kane CJ. Expression of fibrogenic cytokines in rat small intestine after fractionated irradiation. Radiother Oncol 1994; 32:29-36.

170. Zheng $H$, Wang J, Hauer-Jensen $M$. Role of mast cells in early and delayed radiation injury in rat intestine. Radiat Res 2000;153:533-539.

171. Trott KR, Herrmann T. Radiation injury to abdominal organs. Br $\mathbb{E}$ Radiol Suppl $1988 ; 22: 30-32$

172. Hauer-Jensen M, Sauer T, Reitan JB, Nygaard K. Late radiation enteropathy following split-dose irradiation of rat small intestine. Acta Radiol Oncol $1986 ; 25: 203-206$

173. Breiter N, Sassy T, Trott KR, Unsold E. Die endoskopische Verlaufskontrolle und deren histologische Korrelation des chronischen Strahlenschadens am Enddarm der Ratte. Strahlenther Onkol 1988;164:674-680.

174. Langberg $\mathrm{CW}$, Hauer-Jensen $\mathrm{M}$. Influence of fraction size on the development of late radiation enteropathy. An experimental study in the rat. Acta Oncol 1996;35:89-94.

175. Richter KK, Fagerhol MK, Carr JC, Winkler JM, Sung CC, Hauer-Jensen M. Association of granulocyte transmigration with structural and cellular parameters of injury in experimental radiation enteropathy. Radiat Oncol lnvestig 1997;5:275-282.

176. Denham JW, Hauer-Jensen $M$, Kron T, Langberg CW. Treatment-time-dependence models of early and delayed radiation injury in rat small intestine. Int $J$ Radiat Oncol Biol Phys 2000;48:871-887.

177. Hanson WR. Radiation protection of murine intestine by WR-2721, 16,16-dimethyl prostaglandin $\mathrm{E} 2$, and the combination of both agents. Radiat Res 1987;111:361-373.

178. Thomson $\mathrm{AB}$, Cheeseman $\mathrm{CI}$, Walker $\mathrm{K}$. Late effects of abdominal radiation on intestinal uptake of nutrients. Radiat Res $1986 ; 107: 344-353$.

179. Dorr W. Acute radiation effects in normal tissues - Translational aspects of biological research. In: Dorr W, Engenhart-Cabillic R, Zimmermann JS, edito s. Frontiers of radiation therapy and oncology. Vol 37. Basel: Karger; 2002. pp. 1-8.

180. Withers HR, McBride WH. Radiation effects on normal tissues. In: Meyer JL, editor. Radiation injury. Advances in management and prevention. Vol 32. Basel: Karger; 1999. pp. 1-8.

181. van der Kogel AJ. Cell proliferation in normal tissues. In: Steel GG, editor. Basic clinical radiobiology for radiation oncologists. London: Arnold 1995 , pp. 23-27.

182. van der Kogel AJ. Radiobiology of normal tissues. In: Steel GG, editor. Basic clinical radtobiology for radiation oncologists. London: Arnold; 1995. pp. 99-107.

183. Potten CS, Booth C. The role of radiation-induced and spontaneous apoptosis in the homeostasis of the gastrointestinal epithelium: a brief review. Comp Biochem Physiol B Biochem Mol Biol 1997;1 18:473-478.

184. ljiri $K$, Potten $C S$. Further studies on the response of intestinal crypt cells of different hierarchical status to eighteen different cytotoxic agents. Br J Cancer 1987;55:113123.

185. Li YQ, Fan CY, O'Connor PJ, Winton DJ, Potten CS. Target cells for the cytotoxic effects of carcinogens in the murine small bowel. Carcinogenesis 1992;13:36 $1-368$. 
186. Clarke AR, Gledhill S, Hooper ML, Bird CC, Wyllie AH. p53 dependence of early apoptotic and proliferative responses within the mouse intestinal epithelium following gamma-irradiation. Oncogene 1994;9:1767-1773.

187. Merritt AJ, Allen "TD, Potten CS, Hickman JA. Apoptosis in small intestinal epithelial from p5iz-null mice: evidence for a delmyed; p53-independent $G 2 / \mathrm{M}$ associated cell death after gamma-irradiation. Oncogene 1997;14:2759-2766.

188. Ruifrok AC, Mason KA, Lozano G, Thames HD. Spatial and temporal patterns of expression of epidermal growth factor, transforming growth factor alpha and transforming growth factor beta $\mathrm{J}-3$ and their receptors in mouse jejunum after radiation treatment. Radiat $\operatorname{Res} 1997 ; 147: 1-12$.

189. Gunter Smith PJ. Gamma radiation affects active electrolyte transport by rabbit illeum: basal Na and Cl transport. Am J Physiol 1986;250:G540-545.

190. Lebrun F, Benderitter M, Berroud A, Voisin P, Griftiths NM. Potential role of the membrane in the development of intestinal cellular damage after whole-body gamma irradiation of the rat. Can J Physiol Pharmacol 2002;80:686-693.

191. Guzman Stein G, Bonsack M. Liberty J, Delaney JP. Abdominal radiation causes bacterial translocation. J Surg Res 1989;46:104-107.

192. Picard $\mathrm{C}$, Wysocki $\mathrm{J}$, Fioramonti $\mathrm{J}$, Griffiths $\mathrm{NM}$. Intestinal and colonic motor alterations associated with irradiation-induced diarrhoea in rats. Neurogastroenterol Motil $2001 ; 13: 19-26$.

193. Fraser R, Frisby C, Blackshaw LA, Schirmer M, Howarth G, Yeoh E. Small intestinal dysmotility following abdominal irradiation in the rat small intestine. Neurogastroenterol Motil 1998;10:413-419.

194. Becciolini A, Balzi M, Potten CS. Radiation effects on proliferation and differentiation in the rat small intestine. In: Potten CS, Hendry JH, editors. Radiation and gut. 1 ed. Amsterdam: Elsevier Science B.V.; 1995. pp. 85-143.

195. Thomson AB, Cheeseman $\mathrm{CI}$, Walker $\mathrm{K}$. Effect of abdominal irradiation on the kinetic parameters of intestinal uptake of glucose, galactose, leucine, and gly-leucine in the rat. I Lab Clin Med 1983;102:813-827.

196. Thomson AB, Cheeseman CI, Walker K. Effect of external abdominal irradiation on the dimensions and characteristics of the barriers to passive transport in the rat intestine. Lipids 1984;19:405-418.

197. Thomson $\mathrm{AB}$, Cheeseman $\mathrm{Cl}$, Walker $\mathrm{K}$. Intestinal uptake of bile acids: effect of external abdominal irradiation. Int J Radiat Oncol Biol Phys 1984;10:671-685.

198. Overgaard J, Matsui M. Effect of radiation on glucose absorption in the mouse jejunum in vivo. Radiother Oncol 1990;18:71-77.

199. Juby LD, Dixon MF, Axon AT. Abnormal intestinal permeability and jejunal morphometry. J Clin Pathol 1987;40:714-718.

200. Gunter Smith PJ. Gamma vadiation affects active electrolyte transport by rabbit ileum. 11. Comelation of alanine and theophylline response with motphology. Radiat Res 1989;117:419-432.

201. Kirichenko AV, Mason KA, Straume M, Teates CD, Rich TA. Nuclear scintigraphic assessment of radiation-induced intestinal dysfunction. Radiat Res 2000;153:164172 .

202. Hubel KA. Intestinal nerves and ion transport: stimuli, reflexes, and responses. Am J Physiol 1985:248:G261-271. 
203. Souba WW, Klimberg VS, Hautamaki RD, Mendenhall WH, Bova FC, Howard RJ, Bland $K I$, Copeland. EM. Oral glutamine reduces bacterial translocation following abdominal radiation. J Surg Res 1990;48:1-5.

204. Klimberg VS, Salloum RM, Kasper M, Plumley DA, Dolson DJ, Hautamaki RD, Mendenhall WR, Bova FC, Bland Kl, Copeland EM, 3rd, et al. Oral glutamine accelerates healing of the small intestine and improves outcome after whole abdominal radiation. Arch Surg 1990;125:1040-1045.

205. Jensen JC, Schaefer R, Nwokedi E, Bevans DW, 3rd, Baker ML, Pappas AA, Westbrook KC, Klimberg VS. Prevention of chronic radiation enteropathy by dietary glutamine. Ann Surg Oncol 1994;1:157-163.

206. Gallagher MJ, Brereton HD, Rostock RA, Zero JM, Zekoski DA, Poyss LF, Richter MP, Kligerman MM. A prospective study of treatment techniques to minimize the volume of pelvic small bowel with reduction of acute and late effects associated with pelvic irradiation. Int I Radiat Oncol Biol Phys 1986;12:1565-1573.

207. Baglan KL, Frazier RC, Yan D, Huang RR, Martinez AA, Robertson JM. The dosevolume relationship of acute small bowel toxicity from concurrent 5-FU-based chemotherapy and radiation therapy for rectal cancer. Int I Radiat Oncol Biol phys 2002:52:176-183.

208. Withers HR, Elkind MM. Microcolony survival assay for cells of mouse intestinal mucosa exposed to radiation. Int J Radiat Biol Relat Stud Phys Chem Med 1970; $17: 261-267$.

209. Johansson JE, Ekman $T$, Gastro-intestinal toxicity related to bone marrow mansplantation: disruption of the intestinal barrier precedes clinical findings. Bone Marrow Transplant 1997;19:921-925.

210. Johansson JE, Ekman T. Gut mucosa barrier preservation by orally administered IgA-IgG to patients undergoing bone marrow transplantation: a randomised pilot study. Bone Marrow Transplant 1999;24:35-39.

211. Keefe DM, Brealey J, Goland GJ, Cummins AG. Chemotherapy for cancer causes apoptosis that precedes hypoplasia in crypts of the small intestine in humans. Gut 2000;47:632-637.

212. Craig RM, Atkinson AJ, Ir. D-xylose testing: a review, Gastroenterology $1988 ; 95: 223-231$.

213. Shaff RE, Beaven MA. Tumover and synthesis of diamine oxidase (DAO) in ratt tissues. Studies with heparin and cycloheximide. Biochem Pharmacol 1976;25:10571062.

214. Wollin A, Navert H, Bounous $G$. Elfect of intestinal ischemia on diamine oxidase activity in rat intestinal tissue and blood. Gastroenterology 1981;80:349-355.

215. Bieganski $T$, Kusche J, Lorenz W, Hesterberg $R$, Stahlknecht CD, Feussner $K$ D. Distribution and properties of human intestinal diamine oxidase and its relevance for the histamine catabolism. Biochim Biophys Acta 1983;756:196-203.

216. D'Agostino L, Ciacei C, Capuano G, Daniele B, D'Argenio G, Barone MV, Rodino S. Budillon $\mathrm{G}$, Mazzacca $\mathrm{G}$. Metabolic fate of plasma diamine oxidase: evidence of isolated and perfused rat liver uptake. Digestion 1986;34:243-250.

217. Bragg LE, Thompson JS, West WW. Intestinal diamine oxidase levels reflect ischemic injury. J Surg Res 1991;50:228-233. 
218. Bounous $\mathrm{G}$, Echave $\mathrm{V}$, Vobecky SJ, Nawert $\mathrm{H}$, Wollin A. Acute necrosis of the intestinal mucosa with high serum levels of diamine oxidase. Dig Dis Sci 1984; 29 : $872-874$.

219. Rose SG, Thompson JS, Spanta AD, Quigley EM. The effect of intestinal autotransplantation on serum diamine oxidase activity. I Surg Res 1991;50:223-227.

220. Ely MJ, Speicher JM, Catravas GN, Snyder SL. Radiation effects on diamine oxidase activities in intestine and plasma of the rat. Radiat Res 1985;103:158-162.

221. DeBell RM, Ledney GD, Snyder SL. Quantilication of gut injury with diamine oxidase activity: development of a fission neutron $\mathrm{RBE}$ and measurements with combined injury in mouse models. Radiat Res 1987;112:508-516.

222. Jones $\mathrm{ME}$, Anderson $\mathrm{AD}$, Anderson $\mathrm{C}$, Hodes $\mathrm{S}$. Citrulline synthesis in rat tissues. Arch Biochem Biophys 1961;95:499-507.

223. Oehller R, Roth E. Glutamine metabolism. In: Cynober LA, editor. Metabolic and therapeutic aspects of amino acids in clinical nutrition. 2nd ed: CRC Press; 2004. pp. 169-182.

224. Ten Have GA, Bost MC, Suyk Wierts JC, van den Bogaard AE, Deutz NE. Simultaneous measurement of metabolic flux in portally-drained viscera, liver, spleen, kidney and hindquarter in the consicious pig. Lab Anim 1996;30:347-358.

225. Dejong $\mathrm{CH}$, Kampman MT, Deutz NE, Soeters PB. Altered glutamine metabolism in rat portal drained viscera and hindquarter during hyperammonemiat. Gastroenterology 1992;102:936-948.

226. De Blaauw I, Deutz NE, van der Hulst RR, von Meyenfeldt MF. Glutamine depletion and increased gut permeability in nonanorectic, non-weight-losing tumor-bearing rats. Gastroenterology 1997;112:118-126.

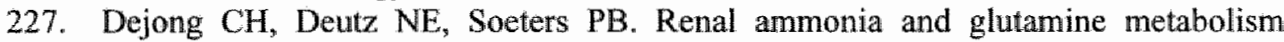
during liver insufficiency-induced hyperammonemia in the rat. $J$ Clin Invest $1993 ; 92: 2834-2840$. 


\section{Chapter 5}

CITRULLINE: A PHYSIOLOGICAL MARKER ENABLING QUANTITATION AND MONITORING OF EPITHELIAL RADIATION-INDUCED SMALL BOWEL DAMAGE

Ludy C.H.W. Lutgens M.D. ${ }^{4}$, Nicolaas E.P. Dentz, M.D., Ph.D. ${ }^{2}$, John Gueulette, Ph.D. ${ }^{3}$, Jack P.M. Cleutjens Ph.D. , Martijn P.F. Berger, Ph.D. ${ }^{5}$, Bradlly G. Wouters Ph. D. ', Maarten F. von Meyenfeldt, M.D., Ph.D.2, Philippe Lambin, M.D., Ph.D. ${ }^{1}$

'MAASTRO, department of Radiation Therapy and Omcology, Uniwersity Hospital Maastricht' Maastricht University 2 deparment of Surgery, University Hospital Maastricht/Maastricht University,

${ }^{3}$ Unité de Radiobiologie et Unité de Radiotherapie, Université Catholique de Lawaim, Bruxelles, Belgiwm. "department of Pathology, Maasiricht University. "department of Methodology and Statistics, Maastricht Uniwersity. The Netherlands.

Int J Radiat Oncol Biol Plys 2003; 57: 1067-1074. 


\section{Introduction}

When abdominal or pelvic cancers are treated with radiotherapy, the small bowel is a major dose- limiting organ both with regard to acute and late treatment related morbidity. The cellular mechanism of small bowel radiation injury has been studied extensively in the laboratory. The intestinal crypt cell and, more recently, the pericryptal endothelial cell ${ }^{2}$ have been designated as target cells for epithelial radiation injury. We have focused our research on epithelial radiation sequelae as a target for intervention of both acute and late small bowel radiation injury.

Radiation damage to intestinal epithelium can be measured by morphological and/or functional endpoints. The application of morphological endpoints such as crypt cell regeneration, ${ }^{3}$ apoptosis $1,2,4$ and mucosal surface measurements ${ }^{5}$ in clinical practice is hampered by the need for tissue sampling. As a consequence, data are mainly derived from rodent studies. $A$ wide diversity of functional disorders thave been observed following ionizing radiation such as changes in trans-epithelial transport processes ${ }^{6.7}$ or the absorption of various nutrients such as carbohydrates, amino acids, proteins, vitamins and bile acid. ${ }^{813}$ Some of these functional changes have been correlated with the epithelial cell mass available for absorption 1, 12, 14, 15 suggesting a cellular basis in at least part of radiation induced functional disorders. Subsequently, such functional tests were evaluated for their applicability as a clinical assay for intestinal damage related to radiation-induced epithelial cell loss. ${ }^{1,}{ }^{14}$ However, as a routine in daily clinical practice these parameters are not suited for repeated measurements.

Our aim is to develop a clinical assay for radiation induced small bowel damage, i.e. an assay sensitive and quantificable at clinically relevant doses. The assay must be applicable in daily clinical practice during the acute and late phases of radiation injury enabling determination of temporal and/or permanent intestinal damage on a routine base. Such an assay should then allow reliable assessments of the therapentic window for new treatment strategies.

In this report, we describe the citrulline kinetics in NMRI mice in response to single dose whole body irradiation (WBI). We hypothesized that the intestinal release of citrulline into the circulation decreases as a finction of the radiation induced reduction of epithelial cell mass. Thus citrullinemia is tested as a quantitative marker for small bowel epithelial radiation injury. For this purpose the time course for citrullinemia has been assessed at $1,2,4,8$ and 11 days alter single WBI doses of $8-12$ Gy and a dose-response relationship for plasma citrulline levell is determined at $84 \mathrm{~h}$ after single WBI doses between 0 - 14.9 Gy. Furthermore, citrullinemia is correlated with parameters for epithelial radiation damage and used for calculation of the dose-modifying factor for Amifostine (WR-2721) ${ }^{16,17}$ a radioprotector for small bowel epithelium.

\section{Methods and Materialls}

\section{Mice}

Female NMRI mice 12-14 weeks old $(23-33 \mathrm{~g})$ were obtained from Harlan Netherlands B.V., Horst, The Netherlands. Mice were housed three per cage under standard 12 hour 
light-dark cycle periods $\left(7: 30\right.$ a.m. to $7: 30$ p.m.) with room temperature maintained at $25^{\circ} \mathrm{C}$. The animals were fed standard mice chow and water ad hithm. All experiments were performed in accordance with the recommendations of the Gude for the Care and Use of Laboratory anmals and approved by the Ethical Conmittee of Animal Research of the Catholic University of Leuven, Brussels.

\section{Irradiation.}

The effect of irradiation on plasma citrulline concentration was studied after a single dose of whole body irradiation (WBD). Three unanesthesized mice of one cage were placed in a prone position in a Perspex air-ventilated jig and exposed to $250 \mathrm{kV}$ photons (Philips) at a dose rate of $0.86 \mathrm{G} / \mathrm{min}$, using an antero-posterior and postero-anterior beam. During treatment the animals were loosely restrained with their legs stretched forwards and backwards, respectively. A Perspex plate ( $4 \mathrm{~mm}$ thickness) on top and at the bottom of the jig ensured the homogeneity of the dose distribution (s. $3 \%$ dose variation).

\section{Plasma citrulline level}

Immediately after blood $(0.2 \mathrm{ml})$ was sampled by a cardiac puncure the animals were terminated for tissue sampling by cervical dislocation. Plasma was obtained by whole blood centrifugation at $8900 \times \mathrm{g}$ at $4^{\circ} \mathrm{C}$ for $5 \mathrm{~min}$. For determination of amino acids, $100 \mu \mathrm{l}$ plasma was deprotemized by adding it to $8 \mathrm{mg}$ dry 5 -sulfosalicylic acid, vortexed, frozen in liquid nitrogen and stored at $-80^{\circ} \mathrm{C}$. Then plasma citrulline level $(\mu \mathrm{M})$ was measured by using highperformance hiquid chromatography. ${ }^{19}$

\section{Morphology}

In all experiments mice were terminated by cervical dislocation. A 2-cm jejunal segnent was excised and lixed in Bouns solution for a maximum of $24 \mathrm{~h}$ prior to the routine processing for histology. Three transverse paraffin sections per mouse were cut at a thickness of $4 \mu \mathrm{m}$ and stained with hematoxylin and eosin.

\section{Morphometric measumements}

Three digitized images per animal at $25 \times$ magnification from the jejunum were evaluated using the calibrated image analysis system (Leica Quantimet $570 \mathrm{C}$; Leica Q570 Qwin version $\mathrm{V}$ 02.01). After digital subtraction of intraluminal contents, the epithelial surface lining is demarcated and measured as a perimetrical length (figures 1 a and $1 \mathrm{~b}$ ). Adjacent villar surfaces are digitally separated to enable measurement of the epithelial surface lining for individual villi. The epithelial lining of intraluminally located villar fragments is accordingly separately measured. The sum of the perimetrical lengths (nm) is then scored representing the total epithelial surface lining per transverse section of the jejunum. For statistical analysis the mean averaged score of 3 images per animal is used.

\section{Morphologic assay}

The microcolony assay, as introduced in 1970 by Withers and Elkind, was used." Strictly $84 \mathrm{~h}$ following irradiation mice were terminated and $2 \mathrm{~cm}$ of jejunum sampled, fixed and 
prepared for sectioning. This time interval is enough to regenerate the crypts and it is assumed that a crypt can regenerate from a single surviving stem cell. Crypts containing $\geq$ 10 cells were considered to be regenerating crypts. For each mouse the number of regenerating crypts per circumference was scored (J.G.) in at least 3 transverse histological sections. For statistical analysis the mean averaged score of 3 transverse sections per animal is used.

Figure 1A \& 1B Mucosal surface lining measurements.

A. Light Microscopic image at $25 \mathrm{x}$ magnification. The image is digitised using the calibrated image analysis system (Leica Quantimet $570 \mathrm{C}$; Leica Q570 Qwin version V 02.01). B. The length $(\mathrm{mm})$ of the digitally demarcated mucosal surface lining is used for statistical analysis. The images shown are obtained at $84 \mathrm{~h}$ after WBI with doses of $9.8 \mathrm{~Gy}$ (left) and 14.9 Gy (right) revealing an epithelial surface lining of $54.3 \mathrm{~mm}$ and $38.6 \mathrm{~mm}$ and corresponding citrulline levels of $15,8 \mu \mathrm{M}$ and $9,3 \mu \mathrm{M}$, respectively.

$\mathbf{A}$
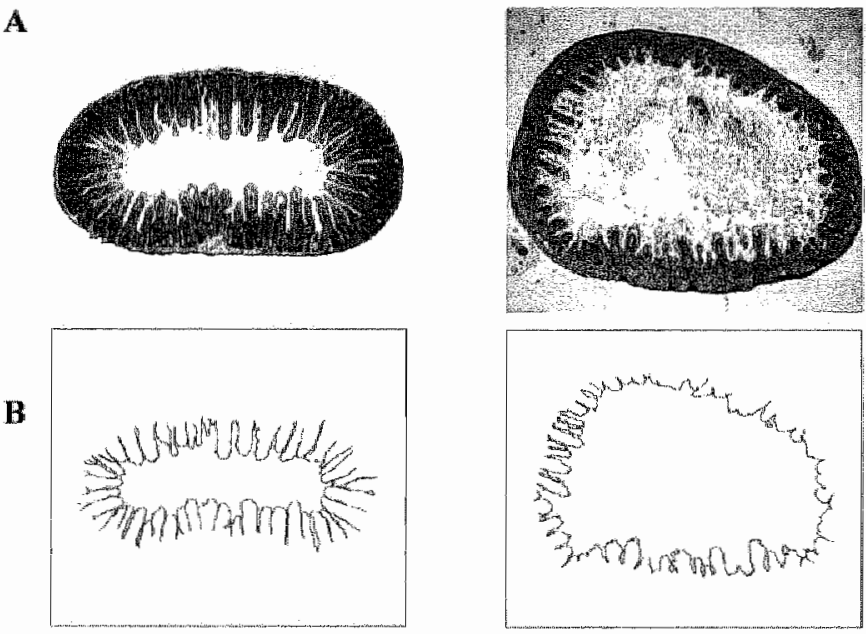

\section{Experimental conditions}

To assess the time course for citrulline after WBI intervals were set at $1,2,4,8$ and 11 days between WBI and blood sampling. In this experiment WBI doses between $8-12$ Gy were applied using 6 mice per dose point at $t=1,2,4$ and 8 days and 12 mice per dose point at $t$ $=11$ days after $\mathrm{WBI}$, respectively.

A dose-response relationship for citrullinemia, jejunal crypt regeneration and mucosal surface lining was assessed at strictly $84 \mathrm{~h}$ after WBI. This interval was chosen in 
accordance with the guidefines for the jejunal microcolony assay ${ }^{3}$ used in the present experiment as one of the morphologic endpoints. WBI doses of $0-10.0$ Gy (dose step 1 Gy) and $8.0 ; 9.8 ; 12.1$ and 14.9 Gy were used. Three mice per dose point were used. No animals were lost due to the experimental procedure yielding data for all endpoints used.

Plasma citrulline level was used as a secondary endpoint to assess the effect of enteral glutamine ${ }^{18}$ on intestinal radiation damage in mice following single dose WBI. The amino acid was supplied as a 3\%-glutamine enriched drinking water solution, starting 4 days prior to radiation until termination at $t=84 \mathrm{~h}$ after WBI. Amifostine (WR-2721) was used as a positive control. ${ }^{16,}{ }^{17}$ Amifostine (Ethyol ${ }^{8}$, USB Pharma, Nijmegen) was stored at $4^{\circ} \mathrm{C}$. Immediately before the experiment $500 \mathrm{mg}$ was dissolved in $10 \mathrm{ml} 150 \mathrm{mM} \mathrm{NaCl}$ solution ( $\mathrm{pH}$ 6.0). Animals were randomly assigned to radiation only (WBI dose $8.0-15.0$ Gy), enteral glutamine feeding (WBI dose 8.7-15.7 Gy) or 10mg Amifostine i.p. $30 \mathrm{~min}$ prior to radiation (WBI dose $11.1-25.2$ Gy), respectively. The DMF of parenteral Amifostine on jejunal epithelial radiation damage was determined using jejunal crypt regeneration and plasma citrullne level assessed at $84 \mathrm{~h}$ after WBI as endpoints. Six mice were used per dose point.

\section{Statistical analysis}

SPSS for windows software (Release 11.0) was used for statistical analysis. For investigation of the dose-response relationship of citrullinemia, raw data of plasma citrulline levels per dose point were used. For examination of a relationship between plasma citrulline levels and morphological endpoints mean values per dose point were used. For the number of regenerated crypts as a function of dose an exponential relation can usually be assumed and a straight line (in log/linear coordinates) can be usually fitted through the experimental points corresponding to less than $70-80$ regenerated crypts. This results from the fact that at these (high) dose levels the number of regenerated crypts corresponds to the number of surviving stem cells, so that the dose-effect relation for crypt regeneration fits the (exponential) distal part of the stem cell survival curve. Bivariate correlations procedure was used for calculation of Pearson's correlation coefficient or Spearman's rho as a measure for a linear or non-linear relationship, respectively, between parameters. One-way ANOVA with additional Tukey's post hoc testing was used to analyze a correlation of plasma citrulline level and jejunal epithelial surface lining with WBI dose at 84h after irradiation. A time and dose effect of plasma citrulline level was tested by Two-Way factorial ANOVA. The significance level was set at $\alpha=0.05$.

\section{Results}

\section{Mucosal surface lining}

The mean ( \pm SEM) mucosal surface lining in 6 control animals (WBI dose 0 Gy) was $67.5 \pm$ $2.5 \mathrm{~mm}$ (range: $58.9-75.3 \mathrm{~mm}$ ). Mucosal surface lining decreased as a function of time after irradiation (Two Way ANOVA; $\mathrm{p}<0.001$ ). Following 8 Gy WBI nadir values were measured at day 2 and day $11(58.0 \pm 2.9 \mathrm{~mm}$ and $53.3 \pm 2.8 \mathrm{~mm} ; \mathrm{p}=11.5$. $)$ whereas for the 
9 Gy dose level the nadir value was measured at day $8(58.0 \pm 6.7 \mathrm{~mm}$; One Way ANOVA: $p=0.2$ ). In contrast, nadir values for the 10,11 and 12 Gy dose levels were measured at 4 days $(52.4 \pm 4.7 \mathrm{~mm} ; 38.3 \pm 2.7 \mathrm{~mm}$ and $45.3 \pm 4.3 \mathrm{~mm}$; One Way ANOVA: $\mathrm{p}=0.034$; $p<0.001$ and $p=0.001$, respectively). Similarly, a significant dose-response relation was observed for mucosal surface lining at the 4-day time point only (Pearson: $r=-0.77$ ) whereas no correlation was seen at the $1,2,8$ and 11-day time points, respectively (Pearson $\mathrm{r}:-0.18 ; 0.19 ;-0.1 \rrbracket$ and -0.15$)$.

A dose-response curve for mucosal surface lining was then assessed at $84 \mathrm{~h}$ after WBI using doses between $1-14.9$ Gy (figure lc). The mucosal surface lining ranged between 38.5 and $109.3 \mathrm{~mm}$ and declined as a function of irradiation dose (One Way ANOVA; $\mathrm{p}=$ 0.002 ). At this time point also a strong correlation between mucosal surface lining and jejunal crypt regeneration was observed (Pearson $r: 0.99$ ).

Figure $1 \mathrm{C}$

Mucosal surface lining measurements.

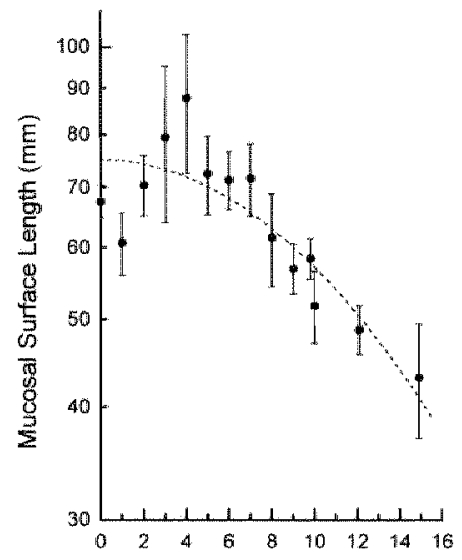

Dose (Gy)

Dose response curve for the mucosal surface lining (mm) 84h after WBI doses of $0-14.9$ Gy. Data are presented as mean \pm SEM. One Way ANOVA: $p=0.002$ ).

\section{Citrullinemia}

The mean ( $\$$ SEM) plasma citrulline level in control animals (WBI dose 0 Gy; $\mathrm{n}=6$ ) was $82.5 \pm 2.5 \mu \mathrm{M}$ (range: $50.1-106.5 \mu \mathrm{M}$ ). The time course of plasma citrulline level as a function of WBI dose was assessed at 1,2,4,8 and 11 days after WBI doses between 8 and $12 \mathrm{~Gy}$. Up to 4 days after WBI no animal died whereas radiation induced mortality increased to $16 \%$ and $57 \%$ (8 Gy), 33\% and 66\% (9 Gy), 66\% and $83 \%(10 \mathrm{~Gy}), 50 \%$ and $43 \%(11 \mathrm{~Gy})$ and $50 \%$ and $75 \%(12 \mathrm{~Gy})$ ar day 8 and 11 after WBI, respectively. 
Plasma citrulline level decreased as a function of dose and time after WBI (Two Way ANOVA; $p=0.002$ and $p=0.001$, respectively). Whereas the time effect was significant for all dose levels used, a significant dose-effect relationship was present only at day 4 after WBI (Pearson: $\mathrm{r}=-0.88$; figure 2a).

As shown in figure $2 \mathrm{~b}$, starting 1 day after WBI the plasma citrulline level progressively decreased irrespective of WBI dose $(p=0.23)$. Following WBI doses between $8-10$ Gy the nadir plasma citrulline level (mean \pm SEM) was observed at 2 days after WBI ( $36.7 \pm 6.8$ $\mu \mathrm{M}(8 \mathrm{~Gy}) ; 34.3 \pm 1.7 \mu \mathrm{M}(9 \mathrm{~Gy}) ; 30.0 \pm 6.5 \mu \mathrm{M}(10 \mathrm{~Gy})$. One Way ANOVA: $\mathrm{p}=0.006 ; \mathrm{p}$ $<0.001$ and $p=0.047$, respectively). In contrast citrullinemia nadir values after WBI doses of 11 and 12 Gy were measured at 4 days after WBI $(13.8 \pm 2.7 \mu \mathrm{M}(11 \mathrm{~Gy})$ and $9.6 \pm 2.2$ $\mu \mathrm{M}$ ( 12 Gy); One Way ANOVA: $\mathrm{p}<0.001$ and $\mathrm{p}<0.001$, respectively). Although a slight recovery of citrullinemia was noticed thereafter, plasma citrulline levels remained significantly lower at the 11-day time point compared to control animals (44.4 $18.7 \mu \mathrm{M}$ (11) Gy) and $28.7 \pm 3.8 \mu \mathrm{M}(12 \mathrm{~Gy}) ;$ One-Way ANOVA: $\mathrm{p}=0.006$ and $\mathrm{p}=0.004$, respectively. figure 2b).

To further explore the dose-response relationship for citrullinemia, plasma levels were measured $84 \mathrm{~h}$ following single WBI doses between 0 and $14.9 \mathrm{~Gy}$. As is shown in figure $2 \mathrm{c}$ plasma citrulline levels decreased as a function of WBI dose with an approximately linear response for the dose-range of $3-12.1$ Gy (Pearson: $r=-0.98$ ). No change in plasma citrulline level could be discriminated up to single WBI doses of $3 \mathrm{~Gy}$, whereas no further decrease in plasma citrulline level was noticed for the 14.9 Gy dose point $(4.7 \pm 1.3 \mu \mathrm{M})$ as compared to the 12.1 Gy dose point $(6.2 \pm 0.3 \mu \mathrm{M})$.

Figure 2A Citrullinemia kinetics.
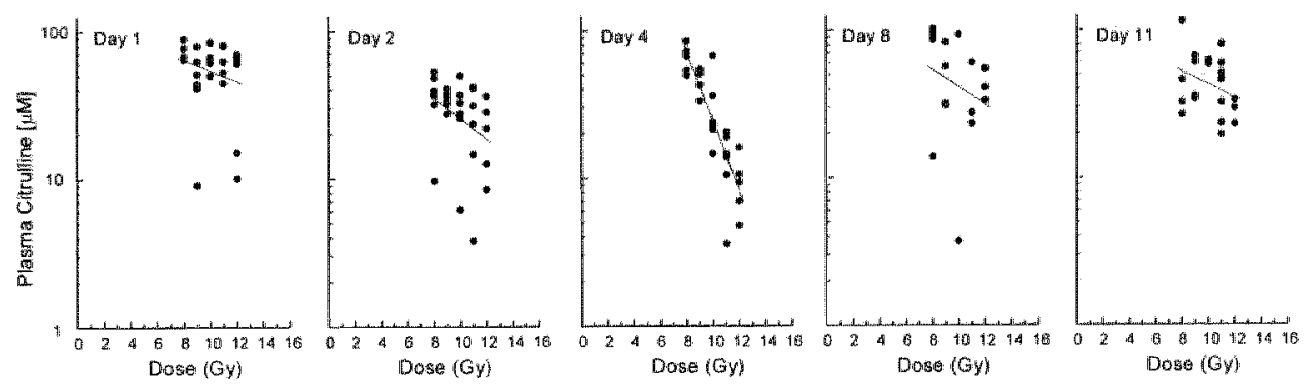

Scatter plots showing the dose-response relationships for plasma citrulline level at $1,2,4,8$ and 11 days after WBI with doses of $8-12$ Gy. Pearson: $r=-0.23 ;-0.42 ;-0.88 ;-0.43$ and 0.32 , respectively. The corresponding p-values are $0.23 ; 0.02 ;<0.001 ; 0.09$ and 0.18 , respectively. 
Correlation of citrullinemia with mucosal surface lining and jejunal crypt regeneration.

The correlation between plasma citrulline level and mucosal surface lining was examined for the $1,2,4,8$ and 11 day time points. A strong correlation was observed for the 4-day and 11 -day time points (Pearson r: 0.96 and 0.75 , respectively), whereas for the 1,2 and 8 day time points the correlation coefficients were $0.41,-0.41$ and 0.32 , respectively. These results were confirmed for the data obtained at $84 \mathrm{~h}$ after WBI doses between $0-14.9 \mathrm{~Gy}$. As shown in figure $2 \mathrm{~d}$ a linear correlation is observed between epithellial surface lining and plasma citrulline level (Pearson: $r=0.77 ; p<0.001$ ).

Figure 2B, 2C \& 2D Citrullinemia kinetics.

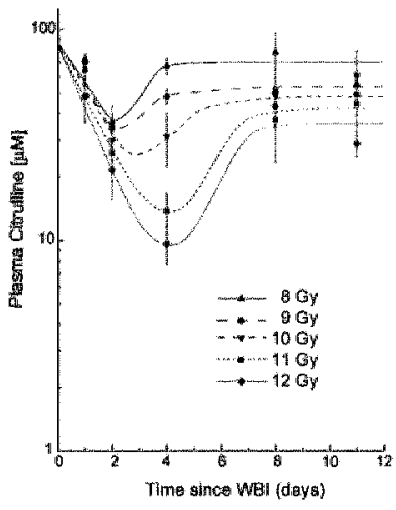

B.

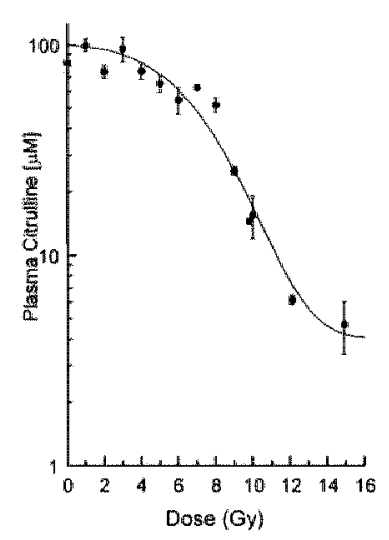

c.

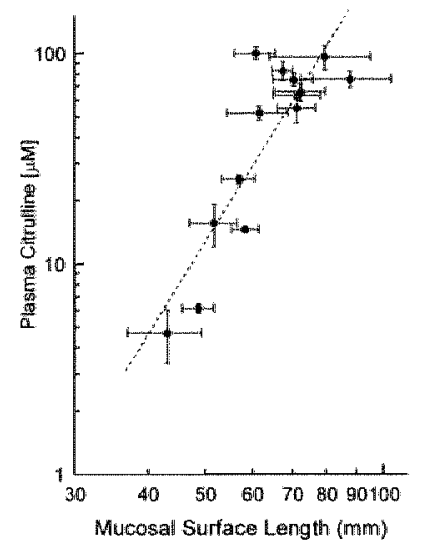

D.

B. Mean ( \pm SEM) plasma Citrulline level $(\mu \mathrm{M})$ as a function of time after single WBI doses of $8-12$ Gy. Plasma citrulline level at day 11 after WBI doses of 11 and 12 Gy are significantly lower as compared to control values $(\mathrm{p}=0.006$ and $\mathrm{p}=0.004$, respectively) $\mathrm{C}$. Plasma citrulline level at $84 \mathrm{~h}$ after whole body irradiation as a function of irradiation dose (Gy). Data points represent mean values \pm SEM. One Way ANOVA; $<0.001$. D. Cortelation between plasma citrulline level and mucosal surface lining at $84 \mathrm{~h}$ after single WBI doses of $0-14.9$ Gy. Data shown represent mean values \pm SEM. Pearson: $r=-0.77$; $\mathrm{p}<0.001)$.

Citrullinemia was then tested as an assay for acute small bowel epithelial radiation injury in an experiment using enteral glutamine suppletion as a radioprotector. For this purpose plasma citrulline level was compared to jejunal crypt survival as an endpoint for small bowel epithelial radiation injury at $84 \mathrm{~h}$ after single WBI. Amifostine was used as a positive control. Enteral glutamine had no effect on epithelial radiation damage (figures $3 a$ and $3 b$ ). The DMF for glutamine (1.0) and Amifostine (1.5) determined at the ED50 level were similar for the 
microcolony assay and citrulline assay (figures $3 \mathrm{a}$ and $3 \mathrm{~b}$ ). As shown in figure $3 \mathrm{e}$ a significant correlation is observed between both endpoints for epithelial radiation damage (Spearman's rho 0.94).

Figure 3 Correlation between citrulline assay and microcolony assay.

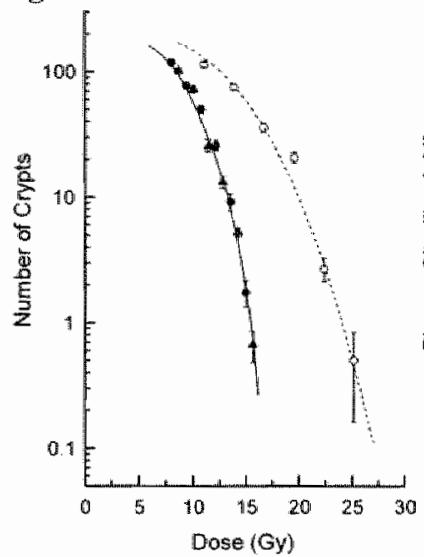

A.

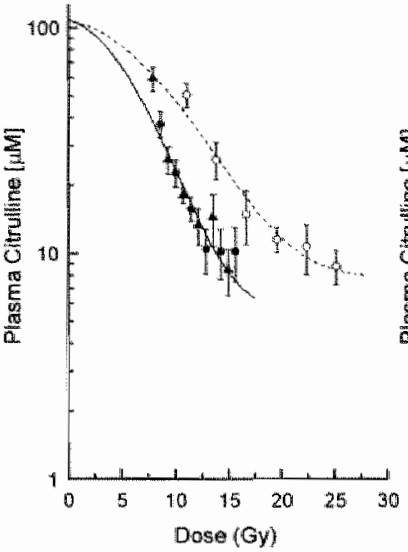

B.

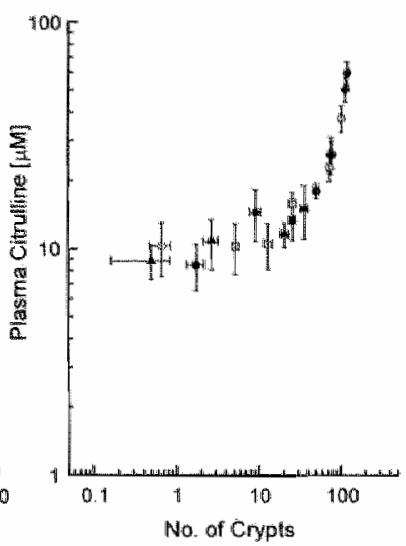

C.

A. Dose response curve using the jejunal microcolony assay as an endpoint for acute small bowel radiation damage $84 \mathrm{~h}$ after WBI. Per dose point 6 mice were used. Data points represent the mean number of crypts per circumference per dose point. $\bullet=$ WBI only; $\mathbf{\Lambda}=$ WBI plus $3 \%$-glutamine enriched drinking water; $0=10 \mathrm{mg}$ Amifostine i.p. 30 min prior to WBI. The dose modification factor computed at the level of 50 crypts per circumference for glutamine and Amifostine is 1.0 and 1.5 , respectively. B. Dose response curve using plasma citrulline level as an endpoint for acute small bowel radiation damage 84h after whole body irradiation. Per dose point six mouse were used. The data points represent the mean plasma citrulline level $(\mu \mathrm{M})$ per dose point. $\bullet=$ WBI only; $\boldsymbol{\Lambda}=$ WBI plus $3 \%-$ glutamine enriched drinking water; 0 $=10 \mathrm{mg}$ Amifostine i.p. $30 \mathrm{~min}$ prior to WBI. The dose modifying factor for glutamine and Amifostine determined at the ED50-level is 1.0 and 1.5 , respectively. C. Scatter plot showing a correlation between plasma citrulline levell $(\mu \mathrm{M})$ and crypt regeneration measured at $84 \mathrm{~h}$ after WBI doses of $8.0 ; 9.4 ; 10.8 ; 12.2 ; 13.6$ and 15.0 Gy (WBI only), $8.7 ; 10.1 ; 11.5 ; 12.9 ; 14.3$; and 15.7 Gy (WBI plus $3 \%$ - glutamine enriched drinking water) and $11.1 ; 13.9 ; 16.7 ; 19.6$; 22.4; 25.2 and 28.0 Gy (WBI plus Amifostine i.p. 30 min prior to irradiation). Spearman's rho $0.83 ; \mathrm{p}<0.001$. 


\section{Discussion}

A decrease of intestinal absorptive function following irradiation has been correlated to morphological changes, i.e. a decrease in the number of functionally active cells, constituting the absorptive mucosal surface. ${ }^{1}, 12,14,15$ In an attempt to develop an assay for detecting radiation induced intestinal damage related to epitheliall cell loss, functional assays have been used such as changes in active glucose transport ${ }^{5}$ and ${ }^{99 \mathrm{~m}}$ Tc-pertechnetaat. ${ }^{14}$ We chose plasma citrulline concentration in our study for its methodological simplicity. ${ }^{20} \cdot 23$ Citrulline accounts for almost $30 \%$ of metabolised glutamine nitrogen in rat small intestine. ${ }^{24}$ The small intestinal enterocyte contains specific enzymes involved in citrulline production but lacks the enzymes necessary for its conversion to arginine. ${ }^{25-27}$ This unique enzymatic profile ${ }^{21}$ and the fact that citrulline is not metabolised by the liver ${ }^{2 x}$ make that the small bowel is the principle source of circulating citrulline. Consequently the plasma citrulline level is highly dependent upon the intestinal cell mass. ${ }^{25}$

The dependence of plasma citrulline level on epithelial cell mass observed in surgical experiments in rodents 20.21 and human studies ${ }^{22} .23$ has been confirmed by us in mice following single dose WBI. We found a linear cortelation (Pearson: $r=0.77$ ) between plasma citrulline levels and a representative parameter for epithelial cell mass, i.e. the epithelial surface lining. Remarkably, a strong correlation between the epithelial cell mass and jejunal crypt regeneration at $84 \mathrm{~h}$ after WBI was obserwed (Pearson: $=0.99$ ). The maximum decrease in epithelial surface lining in our time experiment was noticed on day 4 after WBI. Although a further decrease between day 4 and day 8 cannot be ruled out, these observations aue in agreement with previous studies using mucosal cell mass as an endpoint. ${ }^{5,14}$

The time course of plasma citrulline level after single dose WBI (figure $2 \mathrm{a}$ and $2 \mathrm{~b}$ ) observed by us was comparable to that reported for other functional tests related to a reduced number of functional epithelial cells., ${ }^{54}$ The rapid decline of plasma citrulline level seen at the first 2 days after treatment is independent of the WBI doses used. However, recovery was more rapid. for the lowest dose (i.e. $8 \mathrm{~Gy}$ ) and it was incomplete during the observation period for the highest dose levels used (i.e. 11 and 12 Gy; figure 2b). This time and dose pattern is in agreement with the radiation effect on the hierarchically structured intestinal epithelium." Using the epithelial surface lining as a parameter did not yield significant changes except for the 4-day time point for the highest dose levels (i.e. 11 and 12 Gy). In contrast, for citrullinemia significant changes were observed for all dose levels used at the 4-day time point. Furthermore, plasma citrulline levels remained significantly decreased at the 11-day time point. For the dose range used in our experiments, mean values for mucosal surface lining ranged between $56 \%$ and $130 \%$ of control values, whereas for citrullinemia mean values ranged between $6 \%$ and $121 \%$ of control values. Thus citrullinemia seems to be more sensitive for detecting and monitoring small bowel radiation-induced epithelial cell loss than the representative morphologic endpoint used in these experiments.

We have demonstrated a significant dose-response relationship for citrullinemia at $84 \mathrm{~h}$ and 4 days (figure 2) after single dose WBI. After WBI doses of 1-3 Gy no effect on citrullinemia could be demonstrated. However, this parameter was inversely proportional to WBI doses of 3 
-12 Gy. The spread in baseline plasma citrulline level between mice may cover an effect at lower doses per fraction, which however might be demonstrated if repeated measurements in the same animal are performed. The observation that plasma citrulline levels did not decrease any further beyond doses of $12 \mathrm{~Gy}$ is in agreement with the observation that the mucosal surface lining was intact, i.e denudation was absent at the time point and dose levels used by us.

Encouraged by these results the citrulline assay was compared with the microcolony assay as a test to prove its efficacy in discriminating different levels of snall bowel epithelial radiation damage. Glutamine is the principle fuel for small bowel enterocytes. ${ }^{29}$ Enteral supplementation of this amino acid has been demonstrated to improve intestinal morphometrics ${ }^{18}$ and survival 39 in rats submitted to single dose whole abdominal irradiation. We have used glutamine accordingly to examine its effect on acute epithelial small bowel radiation damage in mice. In these experiments Amifostine (WR-2721), a compound of the class of sullhydryl radioprotectors, was also used as a known positive control. In mice a linear dose response effect for Amifostine exists up to about $400 \mathrm{mg} / \mathrm{kg} \mathrm{bw},{ }^{16,17}$ At this dose, administered $30 \mathrm{~min}$ before radiation by i.p. injection, a DMF of 1.6 is consistently found for mouse jejunum using the microcolony assay to assess crypt cell regeneration 16,17 with an accuracy on the DMF value better than $\pm 5 \%$ for the biological procedure ${ }^{31}$. We observed a DMF of 1.5 using both jejunal crypt survival and citrullinemia as an endpoint, in complete agreement with data reported in the literature. ${ }^{16,17}$ On the contrary, no effect was observed by us for glutamine on epithelial radiation damage (mamuscript in preparation). For experimental conditions, as defined for the use of the microcolony assay ${ }^{3}$ we found a strong correlation (Spearman's rho 0.94 ) between jejunal crypt regeneration and citrullinemia as parameters for epithelial radiation damage, independent of the intervention used (figure 3). Interestingly, enteral supplementation of gllutamine did not have any impact on citrullinemia or crypt survival.

Although the DMF computed for Amifostine for botl endpoints was in complete agreement with literature data ${ }^{16,17}$ the citrulline assay seems less sensitive than the microcolony assay at the higher dose range such as typically used for the microcolony assay as is demonstrated by a greater slope for the curve of the microcolony assay compared to the citrulline assay (figure $3 \mathrm{~b}$ and $3 \mathrm{c}$ ) and the dose-response relationship data (ligure $2 \mathrm{c}$ ). The opposite situation is true for the lower dose range where the threshold dose for the citrulline assay is significantly lower as compared to the microcolony assay, i.e. about 3 Gy versus $8 \mathrm{~Gy}$, respectively. Furthermore, in contrast to the microcolony assay the citrulline assay permits repeated measurements within the same animal. Therefore the citrulline assay and the microcolony assay are supplementary, both with regard to the dose range as with regard to their applicability.

In conclusion, our data demonstrates that after single dose WBI plasma citrulline level kinetics are dose dependent and in accordance with radiation injury to the clonogenic compartment of small intestinal epithelium. Citrullinemia is a simple and sensitive marker for monitoring small bowel epithelial radiation damage after single WBI doses between 8-12 Gy. Furthermore, this parameter enables quantification of epithelial cell loss following doses per fraction between 3 - 12 Gy. The kimetics observed for this parameter challenge its use as an assay for monitoring epithelial radiation-induced intestinal damage in clinical practice. 


\section{herereness}

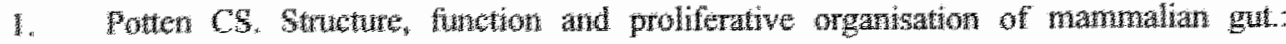
Esevier Schence W. Amsterdam; 1995.

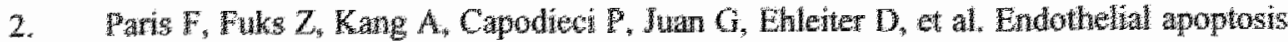
w the primary lesion intiating intestinal radation damage in moe. Seience $2001: 293: 293 \cdot 7$.

3. Withers HR, Elkind MM. Micocolony survival assay for cells of mouse intestinal

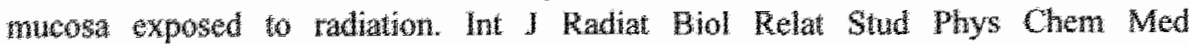
$1970 ; 17: 261-7$.

4. Potten CS, Booth C. The role of radiation-induced and spontaneous apoptosis in the homeostasus of the gastrointestinal epithehum: brief review. Comp Bochem Physiot B Bochen Mol 1997, 18:473-8.

5. Overgard $J$, Matsu M. Effect of radation on glucose absorption in the mouse jejunum in wivo. Radiother Oncol 1990; 18:71-7.

6. Gunter Smith PJ. Gamma radiation affects active electrolyte transport by rabbit iteum: basal Na and Cl transport. An I Physiol 1986;250:G540-5.

7. Lebrun F, Benderiter M, Berroud A, Voisin P, Griffith NM. Potential role of the membrawe in the development of intestinal cellular damage after whole-body gamma rradiation of the rat. Can J Physiol Pharmacol 2002;80:686-93.

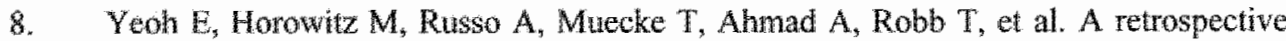
study of the effects of pelvic irradiation for carcinoma of the cervix on gastrointestinal function. Int Radiat Oncol Biol Phys 1993;26:229-37.

9. Travis $\$$, Menzies 1 . Intestinal permeability: functional assessment and significance. Clinical science London, England 1979 1992:82:471-88.

10. Craig RM, Atkinson AJ, Jr, D-xylose testing: a review. Gastroenterology 1988; 95 : 223-31.

11. Thomson $\mathrm{AB}$, Cheeseman $\mathrm{Cl}$, Walker $\mathrm{K}$. Effect of abdominal irradiation on the kinetic parameters of intestinal uptake of glucose, galactose, leucine, and gly-leucine in the rat. J Lab Clin Med 1983;102:813-27.

12. Juby LD, Dixon MF, Axon AT. Abnomal intestinal permeability and jejunal morphometry. J Clin Pathol 1987;40:714-8.

13. Thomson $\mathrm{AB}$, Cheeseman $\mathrm{CI}$, Walker $\mathrm{K}$. Intestinal uptake of bile acids: effect of extemal abdominal irradiation. Int J Radiat Oncol Biol Phys 1984;10:671-85.

14. Kirichenko AV, Mason KA, Straume M, Teates CD, Rich TA. Nuclear scintigraphic assessment of radiation-induced intestinal dysfunction. Radiat Res 2000;153:164-72.

15. Gunter Smith PJ. Gamma radiation affects active electrolyte transport by rabbit ileum. II. Correlation of alanine and theophylline response with morphology. Radiat Res $1989 ; 117: 419-32$.

16. Ito H, Meistrich ML, Barkley HT, Jr., Thames HD, Jr., Milas L. Protection of acute and late radiation damage of the gastrointestinal tract by WR-2721. Int J Radiat Oncol Biol Phys 1986;12:211-9. 
17. Hanson WR. Radiation protection of murine intestine by WR-2721, 16,16-dimethyl prostaglandin E2, and the combination of both agents. Radiat Res 1987;111;361-73.

18. Klimberg VS, Souba WW, Dolson DJ, Salloum RM, Hautamaki RD, Plumley DA, et al. Prophylactic glutamine protects the intestinal mucosa from radiation injury. Cancer 1990;66:62-8.

19. van Eijk HM, Rooyakkers DR, Deutz NE. Rapid routine determination of amino acids in plasma by high-performance liquid chromatography with a $2-3$ microns Spherisorb ODS II column. J Chromatogr 1993;620:143-8.

20. Chen $K$, Nezu $R$, Sando $K$, Haque $S M$, Iiboshi $Y$, Masunari $A$, et al. Infunence of glutamine-supplemented parenteral nutrition on intestinal amino acid metabolism in rats after small bowel resection. Surg Today 1996;26:618-23.

21. Wakabayashi $\mathrm{Y}$, Yamada E, Yoshida T, Takahashi N. Effect of intestinal resection and arginine-free diet on rat physiology. Am J Physiol 1995;269:G313-8.

22. Crenn $\mathbb{P}$, Coudray Lucas C, Cynober L, Messing B. Post-absorptive plasma citrulline concentration: a marker of intestinal failure in bumans. Transplant Proc 1998;30:2528.

23. Crenn P, Coudray Lucas C, Thuillier F, Cynober L, Messing B. Postabsorptive plasma citrulline concentration is a marker of absorptive enterocyte mass and intestinal failure in humans. Gastroenterology 2000;1 19:1496-505.

24. Windmueller HG. Glutamine utilization by the small intestine. Adv Enzymol Relat Areas Mol Biol 1982;53:201-37.

25. Wakabayashi $Y$, Yamada E, Hasegawa $T$, Yamada R. Enzymological evidence for the indispensability of small intestine in the synthesis of arginine from glutamate. I. Pyrroline-5-carboxylate synthase. Arch Biochem Biophys 1991;291:1-8.

26. Wakabayashi Y, Yamada E, Yoshida T, Takahashi H. Arginine becomes an essential amino acid after massive resection of rat small intestine. J Biol Chem 1994;269:3266771.

27. Wu G. Synthesis of citrulline and arginine from proline in enterocytes of postnatal pigs. Am J Physiol 1997;272:G1382-90.

28. Windmueller $\mathrm{HG}$, Spaeth $\mathrm{AE}$. Source and fate of circulating citrulline. Am J Physiof $1981: 241: \mathrm{E} 473-80$.

29. Windmueller HG, Spaeth AE. Identification of ketone bodies and glutamine as the major respiratory fuels in vivo for postabsorptive rat small intestine. I Biol Chem $1978: 253: 69-76$

30. Klimberg VS, Salloum RM, Kasper M, Plumley DA, Dolson DJ, Hautamaki RD, et al. Oral glutamine accelerates healing of the small intestine and improves outcome after whole abdominal radiation. Arch Surg 1960 1990; 125:1040-5.

31. Gueulette I, Menzel HG, Pihet P, Wambersie A. Specification of radiation quality in fast neutron therapy: microdosimetric and radiobiological approach. Recent Results Cancer Res 1998; 150:31-53. 


\section{Chapter 6}

KERATINOCYTE GROWTH FACTOR

AMELIORATES ACUTE GRAFT-VERSUS-HOST DISEASE

IN A NOVEL NONMYELOABLATIVE HAPLOIDENTICAL

TRANSPLANTATION MODEL

Ariane Vanclée, 'Ludy C.H.W. Lutgens, ${ }^{2}$ Ellis B.H. Oving, "Nicolaas E.P. Deutz,"

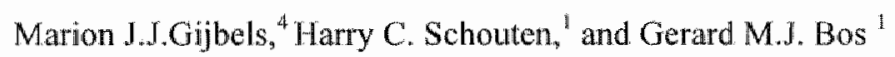

"Department of Internal Medicine, Division of Hematology and Oncology.

Unversity Hosputal Maastricht

'Radiation Therapy and Oncology Marastricht, MAASTRO dimic

"Deparwent of Surgery. Matstrichn Unwersity

"Depastment of Pathology and Departonemt of Molecular Genetics, Maastricht Universify.

Bone Marrow Transplant 2005 (in press) 


\section{Summary}

Allogeneic stem cell transplantations (SCT) are currently being used as a therapy for hematological malignancies, some solid tumors and non-malignant bone marrow deficiencies. Nevertheless, clinical applicability is limited due to toxicity of conditioning regimens, graft-versus-host disease (GVHD) and the scarcity of HLA-identical family donors. New concepts are based on nonmyeloablative conditioning to reduce toxicity, prevention or amelioration of GVHD and the use of haploidentical donors to increase donor availability.

To combine these requirements, we have developed a nonmyeloablative conditioning regimen, consisting of low-dose total body irradiation and cyclophosphanide-based chemotherapy. In a haploidentical Fl $\rightarrow$ Fl mouse model, this nommyeloablative transplantation protocol resulted in stable full donor chimerism, but also in the development of severe GVHD. Administration of keratinocyte growth factor (KGF) reduced GVHD, evident as reduced weight loss and a lesser degree of dermatitis, compared to saline-treated controls. KGF preserved plasma citrulline and TNF- $\alpha$ levels, both indicative for reduced injury to the gastrointestinal tract. This was confirmed by histological findings. Six months after transplantation, survival rates were significantly higher in KGF-treated animals as compared to PBS-treated controls. These results indicate that KGF preserves gut integrity and might therefore contribute substantially to reduction of lethal GVHD in (nonmyeloablative) haploidentical transplantation. 


\section{Introduction}

Allogeneic stem cell transplantations (SCT) are currently being used as a therapy for hematological malignancies, some solid tumors and non-malignant bone marrow deficiencies. Unifortunately, therapeutic success is often hampered by the toxicity of preparative regimens and the occurrence of graft-versus-host disease (GVHD).

Another obstacle limiting clinical applicability is the availability of HLA-identical family donors. Patients have indeed less than $30 \%$ chance of finding a fully matched sibling donor and are therefore often dependent on unrelated bone marrow donors. Even then, a suitable donor cannot be found for a considerable percentage of Caucasian patients. Other ethnic groups that are more polymorphic with respect to HLA are even less likely to find a donor. On the other hand, virtually every patient has a family member that shares one HLAhaplotype, but is mismatched for the other. For this criterion, children, both parents and $50 \%$ of siblings qualify, thereby dramatically increasing the availability of potentially suitable bone marrow.

Regrettably, haploidentical transplantations are associated with an increased risk of toxicity and the development of GVHD due to the immunological barrier between donor and recipient and the intensive conditioning regimen needed to overcome it. ${ }^{2.3}$ Myeloablative conditioning does in fact damage and activate host tissues that in turn secrete inflammatory cytokines, leading to a cytokine cascade and subsequent development of GVHD. Throughout transplantation history, nonmyeloablative conditioning regimens have been developed with the aim to reduce toxicity and decrease transplant related morbidity and mortality. These nonmyeloablative transplantation protocols not only prevented posttransplant immunodeficiency, they also reduced GVHD. ${ }^{5-7}$ However, apart from some case reports ${ }^{8-10}$ and smaller studies, ${ }^{11-13}$ the use of nonmyeloablative conditioning has not extensively been reported for haploidentical donor-recipient combinations.

As it has been shown that alloreactive T-cells in the donor graft are responsible for the induction of GVHD, extensive T-cell depletion (TCD) of the bone marrow inoculum has been proven effective in its prevention and so far, haploidentical transplantations are possible only after this type of intervention. However, an increased risk of relapse, infection. and graft failure was observed following transplantations with TCD bone marrow, indicating that $T$-cell responses are necessary for engraftment, immune recovery and antitumor effects. ${ }^{3,14-16}$ Some therapeutic models have used these T-cell mediated reactions to their advantage and applied alloreactive T-cells to kill residual tumor and bone marrow cells, allowing less severe preparative conditioning." - Alternatively, restoring T-cells after transplantation has been suggested as a valuable option to prevent the side effects of $\mathrm{T}$ cell depletion. ${ }^{20}$ Other experimental approaches to reduce GVHD, such as induction of oral tolerance ${ }^{21}$ or treatment with donor regulatory $\mathrm{T}$-cells ${ }^{22}$, dendritic cells ${ }^{23}$ and NK cells ${ }^{24}$ are currently under investigation as well.

Another GVHD-prophylaxis that has been proven effective in transplantation models with non-TCD bone marrow is keratinocyte growth factor (KGF). KGF is a member of the fibroblast growth factor family, also designated as $\mathrm{FGF}-7$ that specifically influences epithelial cells in vivo and in vitro. ${ }^{25} \mathrm{KGF}$ induces proliferation in keratinocytes, ${ }^{26}$ type II 
pneumocytes, ${ }^{27}$ hepatocytes and gastrointestinal epithelial cells. ${ }^{28}$ It bas also been demonstrated that KGF can enhance survival of crypt stem cells ${ }^{29}$ and might thus be used to protect the gastrointestinal mucosa when administered prior to conditioning. Other researchers have demonstrated that $\mathrm{KGF}$ also exhibits a protective effect independent of conditioning-induced injury. ${ }^{30}$ In mouse models of allogeneic bone marrow transplantation, it was shown that KGF treatment reduced GVHD severity and increased survival ${ }^{31}$ without the impairment of the graft-versus-leukemia effect. ${ }^{32}$ It has to be noted that these studies have described lethal conditioning regimens and either fully mismatched mouse combinations or parent to FI transplantations.

The purpose of our investigation was to develop a haploidentical, nonmyeloablative transplantation model, capable of inducing stable chimerism and to study whether GVHD in such a model could be ameliorated or prevented by KGF. The present study provides evidence that in this particular setting, KGF treatment not only reduces GVHD, but also improves survival of animals receiving a haploidentical allogeneic SCT using a nonmyeloablative conditioning regimen.

\section{Methods and Materials}

\section{Mice}

Female CB6F1 (H-2 $\left.2^{b / d}\right)$ and male B6CBAF $1\left(\mathrm{H}-2^{b / k}\right)$ hybrid mice were purchased from Harlan Netherlands (Horst, The Netherlands). Animals were 7 or 8 weeks of age and were used as recipients and donors respectively. Mice were housed in the animal facility of the University of Maastricht and were allowed normal rodent chow and water ad libitum. Alll experiments were approved by the Animal Ethical Conmittee of Maastricht University.

\section{Conditioning regimen}

In developing the model, animals received a single total body irradiation (TB]) dose of 600 or 400 cGy one day before transplantation (day-1) of 2 frictions of 200 cGy with $24 \mathrm{~h}$ interval on day -2 and -1 . TBI was combined with 150 or $200 \mathrm{mg} / \mathrm{kg}$ Cyclophosphamide intraperitoneally (i.p.) on day -1 . In all experiments with KGF treatment, animals were conditioned with 2 fractions of $200 \mathrm{cGy}$ TBI on day -2 and -1 and $200 \mathrm{mg} / \mathrm{kg}$ Cyclophosphanide on day -1. Animals were placed in a Perspex container, without anesthesia and radiation was delivered by a PHILIPS X-ray unit $(225 \mathrm{kV}, \mathbb{1 0} \mathrm{mA})$ at a doserate of $66 \mathrm{cGy} / \mathrm{min}$. Cyclophosphamide (Endoxan $1 \mathrm{~g}, \mathrm{Baxter}$ ) was obtained from the hospital's pharmacy and further diluted according to the manufacturer"s instructions.

\section{Preparation of cell suspensions and stem cell transplantation (SCT)}

Femora and tibiae of B6CBAF 1 donor mice were flushed with RPMI 1640 (Life Tech., Breda, The Netherlands) using a $25 \mathrm{G}$ needle. Spleens and flushed marrow were filtered through nylon mesh screens to obtain single cell suspensions. One day after termination of 
conditioning (day 0), CB6F 1 recipient mice were injected intravenously with $3.3 \times 10^{7}$ donor bone marrow and $1 \times 10^{8}$ unseparated splenocytes.

\section{KGF treatment}

Recombinant human keratinocyte growth factor (palifermin) was provided by Amgen Inc. (Thousand Oaks, Ca., USA) and dissolved in the supplied reconstitution fluid. Further dilutions were made in phosphate buffered saline (PBS) (Life Tech, Breda, The Netherlands) before injection. Experimental mice were injected subcutaneously with $5 \mathrm{mg} / \mathrm{kg} / \mathrm{day}$, control mice received $200 \mu \mathrm{l}$ PBS. Treatment started 3 days before conditioning (day -5 ) and was continued till 3 days after transplantation $($ day +3 ).

\section{GWHD monitoring}

Animals were monitored daily for clinical signs of GVHD, i.e. weight loss, diarrhea, changes in fur and skin texture and hunched posture. As diarrhea was not a common symptom in these experiments, the traditional score for GVHD in animals could not be applied in our model. In addition to the registration of changes in weight, we applied a scoring system based on dermatitis alone, as it was the most distinct symptom in our experiments. The absence of dermatitis resulted in a score of 0 whereas mild cases of dermatitis, covering less than $50 \%$ of the body surface and restricted to the ears or extremities, received a score of 1 . When dermatitis covered $50 \%$ of the body, a score of 2 was applied to indicate an intermediate form. Animals with a severe form of dermatitis, covering over $50 \%$ of the body surface and resulting in alopecia, received a score of 3 .

\section{Flow cytometry}

To determine chimerism, peripheral blood was collected by orbital punction, using heparinised capillaries and suspended in PBS (Life Tech.) supplemented with $0.1 \%$ fetal calf serum (FCS) (Greiner Bio-One GmbH, Frickenhausen, Germany) and $0.02 \%$ sodium azide (Merck, Darmstadt, Germany). After preincubation with mouse Fc block for 10 minutes, cells were incubated with fluorescein isothiocyanate (FITC)-conjugated mouseanti-mouse $\mathrm{H}-2 \mathrm{~K}^{\mathrm{k}}$ or $\mathrm{H}-2 \mathrm{~K}^{4}$, R-Phycoerythrin (PE)-labeled mouse-anti-mouse $\mathrm{H}-2 \mathrm{~K}^{\mathrm{k}}$ or ratmnti-mouse CD19 and PE-Cy5-labeled rat-anti-mouse CD3, for 30 minutes on ice. All antibodies were purchased from BD Biosciences/Pharmingen (San Diego, Ca, USA). After staining, cells were washed and remaining erythrocytes were lysed by means of FACS Lysing Sollution (BD). Analysis was performed on a FACSsort cytometer (BD).

\section{Plasma citrulline levels}

$0.2 \mathrm{ml}$ of whole blood was collected by orbital punction and centrifuged at $8900 \times \mathrm{x}$ for 5 min at $4^{\circ} \mathrm{C}$ to obtain plasma. To detemine the amino acid levels, $50 \mu$ of plasma was added to $4.5 \mathrm{mg}$ dry 5 -sulfosalicylic acid, vortexed, frozen in liquid nitrogen and stored at $-80{ }^{\circ} \mathrm{C}$ until analysis. Plasma amino acid concentrations were measured using high-performance liquid chromatography, as previously described. 
TNF- $\alpha E L S A$

Mouse TNF- $\alpha$ levels in plasma were determined by enzyme-linked inmunosorbent assay (ELISA) as previously described. ${ }^{34}$ TNF $\alpha$ ELISA's were kindly provided by Prof. W.A. Buurman (department of surgery, University of Maastricht, Maastricht, The Netheriands).

\section{Histology}

Small bowel tissue samples were fixed in $4 \%$ formalin, processed through graded alcohol and embedded in paraffin. Three-micton thick sections were stained with hematoxylin and eosin (H\&E) for histologic examination. Slides were coded and scored blindly for signs of GVHD, defined as single-cell necrosis, desintegration of crypts and cellular inflitration. Four sections with an interval of 60 micron were investigated. Semiquantitavive measurements were used to distinguish between more and less GVHD: 0 : no lesions: 1: less than 10 necrotic cells per four sections; 2: less than 10 necrotic cells per section; 3: more than 10 individual necrotic cells per section; 4 : more than 10 individual necrotic cells per section and disintegration of the crypts.

\section{Morphometry}

Morphometric analysis of small bowel samples was performed as previously described. ${ }^{35}$ Briefly, 3 digitized images per mouse at $20 \mathrm{x}$ magnification were evaluated using the callibrated image analysis system (Leica Quantimet $570 \mathrm{C}$; Leica Qwin Pro V 2.8). After digital substraction of intraluminal contents, the epithelial surface lining was demarcated and measured as a perimetrical length. Adjacent villar surfaces were digitally separated to enable measurement of the epithelial surface lining for individual villi. The sum of the perimetrical lengths ( $\mathrm{mm}$ ) represents the total epithelial surface lining per transverse section. For statistical analysis, the mean averaged score of 3 images per mouse was used.

\section{Statistics}

Results were analyzed according to the Student's unpaired t-test. Values are presented as mean \pm SEM. For statistical analysis of TNF- $\alpha$ values and dermatitis scores, the MannWhitney test was used. Survival curves were conposed using the Kaplan-Meier method and compared with the Mantel-Cox log-rank test. Differences in survival 200 days after transplantation were analyzed with the Fisher"s exact test. To calculate the correlation between the mucosal surface and the citrulline values the Pearson's correlation test was used. In all cases differences were considered statistically significant when probability ( $P$ ) values were less than or equal to 0.05 .

\section{Results}

\section{Development of the model}

To establish a nonmyeloablative transplantation model resulting in stable donor chimerism, different conditioning protocols were tested. Initial regimens consisting of a single TBI dose of $850 \mathrm{cGy}$ or a combination of $600 \mathrm{cGy}$ and $200 \mathrm{mg} / \mathrm{kg}$ Cyclophosphamide (CY) were 
Lethall without bone marrow rescue. As animals died in an anemic state due to bone marrow failure within 14 days after conditioning, these regimens were considered unsuitable. Subsequent experiments used conditioning regimens in which either the radiation dose or the amount of chemotherapy was reduced. These approaches, consisting of $600 \mathrm{cGy}$ and $150 \mathrm{mg} / \mathrm{kg} \mathrm{CY}$ or $400 \mathrm{cGy}$ with $200 \mathrm{mg} / \mathrm{kg} \mathrm{CY}$, were nonmyeloablative and resulted in full donor chimerism. Although the development of GVHD was unpredictable in these transplantation models and varied over experiments (data not shown), 30\% of animals succumbed to lethal GVHD within 45 days after transplantation when the inoculum of $3.3 \times 10^{7} \mathrm{BM}$ cells was supplemented with 3 or $6 \times 10^{7}$ splenocytes.

In later experiments, the radiation dose was divided into two fractions of $200 \mathrm{cGy}$, separated by a 24 hour interval, again in combination with $200 \mathrm{mg} / \mathrm{kg} \mathrm{Cy}$. Animals conditioned according to this protocol $(\mathrm{n}=7)$, survived for more than 3 months without administration of bone marrow, indicating that this conditioning regimen is indeed nonmyeloablative. It has to be noted however that mice transplanted with $3.3 \times 10^{7} \mathrm{BM}$ cells alone did not become chimeric and that the addition of donor splenocytes to the BM inoculum was crucial for inducing engraftment. Although the observation time was limited due to lethal GVHD, animals transplanted with $\mathrm{BM}$ and $1 \times 10^{8}$ splenocytes displayed full donor chimerism until death (data not shown). The development of lethal GVHD made this approach suitable for testing the effects of KGF treatment and in all subsequent experiments, the transplantation was performed with this conditioning regimen, consisting of 2 times $200 \mathrm{cGy}$ and 200 $\mathrm{mg} / \mathrm{kg} \mathrm{CY}$.

\section{KGF reduces GVHD symptoms and weight loss after transplantation}

We examined whether the administration of KGF, had an effect on GVHD-induced symptoms such as weight loss, fur texture and posture. Although control animals succumbing to GVHD (18/19 animals) showed a decrease in body weight before death (residual weight $74.4 \pm 2.5 \%,(n=18)$; data not shown), a remarkable change in weight was already noticed 7 days after transplantation. While animals receiving an allogeneic transplant with PBS had a residual weight of $78.5 \pm 1.4 \%(n=19)$, KGF-treated animals $(n=1.4)$ showed a residual weight of $88.4 \pm 1.6 \%(\mathbb{P}<0.0001)$. Control animals $(\mathrm{n}=11)$ treated with syngeneic bone marrow did not lose weight after transplantation (residual weight $103.4 \pm 1.7 \%$ ), indicating that alloreactive cells in the donor graft are responsible for the weight reduction seen in experimental animals (Figure 1).

A number of animals, 11 in the PBS-group and 1 in the KGF-group, died shortly after transplantation due to severe GVHD-related weight loss. Allogeneic SCT recipients that survived this acute phase of GVHD also displayed differences in skin texture and were therefore compared based on their development of dermatitis. Approximately three weeks after transplantation, PBS-treated animals $(n=8)$ developed a severe, persistent form of dermatitis, corresponding to a score ranging from 1 to 3 (median 3), consistent with GVHD. In KGF-treated recipients $(\mathrm{n}=13)$, dermatitis was either absent at the same time point or reached only a score of 1 (median 1$)(P=0.0007)$. In these cases dermatitis was indeed very mild and mostly limited to the ears or facial area. Most importantly, KGF-treated animals 
displayed a transient form of dermatitis, diminishing within two weeks after onset. Diarthea was not a manifest symptom in this model.

Figure 1

KGF reduces weight loss in the first week after transplantation

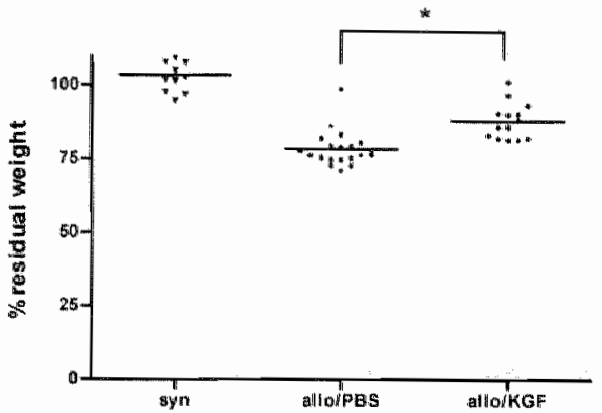

CB6F I recipients were conditioned with 2 times $200 \mathrm{cGy}$ TBI and $200 \mathrm{mg} / \mathrm{kg} \mathrm{CY}$ and transplanted with $3.3 \times 10^{7} \mathrm{BM}$ and $1 \times 10^{8}$ splenocytes of syngeneic (CB6F 1 ) or allogeneic (B6CBAF1) donors. Combined with allogeneic SCT, animals were treated with KGF or PBS, pre and post transplant. Residual weights 7 days after transplantation are shown. ( $)$ Animals receiving a syngeneic $\mathrm{SCT}(\mathrm{n}=11)$ ( $\bullet$ PBS-treated allogeneic SCT recipients $(\mathrm{n}=19)(\bullet)$ KGF-treated allogeneic SCT recipients $(\mathrm{n}=14) * P<0.0001$

\section{$K G F$ decreases injury to the gastrointestinal tract}

The finding that KGF was capable of reducing GVHD-symptoms after nonmyeloablative conditioning, prompted us to investigate whether these effects were due to protection of the gastrointestinal (GI) tract, as it has been reported for a model of lethal irradiation ${ }^{32}$.

According to the model described by ferrara et al. ${ }^{4}$ radiation-induced injury to the Gl tract induces translocation of LPS into the circulation, leading to a subsequent release of TNF $-\alpha$. We hypothesized that if $\mathrm{KGF}$ would also prevent intestinal injury in a model of nonmyeloablative conditioning, TNF- $\alpha$ levels should diminish. Following the publication of Krijanovski et al. ${ }^{2}$ we compared TNF-a values 5 days after syngeneic or allogeneic transplantation, in the latter case combined with PBS or KGF treatment. Initial TNF- $\alpha$ levels, measured before conditioning and transplantation, were below detection level in all groups. PBS- treated animals $(\mathrm{n}=12$ ) showed an increase in TNF- $\alpha$ levels to a median of $149.8 \mathrm{pg} / \mathrm{ml}$ (range $69.5-228.8$ ), while KGF-treated animals $(n=11$ ) only reached a median value of 50.0 $\mathrm{pg} / \mathrm{ml}$ (range $50.0-98.4)(\mathrm{P}=0.0008)$ (Figure 2). In animals transplanted with syngeneic bone marrow and splenocytes (n=11), TNF- $\alpha$ levels were undetectable throughout the experiment, indicating that alloreactive cells are necessary for the onset of the GVHD-related cytokine 
induction in this model, and that the combination of $200 \mathrm{mg} / \mathrm{kg}$ Cyclophosphamide and $2 \mathrm{x}$ 200 cGy irradiation by itself did not induce a measurable elevation of TNF- $\alpha$ levels.

Since it has been demonstrated that citrulline can be used as a marker for radiation-induced injury to the small bowel ${ }^{35}$ we set out to determine the contribution of this amino acid to our transplantation model. Since the plasma citrulline level is highly dependent upon the small bowel epithelial cell mass ${ }^{36}$ loss of small intestinal enterocytes will decrease plasma citrulline levels. Citrulline values were compared in 4 groups of animals, receiving either syngeneic or allogeneic bone marrow and splenocytes, combined with either PBS or KGF treatment. Plasma citrulline values were detemined 7 days after transplantation and are presented as a percentage of the baseline value, measured before conditioning and transplantation. Citrulline levels decreased to $29.17 * 1.59 \%$ of the baseline value in PBStreated controls $(n=17)$, whereas in $K G F$-treated animals $(n=15)$ citrulline levels decreased to $72.62 \pm 3.79 \%(\mathrm{P}<0.000 \mathrm{~V})$. Animals that received a syngeneic transplant, combined with $\mathrm{PBS}$ $(n=5)$ or KGF $(n=5)$ displayed increased citrulline levels of $160.0 \pm 14.9 \%$ and $116.3 \pm 5.83$ $\%$ respectively (Figure 3 ).

To confirm these results, 4-5 animals from each group were sacrificed 7 days after transplantation for histologic examination of the small bowel (Figure 4).

Figure $2 \quad$ KGF reduces TNF- $\alpha$ levels after allogeneic transplantation

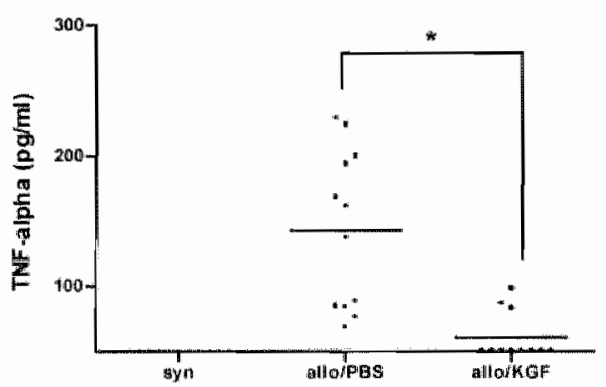

CB6F 1 recipient mice were conditioned with 2 times $200 \mathrm{cGy} \mathrm{TBI}$ and $200 \mathrm{mg} / \mathrm{kg} \mathrm{CY}$, and transplanted with syngencic or allogeneic BM and splenocytes. Allogeneic SCT recipients were treated with PBS or KGF. Plasma TNF- $\alpha$ levels were determined 5 days after transplantation. To calculate statistical significance, values below detection level were set as $50 \mathrm{pg} / \mathrm{ml}$. Combined results from two separate, but identical experiments are shown. ( ) animals treated with syngeneic SCT $(n=11)$, ( ) allogeneic SCT+PBS $(\mathrm{n}=12)$ or $(\bullet)$ allogeneic $\mathrm{SCT}+\mathrm{KGF}(\mathrm{n}=11){ }^{*} \mathrm{P}=0.0008$ 


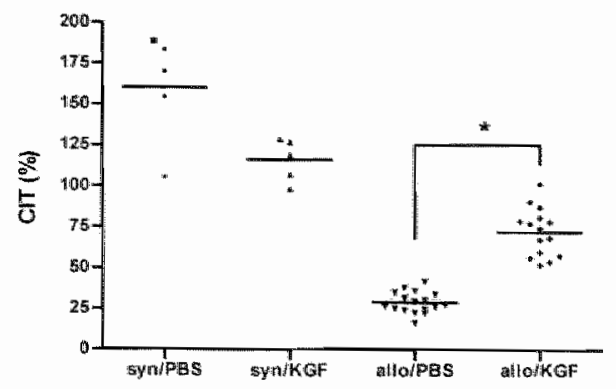

Plasma citrulline levels at day 7 after transplantation are shown as a percentage of the individual start values, measured before conditioning and transplantation. Citrulline values of syngeneic and allogeneic SCT recipients are the result of one and three experiments respectively. Recipients of a syngeneic transplant, treated with PBS $(-)(n=5)$ or KGF ( $)$ $(\mathrm{n}=5)$ and animals treated with allogeneic BM and splenocytes, combined with PBS ( $v)$ $(n=17)$ or KGF $(*)(n=15) * P<0.0001$

Animals that received a syngeneic transplant $(n=4)$ showed almost no necrosis $(0.25 \pm 0.25 ;)$ and animals that received this transplant in combination with $\mathrm{KGF}$ treatment $(\mathrm{n}=5$ ) displayed minimal single-cell necrosis $(1.60 \pm 0.24)$. After allogeneic transplantation, single-cell necrosis reached a score of $3.80 \pm 0.20$ in PBS-treated animals ( $\mathrm{n}=5$ ), while the necrosis in the animals treated with $\mathrm{KGF}(\mathrm{n}=5$ ) was decreased to a score of $1.80 \pm 0.20(\mathrm{P}=0.0001)$, comparable to the level in syngeneic transplanted animals treated with $\mathrm{KGF}$.

Morphometric analysis of the histologic slices revealed a mucosal surface with a median value of $13.75 \mathrm{~mm}$ (range 12.10 - 24.60) and $16.10 \mathrm{~mm}$ (range 14.00 -16.50 ) in animals receiving a syngeneic transplant in combination with $\mathrm{PBS}(n=4)$ or $\mathrm{KGF}(\mathrm{n}=3)$ treatment. respectively. After allogeneic transplantation the mucosal surface decreased to a median value of $10.55 \mathrm{~mm}$ (range $9.80-11.40$ ) in PBS treated animals $(n=4)$, whereas in $\mathrm{KGF}$ reated mice $(\mathrm{n}=4)$ a median value of $13.20 \mathrm{~mm}$ (range 10.12 - 17.20) was measured $(P=0.105)$. Although these results did not reach statistical signiffcance due to the limited number of animals, we were able to confirm our previous findings and demonstrated a correlation between the mucosal surface and the plasma citrulline levels 7 days after transplantation ( $\mathrm{n}=15$; Pearson- $\mathrm{r}=0.60, \mathrm{P}=0.019$ ).

Seven days after transplantation, animals were sacrificed and histologic slices were prepared from the small intestine. (a) Syngeneic transplanted animals showed no necrosis. (b) Minimal single-cell necrosis (arrow) in a syngeneic transplanted animal treated with $\mathrm{KGF}$. (c) mild single-cell necrosis (arrows) and disintegration of crypts (arrowhead) in allogeneic transplanted animals. Also, some cellular infiltration in the lamina propria was observed 
(larger arrows) (d) Minimal single-cell necrosis (arrow) in an allogeneic transplanted anima! treated with KGF.

Figure 4 KGF reduces necrosis of epithelial cells after allogeneic transplantation

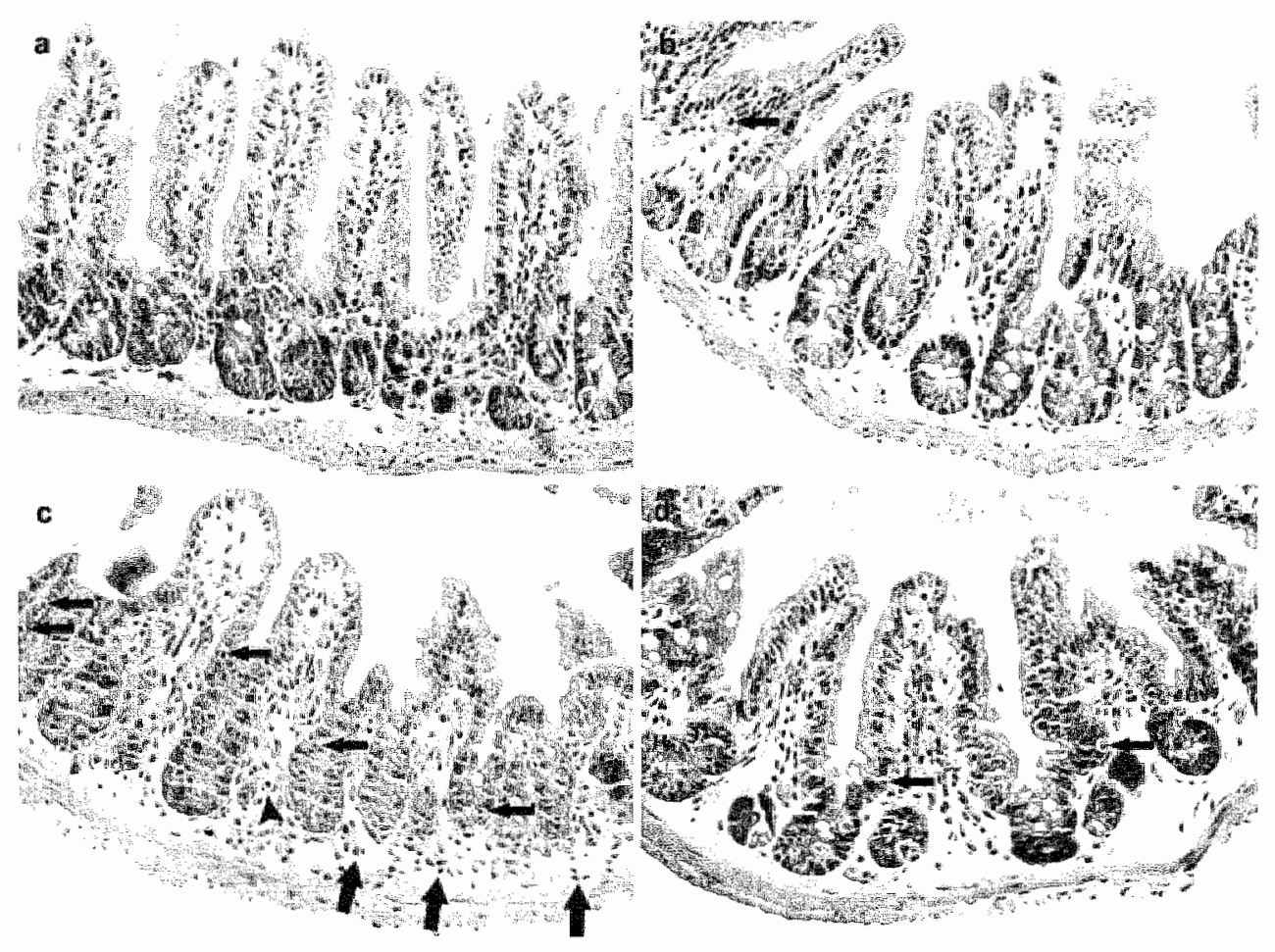

\section{KGF increases survival}

In view of the fact that KGF was capable of reducing GVHD symptoms directly after transplantation, we hypothesized this effect might have long-term advantages leading to an increased survival ratio. Therefore survival was monitored for 200 days after transplantation, in mice receiving either PBS or $5 \mathrm{mg} / \mathrm{kg}$ KGF from three days before conditioning till three days after transplantation. The survival curves represent the sum of three experiments (Figure 5).

In animals treated with KGF overall survival was much higher than in the PBS-treated controls $(P=0.0002)$. Whereas animalls receiving PBS $(n=19)$ had a survival of $5.3 \% 200$ days after transplantation, KGF-treated mice $(n=14)$ still showed a survival of $57.1 \%(P=0.0042)$. 


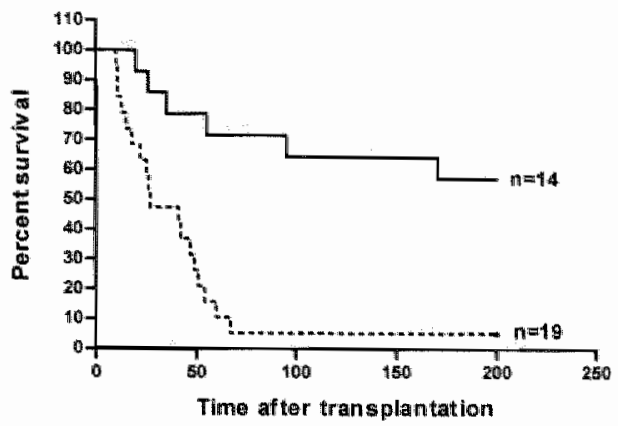

CB6F1 mice were transplanted with $3.3 \times 10^{7}$ B6CBAF 1 BM and $1 \times 10^{8}$ splenocytes and were either treated with PBS or KGF. 200 Days after transplantation, PBS-treated controls (dashed line, $\mathrm{n}=19$ ) showed a survival ratio of $5.3 \%$, compared to a survival ratio of $57.1 \%$ in KGF-treated recipients (solid line, $\mathrm{n}=14)(P=0.0042)$.

\section{KGF permits sustained multilineage chimerism}

At various time points (1,3 and 6 months) after haploidentical transplantation, control-and KGF-treated mice were tested for the presence of donor immune cells in the blood. Animals in both groups were full donor chimeras until death and chimerism was present in the T-and B-cell lineage. In KGF-treated mice, surviving the haploidentical transplantation for an extended period of time $(n=9)$, T-and B-cells were still of donor origin 200 days after allogeneic transplantation (Figure 6). This indicates that the engraftment of haploidentical donor cells, induced with a nonmyeloablative conditioning regimen, is not hampered by KGF treatment.

Figure 6 Sustained multilineage chimerism after KGF-treatment in a nonmyeloablative haploidentical transplantation model.
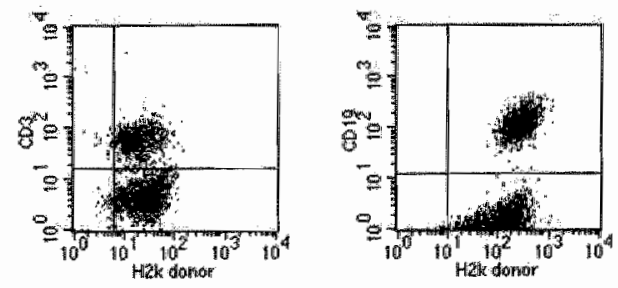

Peripheral blood was analyzed using directly labeled antibodies to T-cell (CD3) and B-cell (CD19) markers and combined with donor- and recipient-specific class I mAbs, anti $\mathrm{H}-2 \mathrm{~K}^{\mathrm{k}}$ and $\mathrm{H}-2 \mathrm{~K}^{\mathrm{d}}$. A representative sample, proving full donor chimerism in the $\mathrm{T}$-and $\mathrm{B}$-cell lineage is shown. Results were similar at all time points $(1,3$ and 6 months) after transplantation. 


\section{Discussion}

In this paper we describe a mouse model of allogeneic SCT in which conditioning is nonmyeloablative and donors and recipients are fully haploidentical. Whereas others often use $P \rightarrow F 1$ combinations, we prefer using a F1 $\rightarrow F 1$ model as it is more similar to the clinical situation, where in haploidentical transplantations patient and donor share one haplotype and are mismatched for the other. This difference is relevant since immune factors might be present in both the host-versus-graft (graft rejection) as well as the graftversus-host direction (GVHD and anti-tumor effect), irrespective of the cells involved.

In devaloping our haploidentical transplantation model we pursued the aims of nonlethal conditioning, long-term chimerism and the prevention of lethal GVHD by means of KGF. Titration of radio-and chemotherapy doses yielded several nonmyeloablative preparative regimens leading to full donor chimeras, with $400 \mathrm{cGy}$ of TBI and $200 \mathrm{mg} / \mathrm{kg} \mathrm{CY}$ being the least toxic strategy. Ultimately, we replaced the initial radiation of $400 \mathrm{cGy}$ with a radiation schedule of two times $200 \mathrm{cGy}$. This definite model, consisting of 2 times $200 \mathrm{cGy} \mathrm{TBI}$, $200 \mathrm{mg} / \mathrm{kg} \mathrm{CY}$ and a bone marrow inoculum of $3.3 \times 10^{7}$ cells was nonmyeloablative and non-toxic with $100 \%$ survival in all syngeneic controls performed thus far.

Nevertheless, we noticed that in our particular experimental situation, splenocytes were crucial for the induction of stable multilineage chimerism and GVHD. Mice transplanted with bone marrow cells alone did not become chimeric and failed to develop GVHD, which can be explained by the amount of T-cells present in the donor inoculum. Analyses of various $\mathrm{BM}$ samples of $\mathrm{B} 6 \mathrm{CBAF} 1$ donor mice $(n=5)$ showed a $\mathrm{T}$-cell content of $2.08 \%$ (range 1.26-3.87) compared to $38.55 \%$ (range $31.14-49.35$ ) in the spleen. These results are in accordance with the observations in C57BL6 mice where T-cells make up only $1 \%$ to $3 \%$ of all bone marrow cells. ${ }^{37}$ Analyses of T-cell subsets revealed that bone marrow contains only $0.78 \%$ (range $0.56-0.91 ; n=3$ ) $\mathrm{CD}^{+}$T-cells as opposed to $25.22 \%$ (range $21.87-35.66, n=5$ ) in splenocyte suspensions. It has been demonstrated previously that marrow $\mathrm{CD}^{+}$and $\mathrm{CD} 8{ }^{*}$ T-cells failed to induce GVHD, even at high numbers, while peripheral $\mathrm{CD} 4^{+} \mathrm{T}$-cells have been proven to be potent inducers of lethal GHVD. ${ }^{38}$

Since adding spleen cells to the bone marrow inoculum did induce high rates of lethal GVHD in our model, we studied the effect of KGF on the development of GVHD. We demonstrated that KGF treatment resulted in reduced GVHD and superior survival. To our knowledge, this is the first report describing a positive effect of KGF on GVHD in a nonmyeloablative conditioning regimen. The use of KGF as GVHD-prophylaxis has been documented in studies using lethal conditioning regimens with mismatched ${ }^{38}$ or $\mathrm{P} \rightarrow \mathrm{Fl}$ donor-recipient pairs. ${ }^{32}$ In our haploidentical mouse model, animals treated with KGF showed a much lower posttransplant weight reduction than their saline-treated counterparts. Moreover, KGF-treated mice developed a mild and transient form of dermatitis, whereas control-treated animals suffered from severe, persistent dermatitis, covering the entire body. Long-term effects of KGF manifested themselves as an improved survival ratio in KGFtreated animals compared to controls. 
Additional proof of beneficial KGF-efects on the development of GVHD was provided by analysis of murine plasma for $\mathrm{TNF}^{-} \alpha$. As conditioning induces damage to and activation of the intestinal mucosa, leading to a release of inflammatory cytokines sueh as TNF- $\alpha$, KGF can be used as a shield to internpt the cytokine cascade and protect the gut epithelium." Indeed, when animals were treated with $5 \mathrm{mg} / \mathrm{kg} \mathrm{KGF}$ for 9 consecutive days, plasma TNF $\alpha$ levels were significantly lower than in control-treated animals. These results, measured 5 days after allogeneic transplantation, are in accordance with the findings in a radiationbased $P \rightarrow F 1$ transplantation model ${ }^{32}$ and are indicative of reduced GI damage, due to a combination of conditioning and allogeneic transplantation. However, our observations differ partly from the theory that conditioning induced cytokine release is responsible for the subsequent development of GVHD. In this nommyeloablative model we did not observe a measurable elevation of TNF- $\alpha$ levels in syngeneic controls, as is the case after" myeloablative TBI. However, local cytokine release, even when it is not quantifiable, cannot be ruled out as a contributing factor in the pathophysiology of GVHD. Reduced TNF- $\alpha$ levels observed after KGF treatment might also reflect reduced GVHD rather then conditioning-induced damage alone. It is also possible that other cytokines, inflammatory as well as anti-inflammatory ${ }^{30}, 40$ play a role in the protective mechanism of KGF in our transplantation model. In our opinion however, the most relevant observation is that KGF also protects from GVHD after nonmyeloablative conditioning regimens in a haploidentical setting.

To determine whether KGF does in fact mediate its positive effect through protection of the Gl tract, we measured plasma citrulline concentrations one week after transplantation. Recently, several reports have demonstrated that citrulline can be used as a quantitative marker for radiation-induced small bowel injury. ${ }^{35,41,42}$ Reduction of small bowel epithelial cell mass through surgery or ionizing radiation is associated with diminished plasma citrulline levels, as demonstrated in rodents ${ }^{35,43,44}$ and patients. ${ }^{45}$ In the present study, we demonstrated that plasma citrulline levels decreased by almost $75 \%$ one week after allogeneic transplantation and that KGF treatment was able to diminish this effect. Control animals treated with a syngeneic transplant and PBS showed elevated citrulline levels, consistent with previous observations in patients in response to radiation treatment." Histologic sections of the small bowel were compared to confirm the previously established relationship between citrulline values and small intestinal damage. We found that after allogeneic transplantation, small intestinal damage as measured by single-cell necrosis and mucosal surface, was lower in KGF-treated animals than in PBS-treated controls. It has to be noted however that in our experiments of nonmyeloablative conditioning overall damage was mild compared to earlier publications where animals were conditioned more intensely. ${ }^{32}, 46$ Animals that received the nonmyeloablative conditioning regimen as a preparation for the syngeneic transplant, showed almost no damage to the GI tract, indicating that most of the necrosis in our model is a result of the development of GVHD. In animals treated with $\mathrm{KGF}$ in combination with a syngeneic transplant, single-cell necrosis was slightly higher than in the PBS-treated counterparts, probably due to a toxic effect of the growth factor. However, this elevation in necrotic score does not seem to interfere with 
the positive effect K.GF has in the allogeneic situation. Taken together, our data indicate that protection of the gut mucosa is the most likely pathway of KGF in GVHD prevention, although a protective effect of KGF on other GVIID target organs through effector immune cells cannot be ruled out.

Since KGF considerably improved survival of animals transplanted with allogeneic BM, this treatment will give us the opportunity to study anti-tumor effects in this mouse model. At present, studies are being performed to analyze the anti-tumor effect of these haploidentical transplantations on both solid tumors as well as hematological malignancies. Although not as GVHD-prophylaxis, KGF has already been applied in clinical trials. When used for the treatment of oral mucositis, KGF was well tolerated by patients, only some mild skin and oral adverse effects occurred. ${ }^{25,}{ }^{47}$ In our animal model, mice exhibited roughened hair for the duration of the KGF treatment. This might be explained by the overall effect of KGF on all epithelial elements, including hair follicles. ${ }^{26,}{ }^{48}$ It is worth mentioning that this fur condition is only temporarily and returns to normal within a few days after cessation of the treatment. Considering this mild side effect, the effect on the small intestine and taking into account some reports about KGF posttreatment not adding to overall survival, ${ }^{31}, 46$ it might be wise to examine whether a short pretransplant KGF treatment is sufficient to prevent lethal GVHD in our setting.

Haploidentical transplantations in man are not yet a frequently performed clinical procedure and the combination with nonmyeloablative conditioning has only been described in some case reports ${ }^{8,10}$ and smaller studies. ${ }^{12}$ However, the anti-tumor effects that were demonstrated in these models of hematological and solid tumors, make this approach an attractive option for clinical cancer treatment.

Recent publications ${ }^{16,24}$ indicate the feasibility of haploidentical transplantations in terms of GVHD prevention and anti-leukemia effects. Unfortunately, the haploidentical procedure leads to severe immunodeficiency, mainly because of strong T-cell depletion necessary to prevent acute GVHD. If KGF could play a positive role in GVHD prevention in clinical haploidentical models, it would allow for more T-cells to be transplanted. It has been shown that donor T-cells are indeed crucial for recovery of immune function after haploidentical transplantations. ${ }^{49}$ Adding KGF treatment to haploidentical transplantations, possibly in combination with standard GVHD-prophylaxis, ${ }^{50}$ might therefore be a valuable clinical option, allowing more transplantations to be performed safely without serious GVHD and immunodeficiency.

In conclusion, the present study demonstrates that in a model of nonmyeloablative haploidentical transplantation $\mathrm{KGF}$ is able to significantly increase overall survival by preserving gut integrity. In addition, our data support the development of clinical trials in haploidentical transplantation regimens, with add-back of increased amounts of T-cells. 


\section{References}

1. Beatty $\mathrm{PG}$, Mori M, Milford E. Impact of racial genetic polymorphism on the probability of finding an HLA-matched donor. Transplantation 1995; 60: 778-783.

2. Henslee-Downey PJ, Abhyankar SH, Parrish RS, et al. Use of partially mismatched related donors extends access to allogeneic marrow transplant. Blood 1997; 89: 3864-3872.

3. Beatty PG, Clift RA, Mickelson EM, et al. Marrow transplantation from related donors other than HLA-identical siblings. N Engl I Med 1985; 313: 765-771.

4. Ferrara $\mathrm{J}$, Levy R, Chao NJ. Pathophysiologic mechanisms of acute graft-vs-host disease. Biol Blood Marrow Transplant 1999; 5: 347-356.

5. Martino R, Caballero MD, Canals $C$, et al. Reduced-intensity conditioning reduces the risk of severe infections after allogeneic peripheral blood stem cell transplantation. Bone Marrow Transplant 2001; 28: 341-347.

6. Mielcarek $\mathrm{M}$, Martin $\mathrm{PJ}$, Leisenring $\mathrm{W}$, et all. Graft-versus-host disease after nonmyeloablative versus conventional hematopoietic stem cell transplantation. Blood 2003; 102: 756-762.

7. Couriel DR, Saliba RM, Giralt S, et all. Acute and chronic graft-versus-host disease after ablative and nonmyeloablative conditioning for allogeneic hematopoietic transplantation. Biol Blood Marrow Transplant 2004; 10: 178-185.

8. Toh HC, Spitzer TR, Preffer F, et al. Fluctuating lymphocyte chimerism, tolerance and anti-tumor response in a patient with refractory lymphoma receiving nonmyeloablative conditioning and a haploidentical related allogeneic bone marrow transplant. Cytokines Cell Mol Ther 2002; 7: 43-47.

9. Obama K, Takemoto Y, Takatsuka Y, Utsunomiya A. Successful reduced-intensity HLA-haploidentical stem ceil transplantation based on the concept of feto-maternal tolerance for an elderly patient with myelodysplastic syndrome. Bone Marrow Transplant 2004; 33: 253.

10. Satoh M, Miyamura K, Yamada M, et al. Haploidentical, non-myeloablative stemcell transplantation for advanced renal-cell carcinoma. Lancet Oncol 2004;5:125126.

11. Gaspar HB, Amrollia P, Hassan A, ef al. Non-myelloablative stem cell transplantation for congenital immunodeficiencies. Recent Results Cancer Res 2002; 159; 134-142.

12. Tamaki $H$, lkegame $\mathbb{K}$, Kawakami $M$, et al. Successful engraftment of HLAhaploidentical related transplants using nonmyeloablative conditioning with fludarabine, busulfan and anti-T-lymphocyte globulin. Leukemia 2003; 17: 20522054.

13. Koenecke $\mathrm{C}$, Shaffer $\mathrm{J}$, Alexander $\mathrm{SI}$, et al. NK cell recovery, chimerism, function, and recognition in recipients of haploidentical hematopoietic cell transplantation following nonmyeloablative conditioning using a humanized anti-CD2 $\mathrm{mAb}$, Medi507.Exp Hematol 2003; 31: $911-923$. 
14. Aversa $\mathbf{F}$, Tabilio A, Velardi A, et al. Treatmert of high-risk acute leukemia with $T$ cell-depleted stem cells from related donors with one fully mismatched HLA haplotype. N Engl J Med 1998; 339: 1186-1193.

15. Horowitz MM, Gale RP, Sondel PM, et al. Graft-verstis-leukemia reactions after bone marrow transplantation. Blood 1990; 75: 555-562.

16. Aversa F, Terenzi $A$, Tabilio $A$, et al. Full haplotype-mismatched hematopoietic stem-cell transplantation: a phase II study in patients with acute leukemia at high risk of relapse. J Clin Oncol $2005 ; 23: 3447-3454$.

17. Slavin $\mathrm{S}$, Nagler $\mathrm{A}$, Naparstek $\mathrm{E}$, et al. Nonmyeloablative stem cell transplantation as an altemative to conventional bone marrow transplantation with lethal cytoreduction for the treatment of malignant and nonmalignant hematologic diseases. Blood 1998; 91: 756-763.

18. Sykes $\mathrm{M}_{3}$ Preffer F, McAfee S, et al. Mixed lymphohaemopoietic chimerism and graft-versus-lymphoma effects after non-myeloablative therapy and HLAmismatched bone-marrow transplantation. Lancet 1999; 353: 1755-1759.

19. Childs $\mathrm{R}_{3}$, Chemoff $\mathrm{A}$, Contentin $\mathrm{N}$, et all. Regression of metastatic renal-cell carcinoma after nonmyeloablative allogeneic peripheral-blood stem-cell transplantation. N Engl J Med 2000; 343: 750-758.

20. Lewalle $\mathrm{P}$, Triffet $\mathrm{A}$, Delforge $\mathrm{A}$, et al. Donor lymphocyte infusions in adult haploidentical transplant: a dose finding study. Bone Marrow Transplant 2003; 31:39-44.

21. Nagler $A$, Ohana $M, A l p e r ~ R$, et al. Induction of oral tolerance in bone marrow transplantation recipients suppresses graft-versus-host disease in a semiallogeneic mouse model. Bone Marrow Transplant 2003; 32: 363-369.

22. Hoffinann P, Ermann J, Edinger $M$, et al. Donor-type $\mathrm{CD} 4(+) \mathrm{CD} 25(+)$ regullatory $\mathrm{T}$ cells suppress lethal acute graft-versus-host disease after allogeneic bone marrow transplantation. Exp Med 2002; 196: 389-399.

23. Sato K, Yamashita N, Yamashita N, et al. Regulatory dendritic cells protect mice from murine acute graft-versus-host disease and leukemia relapse. Immunity 2003 ; 18:367-379.

24. Ruggeri L, Capanni M, Urbani E, et al. Effectiveness of donor natural killer cell alloreactivity in mismatched hematopoietic transplants. Science 2002; 295: 2097 2100.

25. Wirth K, Mertelsmann R. Cytoprotective function of keratinocyte growth factor in tumour therapy-induced tissue damage. Br J Haematol 2002; 116:505-510.

26. Pierce GF, Yatagihara D, Klopchin K, et al. Stimulation of all epithelial elements during skin negeneration by keratinocyte growth factor. J Exp Med 1994; 179: 831 840.

27. Ulich TR, Yi ES, Longmuir $\mathrm{K}_{\mathrm{x}}$ at al. Keratinocyte growth factor is a growth factor for type II pneumocytes in vivo. J Clin Invest 1994 Mar; 93: 1298-1306.

28. Housley RM, Morris CF, Boyle W, et al. Keratinocyte growth factor induces proliferation of hepatocytes and epithelial cells throughout the rat gastrointestinal tract. J Clin Invest 1994; $94: 1764-1777$. 
29. Khan WB, Shui C, Ning S, Knox SJ. Enhancement of murine intestinal stem cell survival after irradiation by keratinocyte growth factor. Radiat Res 1997; 148: 248253.

30. Panoskaltsis-Mortari A, Taylor PA, Rubin JS, et al. Keratinocyte growth factor facilitates alloengraftment and ameliorates graft-versus-host disease in mice by a mechanism independent of repair of conditioning-induced tissue injury. Blood 2000; 96: 4350-4356.

31. Panoskaltsis-Mortari A, Lacey DL, Vallera DA, Blazar BR. Keratinocyte growth factor administered before conditioning ameliorates graft-versus-host disease after allogeneic bone marrow transplantation in mice. Blood 1998; 92: 3960-3967.

32. Krijanovski OI, Hill GR, Cooke KR, et al. Keratinocyte growth factor separates graft-versus-leukemia effects from graft-versus-host disease. Blood 1999; 94: 825831.

33. van Eijk HM, Rooyakkers DR, Deutz NE. Rapid routine determination of amino acids in plasma by high-performance liquid chromatography with a $2-3$ microns Spherisorb ODS II column. J Chromatogr 1993; 620: 143-148.

34. von Asmuth EJ, Maessen JG, van der Linden $\mathrm{CJ}_{*}$ Buurman WA. Tumour necrosis factor alpha (TNF-alpha) and interleukin 6 in a zymosan-induced shock model. Scand J Inmunol 1990; 32: 313-319.

35. Lutgens LC, Deutz NE, Gueulette J, et al. Citrulline: a physiologic marker enabling quantitation and monitoring of epithelial radiation-induced small bowel damage. Int J Radiat Oncol Biol Phys 2003; 57: 1067-1074.

36. Wakabayashi Y, Yamada E, Hasegawa T, Yamada R. Enzymological evidence for the indispensability of small intestine in the synthesis of arginine from glutamate. I. Pyrroline-5-carboxylate synthase. Arch Biochem Biophys 1991; 291: 1-8.

37. Zeng D, Gazit $\mathrm{G}$, Dejbakhsh-Jones $\mathrm{S}$, et al. Heterogeneity of NK1.1+ T cells in the bone marrow: divergence from the thymus. J Immunol 1999; 163: 5338-5345.

38. Zeng D, Hoffmann $P$, Lan $F$, et al. Unique patterns of surface receptors, cytokine secretion, and immune functions distinguish $T$ cells in the bone marrow from those in the periphery: impact on allogeneic bone marrow transplantation. Blood 2002; 99: 1449-1457.

39. Hill GR, Ferrara JL. The primacy of the gastrointestinal tract as a target organ of acute graft-versus-host disease: rationale for the use of cytokine shields in allogeneic bone marrow transplantation. Blood 2000; 95: 2754-2759.

40. Ellison CA, Natuik SA, Fischer JM, et al. Effect of recombinant human keratinocyte growth factor (rHuKGF) on the immunopathogenesis of intestinal graft-vs-host disease induced without a preconditioning regimen. J Clin Immunol 2004; 24:197211.

4l. Lutgens L, Deutz N, Granzier-Peeters M, et al. Plasma citrulline concentration: a surrogate endpoint for radiation-induced mucosal atrophy of the small bowel. A feasibility study in 23 patients. Int J Radiat Oncol Biol Phys 2004; 60: 275-285. 
42. Blijlevens NM, Lutgens LC, Schattenberg AV, Donnelly JP. Citrulline: a potentially simple quantitative marker of intestinal epithelial damage following myeloablative therapy. Bone Marrow Transplant 2004; 34: 193-196.

43. Wakabayashi $\mathrm{Y}$, Yamada $E$, Yoshida T, Takahashi $N$. Effect of intestinal resection and arginine-free diet on rat physiology. Am I Physiol 1995; 269: G313-318.

44. Chen $K$, Nezu $R$, Sando $K$, et al. Influence of glutamine-supplemented parenteral nutrition on intestinal amino acid metabolism in rats after small bowel resection. Surg Today 1996; $26: 618-623$.

45. Crenn P, Coudray-Lucas $C$, Thuillier $F$, et al. Postabsorptive plasma citrulline concentration is a marker of absorptive enterocyte mass and intestinal failure in humans. Gastroenterology 2000; 119: 1496-1505.

46. Farrell CL, Bready IV, Rex KL, et al. Keratinocyte growth factor protects nice from chemotherapy and radiation-induced gastrointestinal injury and mortality. Cancer Res 1998; 58:933-939.

47. Meropol NJ, Somer RA, Gutheil I, et al. Randomized phase I trial of recombinant human keratinocyte growth factor plus chemotherapy: potential role as mucosal protectant. J Clin Oncol 2003; 21: 1452-1458.

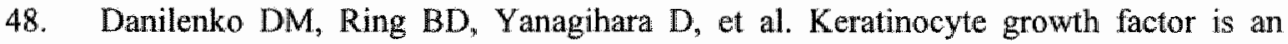
important endogenous mediator of hair follicle growth, development, and differentiation. Normalization of the nu/nu follicular differentiation defect and amelioration of chemotherapy-induced alopecia. Am J Pathol 1995; 147: 145-154.

49. Igarashi $T$, Wynberg J, Srinivasan R, et al. Enhanced cytotoxicity of allogeneic NK cells with killer immunoglobulin-like receptor ligand incompatibility against melanoma and renal cell carcinoma cells. Blood 2004;104: 170-177.

50. Anasetti C. Advances in the prevention of graft-versus-host disease after hematopoietic cell transplantation. Transplantation $2004 ; 77(9$ Suppl):S79-83. 


\section{Chapter 7}

CITRULLINE:

A POTENTIALLY SIMPLE QUANTITATIVE MARKER OF INTESTINAL EPITHELIAL DAMAGE FOLLOWING MYELOABLATIVE THERAPY

N.M.A. Blijlevens', L.C.H.W. Lutgens', A.V.M.B. Schattenberg' and J.P. Donnelly

"Department of Haematology, Unwersity Medical Centre St. Radbond Nijmegevt"

${ }^{2}$ Department of Radiation Therapy and Oncology Maastricht, MAASTRO Clinic,

The Netherlands.

Bone Marrow Transplant 2004 Aug;34 (3):193-6. 


\section{Summary}

We noted a significant decline in the serum concentrations of citrulline of 32 haematopoietic stem cell transplant recipients following intensive myeloablative therapy during the first three weeks after transplant when patients have oral mucositis, a markedly disturbed gut integrity (L/R ratio) and are most at risk of infection and other severe complications. Closer inspection of the citrulline concentrations of 12 patients confirmed that the decline did indeed correspond with the onset of oral mucositis and altered gut integrity. Since serum citrulline is a reliable biochemical marker of small bowel enterocyte mass in hurnans with villous-atrophy associated diseases, it may prove a useful marker of intestinal mucosal damage induced by chemotherapy allowing the relationship between gut mucosal damage and post-transplant complications including infections to be explored more readily. 


\section{Introduction}

Mucositis is a manifestation of mucosal barrier injury and the most frequent cause of morbidity associated with the myeloablative conditioning treatment to prepare for an haematopoietic stem cell transplantation (HSCT). Oral mucositis is easy to recognise whereas detection of intestinal mucosal injury relies essentially on non-specific symptoms like nausea, vomiting, diarrhoea and abdominal cramps, which affect almose every HSCT recipient. An altemative means of recognising gut mucosal barrier injury is required if it is to be better understood and managed. Alterations in permeability and loss of epithelial surface are features of gut injury that can be detected by sugar permeability tests which are non-invasive and generally accepted as a surrogate marker of gut damage in patients treated for cancer. ${ }^{2}$ However, sugar permeability tests are cumbersome and wholly dependent on patient compliance. A marker of intestinal injury that could be determined in blood would be ideal but none has been described so far. Citrulline might prove valuable in this regard since it is an endproduct of glutamine metabolism of small intestinal enterocytes, cells which lack the necessary cytosolic enzymes to convert the amino acid to arginine. ${ }^{3}$ Blood concentrations of citrulline directly reflect the cell mass of the small intestine since the small intestine is the principal source of the amino acid and it is not metabolised by the liver. ${ }^{4}$ In mice, citrulline levels were used to quantify acute small bowel epithelial damage after single-dose whole body irradiation." The high-dose chemotherapy used to prepare patients to receive an HSCT injures the small intestine by inducing crypt apoptosis, hypoplastic villous atrophy and loss of enterocytes. ${ }^{6}$ We had determined the amino-acid profiles in the serum of a cohort of $32 \mathrm{HSCT}$ recipients who had participated in a prospective randomised placebo-controlled study approved by the local Ethics Committee the aim of which was to investigate the possible benefits of parenteral nutrition (PN) supplemented with glutamine-dipeptide. As citrulline was included we were able to relate the concentrations temporally with oral mucositis, gut toxicity and sugar permeability tests (SPT).

\section{Methods and Materials}

\section{Patients}

32 patients (12 F; $20 \mathrm{M}$ ) with mean age 48 years (tange 25-65) had given their informed consent to participate in the prospective study and all had received an HLA-matched T-cell depleted sibling HSCT to treat a haematological malignancy (AML (9), ALL (7), NHL (7), MDS (3), CML (2), MPD (2), CLL (1), MF (1). The preparative regimen consisted of idarubicin to lower the risk of relapse ${ }^{7.8}$ given at a dose of $42 \mathrm{mg} / \mathrm{m}^{2}$ by continuous infusion over 48 hours starting 12 days before transplant (HSCT day -12 ), followed by $120 \mathrm{mg} / \mathrm{kg}$ cyclophosphamide (60 mg/kg per day on HSCT days $-6 \&$ - 5) and 9 Gy of total body irradiation ( 4.5 Gy per day on HSCT days $-2 \&-1$ ). Ciclosporin $3 \mathrm{mg} / \mathrm{kg} / \mathrm{day}$ was given as prophylaxis against GVHD by continuous infusion from HSC $T$ day -1 to +14 followed by 2 $\mathrm{mg} / \mathrm{kg} / \mathrm{day}$ until oral intake was possible. Haematopoietic growth factors were not used. Anti-infective prophylaxis consisted of ciprofloxacin and acyclovir or valaciclovir. Co- 
trimoxazole (sulphamethoxazole-trimethoprim) was given for prophylaxis against Pneumocysis carinii. No prophylactic systemic antifungal agents were given. Cefipime or ceftazidime was administered empirically at the onset of fever. All recipients were given PN supplemented by either glutamine-dipeptide or placebo on HSCT day -6 . The glomerular filtration rate was determined on admission by measuring renal creatinine clearance $(\mathrm{mL} / \mathrm{min})$ and was estimated thereafter from the serum creatinine using the formula of Cockroft. \& Gault."

\section{Mucositis assessment}

Patients were monitored daily for the presence of oral mucositis evidenced by lesions, erythema, oedema, pain, bleeding, dryness and the production of viscous mucous with each item being allocated a score of 0 or normal to 3 or severe. The separate values were summed to yield a daily oral mucositis score (DMS) with 3 grades: DMS grade I ( $1-7$ points) mild mucositis, grade II ( $8-14$ points) moderate mucositis and grade III ( $>14$ points) severe mucositis. ${ }^{10}$ Gut toxicity was scored likewise from 0 to 3 based on the frequency of vomiting and diarrhoea, as well as the occurrence of nausea, abdominal complaints, faecal incontinence and volume. Summation of the separate score yielded the daily gut score (DGS) grade I ( $1-6$ points) represents mild toxicity, grade II (7-12 points) moderate toxicity and grade III ( $>12$ points) severe toxicity. All gut toxicities following chemotherapy were ascribed to mucositis unless there was a more plausible altemative cause such as an adverse drug reaction or proven toxigenic infection.

\section{Sugar permeability test (SPT)}

An isotonic solution was prepared by dissolving $5 \mathrm{~g}$ lactulose (LAC), $1 \mathrm{~g}$ L-rhamnose (RHA), $0.2 \mathrm{~g} \mathrm{3-O-methylglucose} \mathrm{(OMG),} 0.5 \mathrm{~g}$ D-xylose (XYL) in $100 \mathrm{~mL}$ demineralised water, according to good manufacturing practice by our own hospital pharmacy. After an overnight fast, the subjects emptied their bladders and then drank the solution. A light breakfast with a drink was allowed after 2 hours. Urine was collected for 5 hours after which the total volume passed was recorded, and aliquots of approximately $5 \mathrm{~mL}$ were stored in $-80^{\circ} \mathrm{C}$ untill analysis was performed. The first SPT (baseline day) was performed before starting conditioning therapy and was repeated every Wednesday after baseline on HSCT days $-12,-6,0,+7,+14$ and +21 .

\section{Determination of the sugars in wrine}

The concentration of each sugar was determined using gas chromatography with flame ionisation detection with D-glucoheptose as an internal standard. "Data were collected online using Star Chromatography software (Varian, Tempe, Arizona, USA) and peak areas were measured and corrected to the internal standard.

The concentration of each sugar was then estimated in $\mu$ mol/L using standard calibration curves and urinary necovery of each sugar was calculated as a percentage of intake. The coefficient of variance for $\mathrm{LAC}, \mathrm{XYL}, \mathrm{RHA}$ and $\mathrm{OMG}$ were $2.3 \%, 3.7 \%, 3.1 \%$ and $2.3 \%$. Urinary excretion of two sugars, for example lactulose and rhamnose, was expressed as a ratio to minimise the influence of extraneous factors such as gastric emptying and bowel transit time. The lactulose/rhamnose ratio (L/R) was used as an index of intestinal 
permeability or integrity with a $L / R$ ratio of 0.02 or less being considered normal. Similarly, the L-rhannose/3-O-methylglucose (RHA/OMG) D-and xylose/3-O-methylglucose (XYL/OMG) ratios were used respectively as an index of absorptive capacity and mediated cellular transport with a ratio of $0.28{ }^{12}$ and $0.65^{13}$ being considered normal:

\section{Citrulline analysis}

The protocol prescribed serum to be obtained on $\mathrm{HSCT}$ days $-12,-6,0,+7,+14$ and +21 for later amino acid analysis. In practice, this was not always done. Serum taken was stored at $-80^{\circ} \mathrm{C}$. Citruline concentrations $(\mu \mathrm{M})$ were measured by a standard procedure for determining amino acids using automated ion exchange column chromatography.

\section{Data analysis}

The mean and $95 \%$ confidence interval $[95 \% \mathrm{CI}]$ of DMS and DGS scores on each of the days that the SPT was performed were calculated. If these were not recorded, they were classified as missing values. Sugar ratios were first transformed to logarithms and then expressed as the mean with $95 \% \mathrm{Cl}$. A 2 -sided unpaired student's $t$-test was used to calculate significant differences with respect to baseline. One-way analysis of variance of citrulline concentrations (mean with $95 \% \mathrm{Cl}$ ) between $\mathrm{HSCT}$ days was undertaken using SPSS $\mathrm{v}$ 11.0. ANOVA was also used to determine the role, if any, of glutamine supplementation. A p-value of $<0.05$ was considered statistically significant. Correlations between groups were tested by Pearson's $r$ correlation.

\section{Results}

All patients were profoundly neutropenic (granulocytes $<0.1 \times 10^{9} / \mathrm{L}$ ) for the first 14 days after transplant. Five $(16 \%)$ patients died during the first 3 weeks after transplant, 2 with sepsis syndrome after Streptococcus mitis bacteraemia on HSCT day +9 and +12 respectively and 1 each from invasive candidiasis due to Candida albicans on HSCT day +13 , ARDS on HSCT day +13 and VOD on HSCT day +21 . Oral mucositis was present for the first 3 weeks after transplant but, unlike gut toxicity, showed a clear peak 1 week after transplant. The $L / R$ ratio, increased significantly $(p<0.0001)$ on the day of transplant with respect to the baseline (i.e. 12 days after starting myeloablative therapy). The XYL/OMG and RHA/OMG ratios were also significantly decreased during the early post transplant period (Table 1). Some patients were unable or unwilling to drink the solution because of severe mucositis, nausea or vomiting. Citrulline concentrations were significantly $(p<0.0001)$ decreased on the day of transplant as compared to the baseline values with the nadir being observed 1 week later.

To examine the relationship of citrulline and transplant related complications in more detail, we selected the 12 patients from whom blood had been obtained on each of the HSCT days $-12,-6,0,+7$ and +14 for the citrulline assay. Figure $\mathbb{1}$ illustrates a clear downward trend for citrulline concentrations in all but one case (patient \#12).

There was no obvious difference seen between the mucositis and SPT observed in this patient and that found for the other 11 patients (data not shown). The demographics and 
transplant related complications that occurred in these patients are shown in table 2 . There is no common pattern in terms of infectious complications or acute GVHD apparent. Serum creatinine rose significantly for 1 patient ( 4) but citrulline levels remained low. Six patients had received glutamine. The mean citrulline levels were not influenced by the use of glutamine supplementation (ANOVA, $p=0.08$, data not shown).

Citrulline concentrations correlated significantly with DMS $r=-0.36$, DGS $r=-0.25$; L/R ratio $r=-0.41 ; \mathrm{XYL} / \mathrm{OMG}$ ratio $r=0.24$ and $\mathrm{RHA} / \mathrm{OMG}$ ratio $r=0.41$.

Figure 1 Serum citrullline concentrations of 12 allogenic HSCT recipients.

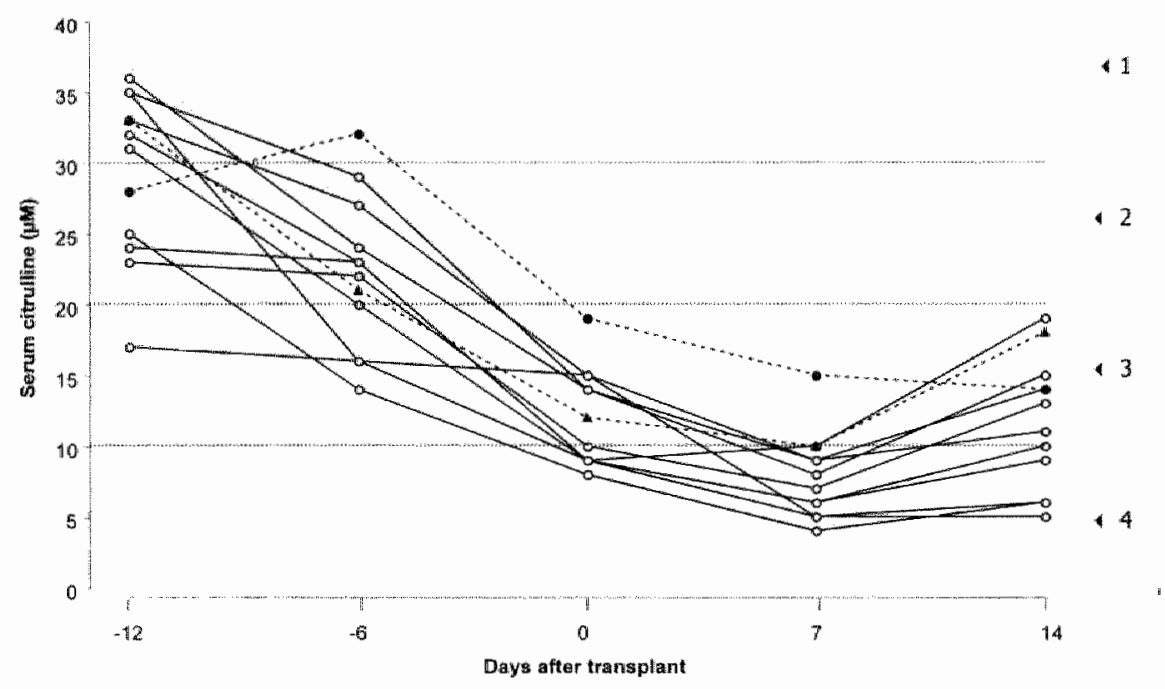

Citrulline concentrations and their relation to the extent of villous atrophy

4 Quartile 1: $>30 \mu \mathrm{M}$ - no villous atrophy

1 Quartile 2: 20-30 $\mu \mathrm{M}$ - partial villous atrophy

1 Quartile 3: 10-20 $\mu \mathrm{M}$ - proximal total villous atrophy

1 Quartile 4: $<10 \mu \mathrm{M}$ - diffuse total villous atrophy

Adapted from Crenn et al. ${ }^{4}$

- A - patient \#4 - - - patient 粆 12 


\section{Table}

Mean (95\% C) of citrulline concentrations, oral mucositis (DMS), gut toxicity (DGS), LR ratio, XYL/OMG ratio and RHA/OMG ratio of $32 \mathrm{HSCT}$ recipients after nyeloablative therapy

\begin{tabular}{|c|c|c|c|c|c|c|c|c|c|}
\hline \multirow[b]{2}{*}{$\begin{array}{l}\text { HSCT } \\
\text { days }\end{array}$} & \multicolumn{3}{|c|}{ CITRULLINE } & \multirow{2}{*}{$\begin{array}{c}\text { DMS } \\
\text { Mear }\end{array}$} & \multirow{2}{*}{$\begin{array}{l}\text { DGS } \\
\text { Mean }\end{array}$} & \multirow[b]{2}{*}{ n } & \multicolumn{3}{|c|}{ SUGAR PERMEABILTY TEST } \\
\hline & $\mathrm{n}$ & $\begin{array}{l}\text { Mean } \\
(95 \% \mathrm{Cl})\end{array}$ & $\mathrm{n}$ & & & & $\begin{array}{c}\mathrm{L} / \mathrm{R} \\
\text { ratio } \\
(95 \% \mathrm{Cl})\end{array}$ & $\begin{array}{c}\text { XYL/OMO } \\
\text { ratio } \\
(95 \% \mathrm{Cl})\end{array}$ & $\begin{array}{c}\text { RHAOMO } \\
\text { rato } \\
(95 \% \mathrm{Cl})\end{array}$ \\
\hline-12 & 25 & $\begin{array}{c}31.8 \\
(28.2-35.3)\end{array}$ & 32 & $\begin{array}{c}0.0 \\
(0.0-0.1)\end{array}$ & $\begin{array}{c}0.1 \\
(0.0-0.2)\end{array}$ & 3.1 & $\begin{array}{c}0.04 \\
(0.04-0.05)\end{array}$ & $\begin{array}{c}0.64 \\
(0.59-0.70)\end{array}$ & $\begin{array}{c}0.25 \\
(0.220 .27)\end{array}$ \\
\hline-6 & 27 & $\begin{array}{c}25.7 \\
(21.7-35.3)\end{array}$ & 25 & $\begin{array}{c}0.4 \\
(0.0 .0 .8)\end{array}$ & $\begin{array}{c}0.9 \\
(0.5-1.3)^{*}\end{array}$ & 29 & $\begin{array}{c}0.04 \\
(0.03-0.06)\end{array}$ & $\begin{array}{c}0.59 \\
(0.54-0.65)\end{array}$ & $\begin{array}{c}0.24 \\
(0.21-0.27)\end{array}$ \\
\hline 0 & 27 & $\begin{array}{c}15.1 \\
(12.8-17.4)^{*}\end{array}$ & 30 & $\begin{array}{c}4.5 \\
(3.4-5.7)^{*}\end{array}$ & $\begin{array}{c}2.8 \\
(2.0 .3 .7)^{*}\end{array}$ & 24 & $\begin{array}{c}0.10 \\
(0.06-0.14)^{*}\end{array}$ & $\begin{array}{c}0.57 \\
(0.50-0.63)^{*}\end{array}$ & $\begin{array}{c}0.25 \\
(0.15-0.36)\end{array}$ \\
\hline$\$ 7$ & 26 & $\begin{array}{c}9.9 \\
(7.9-11.8)^{*}\end{array}$ & 31 & $\begin{array}{c}9.1 \\
(7.3-0.8)^{*}\end{array}$ & $\begin{array}{c}2.1 \\
(0.9-3.3)^{*}\end{array}$ & 14 & $\begin{array}{c}0.18 \\
(0.14-0.22)^{*}\end{array}$ & $\begin{array}{c}0.40 \\
(0.31-0.49)^{*}\end{array}$ & $\begin{array}{c}0.11 \\
(0.05-0.18)^{*}\end{array}$ \\
\hline+14 & 20 & $\begin{array}{c}14.1 \\
(11.2-16.9)^{*}\end{array}$ & 26 & $\begin{array}{c}4.3 \\
(3.1-5,6)^{*}\end{array}$ & $\begin{array}{c}3.4 \\
(2.1-4.6)^{*}\end{array}$ & 16 & $\begin{array}{c}0.20 \\
(0.1 t-0.30)^{*}\end{array}$ & $\begin{array}{c}0.44 \\
(0.38-0.49)^{*}\end{array}$ & $\begin{array}{c}0.11 \\
(0.07 \cdot 0.14)^{\text {th }}\end{array}$ \\
\hline$+2 \|$ & 16 & $\begin{array}{c}14.5 \\
(12.2-16.8)^{*}\end{array}$ & 18 & $\begin{array}{c}2.9 \\
(0.7-5.0)^{*}\end{array}$ & $\begin{array}{c}2.4 \\
(1.3-3.5)^{*}\end{array}$ & 10 & $\begin{array}{c}0.26 \\
(0.01-0.51)^{*}\end{array}$ & $\begin{array}{c}0.45 \\
(0.34-0.57)^{\text {th }}\end{array}$ & $\begin{array}{c}0.11 \\
(0.07-0.15)^{*}\end{array}$ \\
\hline
\end{tabular}

* significantly different with respect to baseline. 
Table 2 Complications in $12 \mathrm{SCT}$ recipients with a complete set of citrulline data.

\begin{tabular}{|c|c|c|c|c|c|c|c|}
\hline Pat & Age & $\operatorname{sex}$ & Dis & $\mathrm{CC}$ & $\begin{array}{c}\text { MIDI } \\
\text { (HSCTday) }\end{array}$ & $\begin{array}{c}\text { CDI } \\
\text { (HSCT day) }\end{array}$ & $\begin{array}{c}\text { acute GVHD (HSCT } \\
\text { day) }\end{array}$ \\
\hline 1 & 52 & $M$ & MUIL & 98 & - & $\overline{-}$ & Grade III (13) \\
\hline 2 & 25 & $M$ & AML & 112 & $\begin{array}{l}\text { Bacteraemig } \\
\text { Staphylococcess } \\
\text { eplderwidis: (1) } \\
\text { ovs (5) }\end{array}$ & CVC exit site (9) & - \\
\hline 3 & 47 & M & AML & 108 & $\begin{array}{l}\text { Bacteraemia } \\
\text { Streptococcus } \\
\text { sentworius (s) }\end{array}$ & - & - \\
\hline 4 & $\$ 2$ & $M$ & AML & 69 & - & - & - \\
\hline 5 & 39 & $7 *$ & CML. & 50 & $\begin{array}{l}\text { Bacteraemia } \\
\text { Staphylococcus } \\
\text { epider pridis (1) }\end{array}$ & $\begin{array}{l}\text { CVC exit site (1) } \\
\text { Oesophagitis (2) } \\
\text { Thrombosis vena } \\
\text { subclavila (14) }\end{array}$ & Grade III (21) \\
\hline 6 & $\$ 7$ & $\mathrm{M}$ & NHL & 49 & $\begin{array}{c}\text { Bacteraemia } \\
\text { S. apordermidis (7) }\end{array}$ & $\begin{array}{c}\text { Pulmonary infiltrate } \\
\text { with sepsis (15) }\end{array}$ & Grade III (16) \\
\hline 7 & 52 & $M$ & NHL & 66 & $\begin{array}{l}\text { Bacteraemia } \\
\text { Stcoprylococcus } \\
\text { epidermidis ( } 5 \text { ) }\end{array}$ & - & Grade I (12) \\
\hline 8 & 46 & Fi & $\mathrm{AML}$ & 88 & $\begin{array}{l}\text { Bacteractuia } \\
\text { Siaphylococcus } \\
\text { epider midis (0) }\end{array}$ & - & - \\
\hline 9 & 45 & $\mathrm{M}$ & ALI. & 128 & 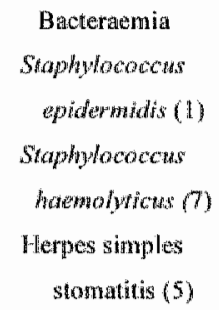 & - & - \\
\hline 10 & 26 & $f$ & ALL & 59 & - & Pulmonary infiltrate (5) & 。 \\
\hline 11 & 41 & $M$ & AML & 76 & - & $=$ & - \\
\hline 12 & 47 & $M$ & Alth & 90 & 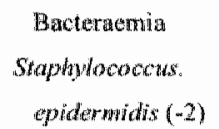 & - & - \\
\hline
\end{tabular}

$\mathrm{CC}=$ measured creatinine clearance on admission $(\mathrm{m} / \mathrm{min}) ; \mathrm{OVS}=$ oral viridans streptococcus; $C V C=$ central venous catheter; acute GVHD overall grade (Glucksberg criteria), 


\section{Discussion}

This was a reasonably homogeneous group with respect to myeloablative regimen, prophylaxis and transplant procedure and citrulline concentrations declined after HSCT at the same time, as oral mucositis and gut toxicity were apparent. Gut integrity, measured by $L / R$ ratio and the absorptive capacity of rhamnose, xylose and 3-O-methylgluscose were also severely perturbed. A mean nadir of $<10 \mu \mathrm{M}$ citrulline was reached about 3 weeks after starting myeloablative therapy i.e. during the first week after transplant. This level is considered predictive of severe and extensive villous atrophy in patients with coeliac disease (figure 1). ${ }^{4}$ Furthermore, applying the thresholds that indicate the severity of villous atrophy documented in patients with coeliac disease helps illustrate the potential clinical value of declining citrulline levels after intense myeloablative therapy in HSCT recipients. ${ }^{4}$ We could not confirm the presence of small bowel villous atrophy e.g. intestinal mucosal damage by endoscopy as the procedure carries a high risk especially shortly after transplant. Never the less, when taken together, the changes in DGS (signs and symptoms), SPT (functionality) and citrulline levels (enterocyte mass) indicate that the mucosal epithelium of the small intestines is severely damaged for a prolonged period after HSC transplant though each measure seems to reflect a different manifestation of damage to the small. intestine.

Interestingly, citrullime levels on admission were lower than those found for healthy individuals $(40 \pm 10 \mu \mathrm{M}){ }^{4}$ and the $L / R$ ratio was also higher. This might reflect residual damage to the small intestine after previous intensive chemotherapy given to induce remission of haematological malignancy or consolidate it.

Several factors are known to influence citrulline kinetics though none seem to apply to this patient population. The kidneys extract most of the citrulline released by the intestines and convert it to arginine. Citrulline levels may therefore be "falsely" increased when creatinine clearance is below $50 \mathrm{~mL} / \mathrm{min}$. We only measured creatinine clearance once and estimated it further from serum creatinine but only one patient showed a significant increase. Enteral feeding can induce a slight decrease in citrulline but the patients in this study were only able to imbibe water and were being given their nutrition parenterally during the observation period. Taking blood samples for amino acids whilst continuing parenteral nutrition can also confound but this is unlikely to be important for this patient population since levels none the less continued to decline.

These results show that low serum citrulline concentrations do coincide with and appear to correspond to severe and extensive mucosal barrier injury of the small intestine. If so, this simple test may provide another potentially useful tool for studying the relationship between mucosal barrier injury and other post-transplant complications such as malnutrition, infection and graft-versus host disease. 


\section{References}

1. Elting LS, Cooksley C, Chambers M, Cantor SB, Manzullo E., Rubenstein EB. The burdens of cancer therapy: clinical and economic outcomes of chemotherapy-induced mucositis. Cancer 2003;98:1531-1539.

2. Blijlevens NMA, Donnelly IP, De Pauw BE. Mucosal barrier injury: biology, pathology, clinical counterparts and consequences of intensive treatment for haematological malignancy: an overview. Bone Marrow Transplant 2000;25:1269. 1278.

3. Wu G. Synthesis of citrulline and arginine from proline in enterocytes of postnatal pigs. Am J Physiol 1997;272:313-318.

4. Crenn P, Vahedi $K$, Lavergne-Slove A, Cynober L, Matuchansky C, Messing B. Plasma citrulline: a marker of enterocyte mass in villous atrophy-associated small bowel disease. Gastroenterology 2003;124:1210-1219.

5. Lutgens L.C.H.W., Deutz N.E.P, Gueulette J., Cleutjens J.P.M., Berger M.P.F., Wouters B.G., von-Meyenfeldt MF, Lambin P. citrulline: a physiologic marker enabling quantitation and monitoring of epithelial radiation-induced small bowel damage. lnt J Radiat Oncol Biol Phys 2003;57:1067-1074.

6. Keefe DMK, Brealey J, Goland GJ, Cummins AG. Chemotherapy for cancer causes apoptosis that precedes hypoplasia in crypts of the small intestine in humans. Gut $2000 ; 47: 632-637$.

7. Schaap N, Schattenberg A, Bar B, Preijers F, Geurts van Kessel A, van der Maazen R, De Boo T, De Witte T. Outcome of transplantation for standard-risk leukaemia with grafts depleted of lymphocytes after conditioning with an intensified regimen. British Joumal of Haematology 1997;98:750-759.

8. Muus $P$, Domelly $P$, Schattenberg A, Linssen $P$, Minderman $H$, Dompeling $E_{y}$ deWitte $T$. Idarubicin-related side effects in recipients of T-cell-depleted allogeneic bone marrow transplants are schedule dependent. Semin Oncol 1993;20:47-52.

9. Cockcroft D.W.* Gault M.H. Prediction of creatinine clearance from serum creatinine, Nephron 1976;16:31-41.

10. Donnelly JP, Muus P, Schattenberg A, de-Witte T, Horrevorts A, DePauw BE. A scheme for daily monitoring of oral mucositis in allogeneic BMT recipients. Bone Marrow Transplant 1992;9:409-413.

11. Jansen G, Muskiet FAJ., Schierbeek H., Berger R., Van melle G. Capillary gas chromatographic profiling of urinary, plasma and erythrocyte sugars and polyols as their trimethylsilyl derivates, precedied by a simple and rapid prepurification method. Clinica Chimica Acta 1986;157:277-294.

12. Johnston ID, Harvey CJ, Menzies IS, Treacher DF. Gastrointestinal permeability and absorptive capacity in sepsis. Crit Care Med 1996;24:1144-1149.

13. Lim SG, Menzies IS, Lee CA, Johnson MA, Pounder RE. Intestinal permeability and function in patients infected with Human Immunodeficiency Virus: a comparison with Coeliac Disease. Scand IGastroenterol 1993;28:573-580. 


\title{
Chapter 8
}

MONITORING MYELO-ABLATIVE THERAPY INDUCED SMALL BOWEL TOXICITY BY SERUM CITRULLINE CONCENTRATION: A COMPARISON WITH SUGAR PERMEABILITY TESTS

\author{
Ludy C.H.W. Lutgens, M.D. ${ }^{1}$, Nicole M.A. Blijlevens, M.D ${ }^{2}$, \\ Nicolaas E.P. Deutz, M.D., Ph.D. ${ }^{*}$, J. Peter Donnelly Ph.D. ${ }^{2}$, \\ Philippe Lambin, M.D., Ph.D. ${ }^{1}$, Ben E. de Pauw M.D., Ph.D. ${ }^{2}$. \\ 'Dept. of Radiation Oncalogy (MAASTRO), University Hospital Macstricht. \\ 2Dept of Haematology, University Medicle Centre St. Radboud, Nijnegem. \\ "Dept of Swargery, Maxastrichr Unwersity. Maastricht the Netherlands.
}




\begin{abstract}
Dackground. Intestinal mucositis is an important cause of cancer treatment related morbidity and mortality, carrying a serious economic burden. Currently, objective parameters are lacking which would enable the monitoring of gut damage in routine clinical practice, thus hindering development of clinical studies designed to investigate potential new strategies aimed at reducing or preventing this side-effect. The authors investigated the characteristics of serum citrulline concentration in comparison to sugar permeability tests with respect to its use as a marker for cancer treatment induced small bowel injury.

Methods. In a prospective study 10 patients with haematological malignancies receiving myeloablative therapy had gut toxicity assessed with sugat permeability tests. Serum citrulline concentration was additionally determined using archival serum samples. The association between both parameters and their respective characteristics were analyzed and compared with literature data.

Results. Sensitivity and specificity were better for the citrulline assay. Maximum gut damage assessed with the citrulline assay was observed 1-2 weeks earlier than using sugar probes. Similarly, citrulline indicated recovery of gut damage at 3 weeks after transplant: whereas most sugar permeability tests were still abnormal.

Conclusions. The methodologicall simplicity, the low costs and the lack of methodological drawbacks make the citrulline assay the first choice for measuring and monitoring treatment related gut damage which provides an objective parameter for cancer treatment related gut toxicity.
\end{abstract}




\section{Introduction}

An increased use of multiple treatment modalities is characteristic for current developments in curative cancer treatment. This strategy has yielded superior treatment results in a variety of solid tumors allbeit

treatment related acute toxicity is increased as well. ${ }^{1-5}$ In patients with haematological malignancies epithelial gut damage is suggested as a causal factor in the life-threatening graftversus-host disease following myeloablative therapy.' In general, severe mucositis has a detrimental effect on treatment outcome due to necessary reductions in treatment intensity and/or treatment interruption. In addition to these detrimental acute effects, epithelial gut damage has also been suggested as one of several mechanisms contributing to late treatment related sequellae. ${ }^{7}$ Taking into account mucositis associated complicating factors such as a longer hospital stay, an increased number of infectious events and nutritional support, Elting et al $^{8}$ recently estimated an incremental cost of $\$ 2725$ and $\$ 5565$ per chemotherapy cycle associated mucositis grade 1-2 and grade 3-4, respectively. Hence, prevention and/or reduction of epithelial gut damage is thus expected to have a significant clinical and socio-economic impact. However, clinical studies addressing treatment induced gut damage are hampered by the fact that objective parameters, which enable monitoring of damage in routine clinical practice, are lacking.

Until today, clinical symptoms are most frequently used as surrogate endpoint for gut damage. Besides the fact that toxicity grading systems are not used uniformly by investigators they are being adjusted on a regular basis. More important however, clinical symptoms correlate poorly with objective parameters of gut damage such as sugar permeability tests (SPT), ${ }^{10-12}$ altered histomorphology ${ }^{13}$ or treatment related parameters," illustrating the complexicity of the pathophysiology of clinical symptoms related to cytotoxic treatment induced small bowel damage. ${ }^{14-16}$

At present, morphological parameters and SPT's are the objective endpoints used in preclinical and clinical studies. Both methods, however, are not suited for monitoring purposes in routine clinical practice. In a preclinical study, we recently demonstrated that plasma citrulline concentration is a radiation dose-dependent parameter that correlates with radiation-induced small bowel morphological endpoints such as mucosal surface or crypt regeneration. ${ }^{17}$ In a subsequent clinical study we demonstrated that plasma citrulline concentration correlates with small bowel radiation dose and volume parameters. ${ }^{5}$ Similarly we observed decreased citrulline levels in response to myelo-ablative therapy. ${ }^{\text {\& }}$ In addition to surgery, ${ }^{10}$ celiac and non-celiac disease ${ }^{20}$ and acute cellular rejection following small bowel transplantation, 21,22 cytotoxic treatment was thus identified as another event associated with small bowel epithelial cell loss that can be monitored by plasma citrulline.

The aim of the present study has been to compare the citrulline assay with a currently used method for measuring small bowel damage, i.e. the sugar permeability test. For this purpose we analyzed a group of 10 patients who were uniformly treated in a prospective pharmacokinetic study for a haematological malignancy. We hypothesized that changes in citrullinaemia correlate with changes in absorption of sugar probes associated with loss of mucosal surface and with changes in gut permeation as assessed with multiple sugar probes. 


\section{Methods and Materials}

Subjects

Patient characteristics are summarized in Table 1. Between June 1999 and December 2000 10 patients (mean age 43 yrs; range $22-59$ ) received a haematopoietic stem cell transplant (HSCT) for a haematological malignancy at the department of Haematology, University Medical Centre St. Radboud, Nijmegen.

Table 1

Patient and tumor characteristics and clinical parameters

\begin{tabular}{|c|c|c|c|c|c|c|c|}
\hline Pt & Giender & Agle & Dlagnosis & $\begin{array}{l}\text { Max } \\
\text { DGs }\end{array}$ & Bacteraemila & LOS & FI \\
\hline 1 & $M$ & 32 & ALLL. & 2 & Yess & 33 & 0.39 \\
\hline 2 & $F$ & 48 & NHL & 1 & - & 33 & n.a. \\
\hline 3 & $F$ & 47 & ARHL. & 1 & Yess & 30 & 0.06 \\
\hline 4 & $M$ & 52 & NHL & 1 & Yes & 42 & 0.24 \\
\hline 5 & $F$ & 59 & $M F$ & 1 & - & 39 & 0.00 \\
\hline 6 & $M$ & 32 & AMLL & 1 & . & 4.2 & 0.06 \\
\hline 7 & $M$ & 30 & ALL & 2 & Yes & 107 & 0.29 \\
\hline 8 & $\mathrm{~F}$ & 59 & CML & 2 & Yes & 44 & 0.56 \\
\hline 9 & $M$ & 22 & $\mathrm{ALL}$ & 1 & Yas & 35 & 0.06 \\
\hline 10 & $F$ & 52 & CML. & 2 & - & 38 & 0.28 \\
\hline
\end{tabular}

Abbreviations: $\mathrm{DGS}=$ Daily Gut Score. $\mathrm{FI}=$ Fever index indicating the ratio between the number of days at which a body temperature $\geq 38^{\circ} \mathrm{C}$ was registered and the total number of days during the study period on which the body temperature was registered. LOS = Length ol hospital stay in days. ALL = acute lymphatic leukemia. AML = acute myeloid leukemia. $\mathrm{CML}=$ chronic myeloid leukemia. NHL = Non-Hodgkin's lymphoma. MF = myelofibrosis.

All patients had given their informed consent to participate in a prospective study investigating the pharmacokinetics and safety of 14 days intravenous itraconazole nanocrystals in subjects receiving a HLA-matched partial T-cell depleted sibling bone marrow transplant. The conditioning regimen consisted of idarubicin given at a dose of 42 $\mathrm{mg} / \mathrm{m}^{2}$ by continuous infusion over $48 \mathrm{~h}$ starting 12 days before transplant (HSCT day -12 ), followed by $120 \mathrm{mg} / \mathrm{kg}$ cyclophosphamide $(60 \mathrm{mg} / \mathrm{kg}$ per day on HSCT day -6 and -5$)$ and 9 Gy of total body irradiation (TBI) in 2 fractions (4.5 Gy per fraction on HSCT day -2 and -1 ). The total duration of the study period was 34 days, from HSCT day -12 until HSCT day +21 . For prophylaxis against graft versus host disease patients were administered cyclosporine at $3 \mathrm{mg} / \mathrm{kg}$ per day by contimuous infusion from HSCT day -1 to HSCT day 
+14 followed by $2 \mathrm{mg} / \mathrm{kg}$ per day until oral intake was possible. Parenteral nutritional support was started on HSCT day -7 and was sustaimed until the daily oral intake was sufficient. No agents were applied that are thought to ameliorate alimentary tract mucositis (i.e. amifostine, glutamine, KGF). Anti-infective prophylaxis consisted of ciprofloxacin, acyclovir and sulphamethoxazole-trimethoprim. Anti-fungal prophylaxis started on HSCT day -6 consisting of intravenous itraconazole $200 \mathrm{mg}$ twice daily for 2 days followed by $200 \mathrm{mg}$ once daily for 10 days. All patients were treated with meropenem pre-emptively from the day after transplant until neutrophil recovery $\left(>0.5 \times 10^{9} / \mathrm{L}\right)$. The glomerular filtration rate was determined on admission by measuring renal creatinine clearance ( $\mathrm{mL} / \mathrm{min}$ ) and was estimated thereafter from the serum creatinine using the formula from Cockroft \& Gault. ${ }^{23}$

\section{Clinical toxicity assessment}

Gut toxicity was scored daily using 6 items, i.e. the frequency of vomiting and diarrhea, occurrence of nausea, abdominal complaints, fecal incontinence and fecal volume. ${ }^{12}$ Each of these items was allocated a score between 0 (normal) and 3 (severe). Summation of the scores yielded a daily gut score (DGS) with 3 grades: mild toxicity = DGS grade I (1.6 points), moderate toxicity $=$ DGS $I I(7-12$ points $)$ and severe toxicity $=$ DGS grade III $(13-18$ points). All gut toxicities following cytotoxic treatment were ascribed to mucositis, unless there was a more plausible alternative cause, such as an adverse drug reaction or proven toxigenic infection.

\section{Sugar permeability test (SPT)}

An isotonic solution was prepared by dissolving $5 \mathrm{~g}$ lactulose (LAC), $1 \mathrm{~g}$ L-rhamnose (RHA), 0.5 gram D-xylose (XYL) and 0.2 gram 3-O-methyl-D-glucose (OMG) in $100 \mathrm{~mL}$ demineralised water, according to good manufacturing practice by the pharmacy of UMC Nijmegen. Following an overnight fast, the subjects emptied their bladders and then drank the test solution. A light breakfast with a drink was allowed after 2 hours. Urine was collected for 5 hours. The total volume was recorded and aliquots of $5 \mathrm{~mL}$ were stored in $-80^{\circ} \mathrm{C}$ until analysis. The first (baseline) SPT was performed on $\mathrm{HSCT}$ day -12 before starting conditioning therapy and was repeated on HSCT day $-7,0,+7,+14$ and +21 , yielding 6 time points in 5 weeks per patient.

\section{Urinary excretion ratios of differential sugar permeability tests}

Urinary excretion was determined using gas chronatography with flame ionization detection with D-glucoheptose as an internal standard. ${ }^{24}$ Data were collected online using Star Chromatography software (Varian, Tempe, Arizona, USA) and peak areas were measured and corrected for the internal standard. Urinary recovery of each sugar was expressed as a percentage of the intake and the lactulose / rhamnose ratio $(\mathrm{L} / \mathrm{R}){ }_{s} \mathrm{D}-\mathrm{xylose} / 3-\mathrm{O}-$ methyl-Dglucose ratio (XYL/OMG) and rhamnose / 3-O-methyl-D-glucose ratio (RHA/OMG) were calculated. The $L / R$ ratio is considered to be a measure of intestinal permeability, whereas the XYL / OMG and RHA / OMG ratios are used as an index of epithelial absorptive capacity 
and mediated cellular transport, respectively. A ratio of $\leq 0.02,^{25,26} \geq 0.28^{27}$ and $\geq 0.65^{28}$ is considered normal.

\section{Determination of plasma citrulline concentration}

The protocol prescribed to obtain serum daily from HSCT day -6 until HSCT day +1 , every other day thereafter until HSCT day +7 and again daily thereafter until HSCT day +12 and finally at HSCT day +21 yielding 17 time points in 4 weeks per patient. The serum was stored at $-80^{\circ} \mathrm{C}$ until analysis. For determination of amino acids $250 \mu \mathrm{L}$ serum was deproteinized by adding it to $22 \mathrm{mg}$ dry 5-sulfosalicylic acid. Plasma citrulline concentration (umol/L) was measured by using high-performance liquid chromatography. ${ }^{29}$

\section{Staristical analysis}

SPSS for windows software (Release 11.0) was used for statistical analysis. All results are expressed as the mean with $95 \% \mathrm{CI}$. One-way analysis of variance (ANOVA) was used to analyze changes in citrulline concentration and dual sugar test ratios, respectively. A paired sample $t$ test was done to investigate differences with respect to baseline values. A Pearson correlation procedure was done using the raw data of citrulline concentration, urinary recovery and dual sugar test ratios to test a correlation between these parameters. A p-value $<0.05$ was considered statistically significant.

\section{Results}

\section{Clinical Parameters}

No treatment-related lethal sequellae occurred. Patient demographics are summarized in Table 1. Throughout the study period a mild (DGS grade 1) and moderate (DGS grade II) intestinal toxicity was observed in 6 and 4 patients, respectively. All but 1 patient (\#5) had microbiologically and/or clinically defined infectious events during the study period. Fever (body temperature $\geq 38^{\circ} \mathrm{C}$ ) was present on $\geq 1$ day in all patients who experienced infectious events. A fever index was calculated as the ratio between the number of days with a body temperature $\geq 38^{\circ} \mathrm{C}$ and the total number of days on which the body temperature was registered. The mean fever index was 0.21 (range $0.00-0.56$ ) (Table 1). A micrococcus sendentarims and a staphylococcus epidermidis bacteraemia were identified in 1 and 5 patients, respectively. No association was observed between any of these clinical parameters and bacteraemia (data not shown).

\section{Citwline coscentration}

The mean citrulline concentration in 10 patients at HSCT day -6 was $25.7(95 \% \mathrm{Cl} 17.1$ $34.4 \mu \mathrm{mol} / \mathrm{L}$ ) (Table 2). During the complete study period a significant decline in citrulline concentration was observed (One-way ANOVA: $p<0.001$. Figure 1) with the lowest concentration measured at HSCT day +5 (mean $8.9 \mu \mathrm{mol} / \mathrm{L} ; 95 \% \mathrm{Cl} 4.4-13.4 \mu \mathrm{mol} / \mathrm{L})$. 


\section{Urinary sugar recovery and sugar permeability test}

The results of urinary sugar excretion (\% intake) and SPT ratios determined at HSCT day -12 (baseline), $-7,0,+7 x+14$ and +21 are summarized in Table 3 and 4 .

Comparison with baseline values yielded significantly increased LAC excretion on $\mathrm{HSCT}$ day $+7(\mathrm{p}=0.029)$ and significantly decreased RHA excretion on HSCT day +14 . On performing one-way ANOVA, only alterations in RHA excretion were significant $(p=0.025)$.

When compared to baseline values the L/R ratio was significantly increased on HSCT day +7 and $+21(\mathrm{p}=0.020, \mathrm{p}=0.012)$. The RHA/OMG ratio was significantly decreased on HSCT day $+7,+14$ and $+21(p=0.027, p=0.033$ and $p=0.036$, respectively). On performing one-way ANOVA, only alterations in the XYL/OMG ratio and the RHA/OMG ratio were significant $(p=0.032$ and $p<0.001$, respectively).

Table 2 Time-course of citrulline concentration $(\mu \mathrm{mol} / \mathrm{L})$ for all study time points.

\begin{tabular}{rrrrl} 
day & mean & $95 \% \mathrm{Cl}$ & n & tost \\
\hline-6 & 25.7 & $17.1-34.4$ & 10 & \\
-5 & 21.5 & $14.4-28.6$ & 10 & 0.177 \\
-4 & 18.1 & $10.2-26.1$ & 10 & 0.057 \\
-3 & 18.6 & $9.5-27.8$ & 10 & 0.075 \\
-2 & 15.6 & $9.9-21.2$ & 10 & 0.004 \\
-1 & 14.5 & $8.4-20.7$ & 10 & 0.006 \\
0 & 12.3 & $8.0-16.5$ & 10 & 0.004 \\
1 & 11.6 & $6.6-16.6$ & 10 & 0.000 \\
3 & 9.7 & $5.3-14.1$ & 10 & 0.000 \\
5 & 8.9 & $4.4-13.4$ & 10 & 0.000 \\
7 & 9.9 & $5.5-14.2$ & 10 & 0.000 \\
8 & 11.3 & $6.3-16.3$ & 10 & 0.001 \\
9 & 11.5 & $6.1-17.0$ & 10 & 0.001 \\
10 & 12.4 & $10.5-14.2$ & 8 & 0.016 \\
11 & 15.7 & $8.6-22.9$ & 8 & 0.000 \\
12 & 13.8 & $6.1-21.4$ & 9 & 0.002 \\
21 & 20.1 & $11.1-29.1$ & 9 & 0.109
\end{tabular}

Abbreviations: day $=$ number of days to haematopoietic stem cell transplant. Statistics: 2-sided paired samples $/$ test. Comparison with baseline level assessed at HSCT day -6. Data correspond to Figure 1. Compared to the first sample at HSCT day -6 , the citrulline concentration was significantly decreased between HSCT day -2 and +12 . At HSCT day +21 the citrulline concentration was no longer different from the value at HSCT day -6 .

Correlation between citrulline concentration, clinical parameters, urinary sugar excretion and dual-sugar test ratios

Since no serum was available before the start of treatment the value assessed at HSCT day -6 is referred to as the baseline in this analysis. The citrulline nadir, calculated as percentage of the baseline, but not the absolute value $(\mu \mathrm{mol} / \mathrm{L})$, was significantly correlated with the maximum DGS $(p=0.033)$. The maximum DGS significantly correlated with the urinary RHA and XYL recovery $(p=0.047$ and $p=0.050)$. No correlation was observed between these parameters and dual-sugar test ratios (data not shown). 
The citrulline data obtained at HSCT day -6 and +12 were used for the calculation of correllations with SPT data obtained at HSCT day -7 and +14 , respectively. Thus citrulline and SPT data were available for comparison at 5 time points during 4 weeks, i.e. HSCT day $7,0,+7,+14$ and +21 . The time-course of the respective parameters is shown in Figure $2 \mathrm{c}$. The time-course of citrulline indicates a maximum damage at HSCT day +7 as compared to HSCT day +14 for the urinary recovery of the individual sugar probes and to some extent for the L/R ratio and to HSCT day +21 for the XYL/OMG and RHA / OMG ratios, respectively. A recovery of intestinal damage during the study period is indicated by the citrulline, RHA, $X Y L$ and $O M G$ urinary recovery data and the $L / R$ ratio in contrast to $L A C$ recovery and the XYL / OMG ratio and the RHA / OMG ratio. Interestingly, urinary recovery of all sugar probes was increased 1 week after initiation of the conditioning regimen.

The L/R and the urinary recovery of all 4 sugars significantly correlated with each other whereas none correlated with the citrulline concentration (Figure 2). The citrulline concentration $(\mu \mathrm{mol} / \mathrm{L}$ ) correlated with the RHA / OMG ratio ( $\mathrm{p}=0.025)$. No correlation was observed with the $L / R$ and $X Y L / O M G$ ratio.

Figure 1 Time-course of plasma citrulline concentration ( $\mu \mathrm{mol} / \mathrm{L})$ between HSCT day -6 and +21

Dotted lines represent
upper and lower
bound of $95 \%$ CI.
One-way ANOVA;
$\mathrm{p}<0.001$. The mean
citrulline concentra-
tion measured
between HSCT day
+1 and HSCT day +9
was significantly
different as compared
to vallues measured at
HSCT day -6
(Tukey's post-hoc
testing: $p=0.035$,
$\mathrm{p}=0.007, \mathrm{p}=0.003$,
$\mathrm{p}=0.008, \mathrm{p}=0.029$ and
$\mathrm{p}=0.035$ for HSCT
day $+1,+3,+5,+7$,
+8 and +9,
respectively).

Dotted lines represent upper and lower bound of $95 \% \mathrm{CI}$. One-way ANOVA; $\mathrm{p}<0.001$. The mean centration measured between HSCT day +1 and HSCT day +9 was significantly diferent as compared HSCT day -6 (Tukey's post-hoc testing: $p=0.035$, $p=0.008, p=0.029$ and $\mathrm{p}=0.035$ for $\mathrm{HSCT}$ +8 and +9 respectively).

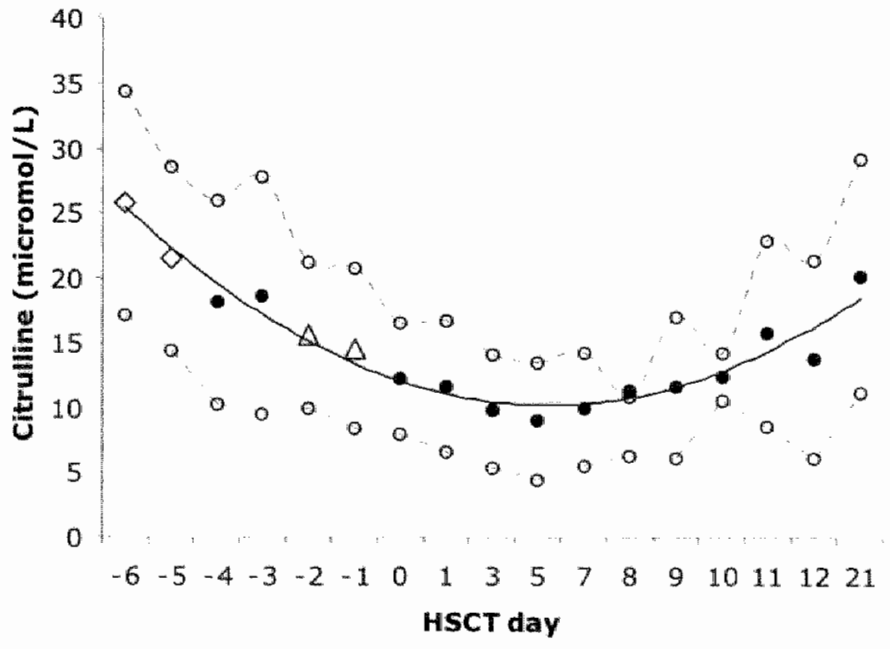

Abbreviations: $\mathrm{HSCT}=$ haematopoietic stem cell transplantation. Symbols: $\theta=120 \mathrm{mg} / \mathrm{kg}$ cyclophosphamide $(60 \mathrm{mg} / \mathrm{kg}) . \Delta=4.5$ Gy Total Body Irradiation.

Trendline: polynomial, $2^{\text {nd }}$ order. 

permeability test ratios.

Citruline

LR ratio

Xo ratio

R/O ratio

\begin{tabular}{|c|c|c|c|c|c|c|c|c|c|c|c|c|c|c|}
\hline deay & $\mu$ & Mean & $95 \% \mathrm{cl}$ & & $\mathbb{N}$ & Metian? & $95 \% \mathrm{Gl}$ & & $N$ & Méan & $95 \% \mathrm{CH}$ & $\mathrm{N}$ & Mean & 95 현 \\
\hline-12 & - & . & uns & & to. & 0.04 & $0.03-0.00$ & & 10 & 0.68 & $D 50-2.80$ & 10 & 0.23 & $0.17-0.20$ \\
\hline .7 & 10 & 25.7 & $17.1-34.2$ & & 10 & 005 & $0.03-0.07$ & & io & 0.65 & $0.52-0.70$ & 10 & 0.29 & $0.22-0.35$ \\
\hline 0 & 10 & 12.3 & $12.3-16.5$ & 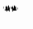 & 8 & $0: 13$ & $0.00-0.27$ & & 8 & $0.6 \pi$ & $0.45-0.7 ?$ & 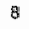 & 0.21 & $0.15-0.28$ \\
\hline+7 & 10 & 9.9 & $5.5-14.2$ & $\cdots$ & $g_{i}$ & 0.12 & $0.05-0.17$ & * & 8 & 0.51 & $0.47-0.57$ & $a$ & 0.43 & $0.70-0.10$ \\
\hline+14 & $\theta$ & 13.8 & $6 x-21.4$ & $m$ & 7 & a $1: g_{1}$ & $0.02-0.34$ & & 7 & 0.51 & $0.43=0.58$ & 7 & 0.13 & $0.07-020$ \\
\hline$+2 \pi$ & 9 & 201 & $11.4-29.1$ & & 5 & a.13 & $0.06-0.20$ & * & 5 & 0.45 & $0.33-0.58$ & 5 & 0.09 & $0.07-0.20$ \\
\hline
\end{tabular}

Abbreviations: day $=$ mumber of days to haematopoietic stem cell transplant (HSCT); $N=$ number of individuals tested; $L / R=$ lactulose $/$ rhamnose; X/O $=\mathrm{D}$-xylose $/ \mathrm{O}$. methylglucose; $\mathrm{R} / \mathrm{O}=$ rluamnose $/ \mathrm{O}$-methylglucose. Test-Statistics: 2 -sided paired samples $t$ test to investigate changes relative to the baseline value (i.e. HSCT day -12 for sugar permeability tests and HSCT day -7 for citrulline). Citrulline data obtained at HSCT day 6 and +12 were used for calculation of correlations with SPT data obtained at HSCT day -7 and +14 , respectively. P-yalues: $*<0.05 ; * *<0.01$ and $* * *<0.001$

Table $4 \quad$ Tine-course of urinary sugar recovery $(\%$ intake)

\begin{tabular}{|c|c|c|c|c|c|c|c|c|c|}
\hline & & \multicolumn{2}{|c|}{ Lactulose } & \multicolumn{2}{|c|}{ Rhammose } & \multicolumn{2}{|c|}{ D-Xylose } & \multicolumn{2}{|c|}{ 3-O-mothy } \\
\hline day & $\mathrm{N}$ & Mean & $95 \% \mathrm{Cl}$ & Mean & $95 \% \mathrm{Cl}$ & Mean & $95 \% \mathrm{Cl}$ & Mean & $95 \% \mathrm{Cl}$ \\
\hline-12 & 10 & 0.2 & $0.1-0.3$ & 4.4 & $25-63$ & 13,2 & $72-193$ & 19.5 & $12.0-27.0$ \\
\hline-7 & 10 & 0.4 & $0.1-0.7$ & B. 1 & $34-129$ & 17.5 & $7.6-27.4$ & 27.4 & $13.4-44.4$ \\
\hline 0 & 8 & 0.7 & $-0.2-0.2$ & 6.2 & $15-10.8$ & 178 & $2.7-33.0$ & 28.3 & $5.3-54.3$ \\
\hline+7 & 8 & 0.3 & $0.2-0.4$ & 2.6 & $1.3-4.0$ & 10.4 & $5.6-15.2$ & 20.4 & $11.0-27.9$ \\
\hline+14 & 7 & 0.3 & $-0.0-0.7$ & 2.5 & $0.3-4.8 *$ & 9.6 & $3.7-15.5$ & 19.2 & $7.2-312$ \\
\hline+21 & 5 & 0.2 & $0.1-0.6$ & 1.7 & $-0.2-3.5$ & 11,3 & $-1.0-23.7$ & 26.0 & $-5.1-57.0$ \\
\hline
\end{tabular}

Abbreviations: day $=$ number of days to haematopoietic stem cell transplant; $\mathbb{N}=$ number of individuals tested; Test-Statistics: 2-sided paired samples $/$ test to investigate changes relative to baseline values at $\mathrm{HSCT}$ day -12 . P-values: $*<0.05 ; *<00.01$. One-way ANOVA: Rhamnose $p=0.025$. Lactulose, $D$-xylose and 3-O-methyl-D-glucose: $p=n . s$. 
Figure 2 Time course of plasma citrulline concentration $(\mu \mathrm{mol} / \mathrm{L})(\mathrm{A})$, urinary sugar recovery $(B)$ and dual-sugar test ratios $(C$ ) detemined on HSCT day $-12,-7$, $0,+7,+14$ and +21 .

A

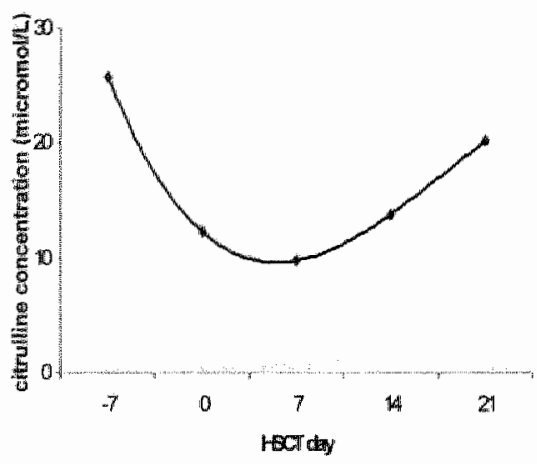

B

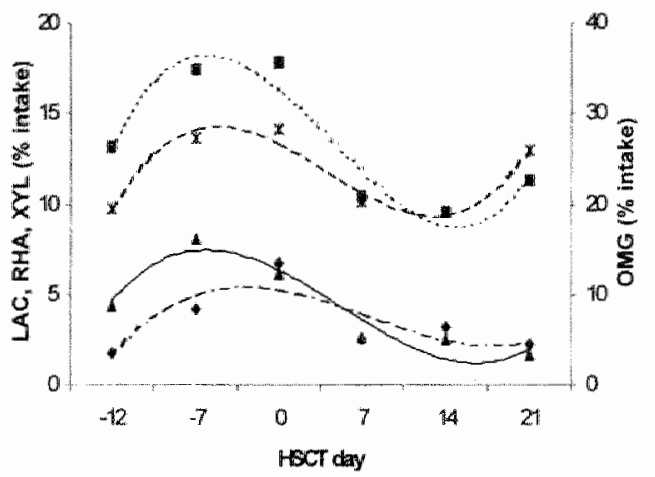

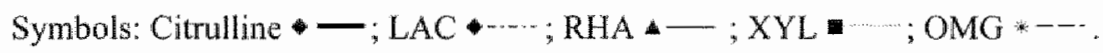

C

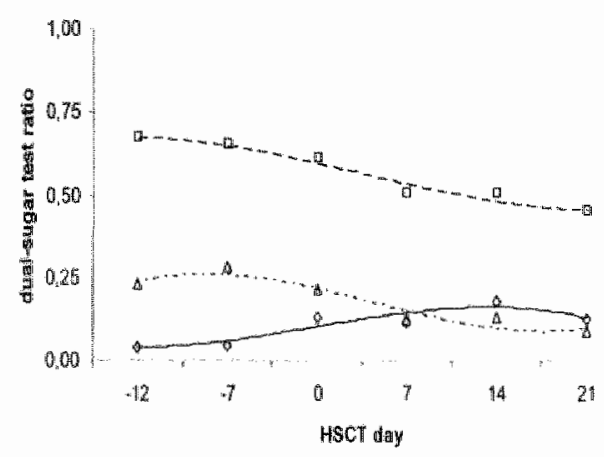

Dual-sugar test ratio: L/R (o- ); XYL/OMG ( $-\cdots)$; RHA/OMG $(\Delta \cdots \cdots)$.

Trendline: $3^{\text {rd }}$ order polynomial. For presentation purposes urinary sugar recovery data as presentated in figure A are multiplied by a factor $10^{3}$ (LAC) or by a factor $10^{2}$ (RHA, XYL and OMGi). Data points in figure $A$ and $B$ represent mean walues. Note that sugar baseline values are not shown (i.e. HSCT day -12). 


\section{Discussinton}

In the present study the use of serum citrultine concentration as a marker for oytotoxic treamentinduced gut damage ${ }^{n, 17,}$, is hurther established. We observed a discrepancy beiween the time-course of 2 objective endpoints for epithelial gut damage; 1 , the serum cinume concentration and the sugar permeability test. In contrast to the sugar probe results, the timecourse for citullne is in agreement with known kumetics of epithelial cell loss following radiotherapy ${ }^{30}$ and chemotherapy. ${ }^{13}$

Gut pemeabinty testing is a non-invasive method for assessment of altered gut barier function as an endpoint for intestinal damage. ${ }^{25,26}$ At present, the sugar pemeatility test (SPT) is the objective endpoint used in clinical studies to quantify gut damage ${ }^{12,31}$ and to assess treatment effects aimed at mucoprotection. ${ }^{32}$ By using simultaneously multiple sugar probes, chosen on behalf of different permeation pathways, information about intestinal absorptve capacity is obtained in addition to information about intestinal permeability. It is now generaly accepted that alterations in the $L / R$ ratio provide an index for the intestinal permeability whereas the recovery of RHA, XYL and OMG and their ratios provide an index for the intestinal absorptive capacity. ${ }^{26,33}$ Following myeloablative therapy increased gut permeability (L/R ratio) and decreased absomptive capacity (RHA/OMG ratio) was observed (Table 2a) in accordance with previous results 12,18 and reports fiom literature. ${ }^{10,}{ }^{13}$ Remarkably, the decrease of the XYL / OMG ratio was not statistically significant in contrast to previous findmgs in a group of 56 similarly treated patients in our department. ${ }^{12}$ Similarly winary recovery data did not display major changes (Table 2b). The small number of patients in the present series and the relatively large standard variation may explain this finding.

We have performed a series of pre-clinical and clinical experiments aimed to develop an objective parameter that enables monitoring of gut damage in routine clinical practice." 17 Cytotoxic reatment induces an intestinal epithelial cell loss. ${ }^{13 .}$. 30 Plasma citrulline concentration is a surrogate endpoint for the small intestinal epithelial cell mass, irrespective of the underlying cause of cell loss, such as surgical resection, ${ }^{19,34,35}$ celiac and non-celiac disease $^{20}$ or cellular rejection after small bowel transplantation. ${ }^{21,} 22$ We identified plasma citrulline concentration as a simple and sensitive marker enabling quantitation of cytotoxic treatment induced small bowel epithelial cell loss." 17 This was then confirmed in patients subjected to myeloablative therapy. ${ }^{18}$ In the present study the citrulline concentration was determined in archival serum samples obtained during an observation period of 5 weeks in a series of 10 patients who were uniformly treated with intensive myeloablative therapy. The results are in complete agreement with previous data obtained in similarly treated patients and clearly demonstrate the reproducibility and simplicity of the assay enabling close monitoring of this type of treatment-induced gut damage as illustrated in Figure 1.

In contrast to Crenn et al ${ }^{20}$ we were not able to correlate the citrulline level with the degree of mucosal atrophy. Instead, clinical symptoms ${ }^{12}$ associated with mucosal atrophy were used as a surrogate endpoint, in addition to sugar permeability tests. The absolute citrulline concentration $(\mu \mathrm{mol} / \mathrm{L})$ did not correlate with this endpoints whereas the normalized citrulline level ( $\%$ baseline) correlated with the maximal gut toxicity obserwed during the observation period. A similar correlation was observed between the urinary recovery of RHA and XYL 
$(\%$ intake) and maximal gut toxicity. There are several limitations however to the use of these surrogate endpoints such as carricd out here. Firstly, in contrast to the serum citrulline concentration, which is considered to be highly dependent upon the small intestinal cell mass ${ }^{36}, 37$ the gut toxicity score as used here does not specifically address small intestinal toxicity but merely gastrointestinal toxicity in general. Secondly, mucosal denudation is merely one of several events underlying clinical symptoms related to cytotoxic treatment. ${ }^{13-16}$

Comparison of the citrulline assay with the SPT results yielded some striking differences between both endpoints. The citrulline level ( $\mu$ mol/L or \% baseline) did not correlate with gut permeability (L/R ratio). Except for a correlation with the RHA / OMG ratio, no other correlation was observed with parameters indicative for the absorptive capacity used in this study, i.e. XYL / OMG ratio or the urinary recovery of RHA, XYL and OMG, respectively. Furthermore, the time-course of both endpoints was essentially different. (Figure 2). The maximum damage and recovery were recorded between 1-2 weeks earlier by citrulline, in comparison to the sugar probe test results. In contrast to the time-course of urinary sugar probe recovery, the time-course for citrulline observed is in complete agreement with that observed for other function tests related to a reduced number of epithelial cells ${ }^{17}$ and with known kinetics of injured gut epithelium following radiotherapy ${ }^{30}$ or chemotherapy. ${ }^{13}$ Remarkably, the RHA recovery, considered to be the most appropriate estimate of the mucosal surface available for absorption ${ }^{33}$ and citrulline concentration during the initial study period, yielded contradictory results concerning their relationship with mucosal atrophy and known kinetics of this mucosal event. ${ }^{13,30}$ The initial increase in the sugar probe recovery and in RHA recovery in particular, may be explained by alterations in the permeation pathway or by altered pre-absorptive factors such as gastric emptying or small bowel transit time, both factors being frequently affected by this type of treatment. Unfortunately, no serum was available for citrulline analysis at HSCT day -12 . However, the citrulline concentrations measured at HSCT day -6 , (i.e. one week after initiation of the conditioning regimen) are comparable to baseline citrulline concentrations in a previous study "(mean $30.9 \mu \mathrm{mol} / \mathrm{L}$; $95 \%$ CI $26.6-35.2 \mu \mathrm{mol} / \mathrm{L}$ ). Hence, it is reasonable to assume that a change, if any, occurring in the citrulline level during the first week of the conditioning regimen would be a minor decline. Finally, the average $95 \%$ confidence interval was significantly larger for LAC, RHA, $X Y L$ and OMG as compared to citrulline data $(p=0.001)$ (Table 2). Although the sugar tests showed remarkable changes during the study period (Figure 2) statistical significance was moderate (Table 2) compared to citrulline.

Gastrointestinal mucositis is a common side effect of cancer treatment, not infrequently persistent, ${ }^{38}$ which causes a major economic burden. ${ }^{8}$ In addition to tumor control, data on normal tissue damage are required to assess the therapeutic value of treatment regimens. In case of small bowel damage, clinical signs and symptoms expressed in toxicity scores are the current standard. For the reasons described before, there is an urgent need for an objective parameter. Ideally, such a marker should then be easily accessible and independent of medication and metabolic events such as diet and nutritional status. Previous attempts have been made to develop a simple blood test for measuring gut damage. ${ }^{39,}{ }^{40}$ However, so far none are used in clinical practice. We suggest that serum citrulline fulfils most, if not all, of these requirements. In addition to yie/ding highly reproducible results, being a sensitive and a 
specific marker for epithelial cell loss, this assay can be applied as a simple blood test and is relatively cheap.

In summary, the results of serum citrulline concentration used as a marker for cytotoxic treatment induced intestinal damage are highly reproducible. As a whole, the citrulline concentration seems to be a quantitative parameter independent of the underlying cause for epithelial cell loss. ${ }^{9,17-21}$ Compared to sugar permeability tests the citrulline assay is more sensitive and more specific for measuring small bowel epithelial cell loss. Also, this assay enables more accurate assessment of induction and repair kinetics of damage. The methodological simplicity, the low costs and the lack of methodological drawbacks as mentioned, make this assay the first choice for measuring and monitoring treatnent related gut damage. In addition, it provides an objective parameter to the clinician that enables standardized assessment of treatment related morbidity. 


\section{References}

1. Han SC, Kim DH, Higgins SA, Carcangiu ML, Kacinski BM. Chemoradiation as primary or adjuvant treatment for locally advanced carcinoma of the vilva. Int $I$ Radiat Oncol Biol Phys 2000; 47 (5): 1235-44.

2. Green JA, Kirwan JM, Tierney JF, Symonds P, Fresco L, Collingwood M, et al. Survival and recurrence after concomitant chemotherapy and radiotherapy for cancer of the uterine cervix: a systematic review and meta-analysis. Lancet 2001; 358 (9284): 781-6.

3. Pahiman $L$, Hohemberger $W$, Gunther $K$, Fietkau $R$, Metzger $U$. Is radiochemotherapy necessary in the treatment of rectal cancer? Eur $J$ Cancer 1998; $34(4): 438-48$.

4. Curran WJ, Jr. Evolving chemoradiation treatment strategies for locally advanced non-small-cell lung cancer. Oncology 2003; 17 (12 Suppl 13): 7-14.

5. Stehman FB, Rose $P G$, Greer BE, Roy $M$, Plante $M$, Penalver $M$, et al. Innovations in the treatment of invasive cervical cancer. Cancer 2003; 98 (9 Suppl): 2052-63.

6. Hill GR, Crawford JM, Cooke KR, Brinson YS, Pan L, Ferrara JL. Total body irradiation and acute graft-versus-host disease: the role of gastrointestinal damage and inflammatory cytokines. Blood 1997; 90 (8): 3204-13.

7. Richter $\mathrm{KK}$, Langberg $\mathrm{CW}$, Sung $\mathrm{CC}$, Hauer Jensen $\mathrm{M}$. Increased transforming growth factor beta (TGF-beta) immunoreactivity is independently associated with chronic injury in both consequential and primary radiation enteropathy. Int $J$ Radiat Oncol Biol Phys 1997; 39 (1): 187-95.

8. Elting LS, Cooksley C, Chambers M, Cantor SB, Manzullo E, Rubenstein EB. The burdens of cancer therapy. Clinical and economic outcomes of chemotherapyinduced mucositis. Cancer 2003; 98 (7): 1531-9.

9. Lutgens L, Deutz N, Granzier-Peeters M, Beets-Tan R, De Ruysscher D, Gueulette J, et al. Plasma citrulline concentration: a surrogate endpoint for radiation-induced mucosal atrophy of the small bowel. A feasibility study in 23 patients. Int $J$ Radiat Oncol Biol Phys 2004; (in press).

10. Johansson JE, Ekman T. Gastro-intestinal toxicity related to bone marrow transplantation: disruption of the intestinal barrier precedes clinical findings. Bone Marrow Transplant 1997; 19 (9): $921-5$.

11. Johansson JE, Ekman T. Gut mucosa barrier preservation by orally administered IgA$\lg \mathrm{G}$ to patients undergoing bone marrow transplantation: a randomised pilot study. Bone Marrow Transplant 1999; 24 (1): 35-9.

12. Blijlevens NM, van"t Land $B$, Donnelly JP, M'Rabet $L$, de Pauw BE. Measuring mucosal damage induced by cytotoxic therapy. Support Care Cancer 2004; 12 (4): $227-33$.

13. Keefe DM, Brealey J, Goland GJ, Cummins AG. Chemotherapy for cancer causes apoptosis that precedes hypoplasia in crypts of the small intestine in humans. Gut $2000 ; 47(5): 632-7$. 
14. Thomson AB, Keelan M, Thiesen A, Clandinin MT, Ropeleski M, Wild GE. Small bowel review: diseases of the small intestine. Dig Dis Sci 2001; 46 (12): 2555-66.

15. Griffiths NM. The example of gastrointestinal damage induced by ionising radiation: are there accessible markers? Cell Mol Biol 2001; 47 (3): 427-35.

16. MacNaughton WK. Review article: new insights into the pathogenesis of radiationinduced intestinal dysfunction. Aliment Pharmacol Ther 2000; 14 (5): 523-8.

17. Lutgens LC, Deutz NE, Gueulette J, Cleutjens JP, Berger MP, Wouters BG, et al. Citrulline: A physiologic marker enabling quantitation and monitoring of epithelial radiation-induced small bowel damage. In J Radiat Oncol Biol Phys 2003; 57 (4): 1067-74.

18. Blijlevens NMA, Lutgens LCHW, Schattenberg A, Donnelly JP. Citrulline: a potentially simple quantitative marker of intestinal epithelial damage following myeloablative therapy. Bone Marrow Transplant 2004; 34(3): 193-196.

19. Crenn P, Coudray Lucas C, Thuillier F, Cynober L, Messing B. Postabsorptive plasma citrulline concentration is a marker of absorptive enterocyte mass and intestinal failure in humans. Gastroenterology 2000; 119 (6): 1496-505.

20. Crenn P, Vahedi K, Lavergne Slove A, Cynober L, Matuchansky C, Messing B. Plasma citrulline: A marker of enterocyte mass in villous atrophy-associated small bowel disease. Gastroenterology 2003; 124 (5): 1210-9.

21. Gondolesi G, Fishbein T, Chehade M, Tschernia A, Magid M, Kaufman S, et al. Serum citrulline is a potential marker for rejection of intestinal allografts. Transplant Proc 2002; 34 (3): 918-20.

22. Pappas PA, Saudubray JM, Tzakis AG, Rabier D, Carreno MR, Gomez Marin O, et al. Serum citrulline as a marker of acute cellular rejection for intestinal transplantation. Transplant Proc 2002; 34 (3): 915-7.

23. Cockcroft DW, Gault MH. Prediction of creatinine clearance from serum creatinine. Nephron 1976; 16 (1): 31-41.

24. Jansen G, Muskiet FA, Schierbeek H, Berger R, van der Slik W. Capillary gas chromatographic profiling of urinary, plasma and erythrocyte sugars and polyols as their trimethylsilyl derivatives, preceded by a simple and rapid prepurification method. Clin Chim Acta 1986; 157 (3): 277-93.

25. Bjarnason I, MacPherson A, Hollander D. Intestinal permeability: an overview. Gastroenterology 1995; 108 (5): 1566-81.

26. Travis S, Menzies I. Intestinal permeability: functional assessment and significance. Clin Sci 1992; 82 (5): 471-88.

27. Johnston JD, Harvey CJ, Menzies IS, Treacher DF. Gastrointestinal permeability and absorptive capacity in sepsis. Crit Care Med 1996; 24 (7): 1144-9.

28. Lim SG, Menzies IS, Lee CA, Johnson MA, Pounder RE. Intestinal permeability and function in patients infected with human immunodeficiency virus. A comparison with coeliac disease. Scand J Gastroenterol 1993; 28 (7): 573-80.

29. van Eijk HM, Rooyakkers DR, Deutz NE. Rapid routine determination of amino acids in plasma by high-performance liquid chromatography with a 2-3 microns Spherisorb ODS II column. J Chromatogr 1993; 620 (1): 143-8. 
30. Becciolini A, Balzi M, Potten CS. Radiation effects on proliferation and

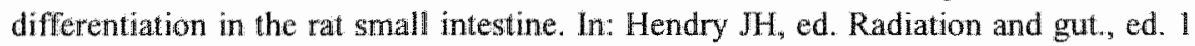
Amsterdam: Elsevier Seience B. V., 1995: 85-143.

31. Blijlevens NM, Donnelly JP, de Pauw BE. Impaired gut function as risk factor for invasive candidiasis in neutropenic patients. BrJ Haenatol 2002; 117 (2): 259-64.

32. Yoshida S, Matsui M, Shirouzu Y, Fujita H, Yamana $H$, Shirouzu K. Effects of glutamine supplements and radiochemotherapy on systemic immune and gut barrier function in patients with advanced esophageal cancer. Am Surg 1998; 227 (4): 48591.

33. Menzies IS, Zuckerman MJ, Nukajam WS, Somasundaram SG, Murphy B, Jenkins AP, et al. Geography of intestinal permeability and absorption. Gut 1999; 44 (4): 483-9.

34. Wakabayashi $\mathrm{Y}$, Yamada $\mathrm{E}$, Yoshida $\mathrm{T}$, Takahashi $\mathrm{N}$. Effect of intestinal resection and arginine-free diet on rat physiology. Am J Physiol 1995; 269 (2 Pt 1): G3 13-8.

35. Chen $K$, Nezu R, Sando K, Haque SM, liboshi $Y$, Masunari A, et al. Influence of glutamine-supplemented parenteral nutrition on intestinal amino acid metabolism in rats after small bowel resection. Surg Today 1996; 26 (8): 618-23.

36. Hoogenraad $\mathrm{N}$, Totino $\mathrm{N}$, Elmer H, Wraight $\mathrm{C}$, Alewood P, Johns RB. Inhibition of intestinal citruline synthesis causes severe growth retardation in rats. Am IJ Physiol 1985; 249 (6 Pt 1): G792-9.

37. Wakabayashi Y, Yamada E, Hasegawa T, Yamada R. Enzymological evidence for the indispensability of small intestine in the synthesis of arginine from glutamate. $I$. Pyrroline-5-carboxylate synthase. Arch Biochem Biophys 1991; 291 (1): 1-8.

38. Yeoh E, Horowitz M, Russo A, Muecke T, Robb T, Chatterton B. The effects of abdominal irradiation for seminoma of the testis on gastrointestinal function. I Gastroenterol Hepatol 1995; 10 (2): 125-30.

39. Overgaard J, Matsui M. Effect of radiation on glucose absorption in the mouse jejunum in vivo. Radiother Oncol 1990; 18 (1): 71-7.

40. Sorensen SH, Proud FJ, Rutgers HC, Markwell P, Adam A, Batt RM. A blood test for intestinal permeability and function: a new tool for the diagnosis of chronic intestinal disease in dogs. Chin Chim Acta 1997; 264 (1): 103-15. 


\section{Chapter 9}

PLASMA CITRULLINE CONCENTRATION: A SURROGATE ENDPOINT FOR RADIATION-INDUCED MUCOSAL ATROPHY OF THE SMALL BOWEL. A FEASIBILITY STUDY IN 23 PATIENTS

Lutgens $L^{\prime}$, Deutz $N^{2}$, Granzier-Peeters $M^{\prime}$, Beets-Tan $\mathbb{R}^{3}$, De Ruysscher $D^{\prime}$. Gueulette $\mathrm{J}^{4}$, Cleutjens $\mathrm{J}^{5}$, Berger $\mathrm{M}^{6}$, Wouters $\mathrm{B}^{\prime}$, won Meyenfeldt $\mathrm{M}^{2}$, Lambin $\mathrm{P}^{\text {t }}$

"MAASTRO, department of Radiation Therapy and Oncology, University Hospital Maasticht/ Mastricht University

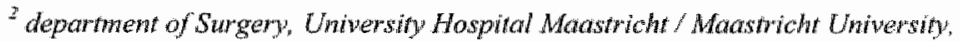

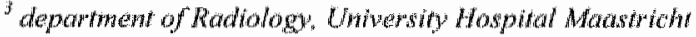

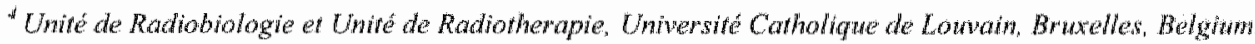
"deparment of Pathology, Masthich University. "department of Methodology and Statistics, Marasticht University The Metherlands

Int J Radiat Oncol Biol Phys 2004; 60 (1):275-85. 


\section{Introduction}

When treating abdominal or pelvic cancers with radiotherapy, either alone or combined with chemotherapy, the small bowel is the organ most frequently encountered as dose limiting normal tissue, both with regard to acute and late treatment related morbidity. A wide diversity of functional disorders have been observed following ionizing radiation such as motility dysfunction ${ }^{1,2}$ changes in trans-epithelial transport processes ${ }^{3,4}$ or the absorption of various nutrients such as carbohydrates, amino acids, proteins, vitamins and bile acid. ${ }^{5-10}$ Acute radiation-induced smalı bowel toxicity may necessitate treatment internuption, an established detrinental factor for treatment outcome. ${ }^{11}$ After radiation doses of $45-50 \mathrm{~Gy}$, typically delivered during 5 weeks in 25 fractions, actuarial 5-year rates of severe stromal small bowel injury such as fistulas and strictures is usually less than $5 \% .^{12}$ In contrast, persisting functional changes causing chronic diarrhea, malabsorption and other symptoms associated with epithelial small bowel damage have been reported in $40-50 \%$ of patients. ${ }^{5,12}-15$ Both radiation dose and irradiated small bowel volume have been demonstrated as determinants for radiation-induced small bowel toxicity. ${ }^{12,16,17}$

Several functional changes have been correlated with an impaired absorptive capacity due to radiation-induced epithelial cell loss. ${ }^{\% 18-20}$ At present, no simple biological marker is available which is sensitive and specific for radiation-induced small bowel mucosal atrophy. Plasma citrulline has been suggested as a marker for functional small bowel enterocyte mass. ${ }^{21}-26$ Citrulline, a nitrogen endproduct of small bowell enterocyte glutamine metabolism, accounts for almost $30 \%$ of metabolised glutamine nitrogen in the rat small intestine. ${ }^{27}$ The small intestinal enterocyte contains specific mitochondrial enzymes involved in citrulline production but lacks the cytosolic enzymes necessary for its conversion to arginine. ${ }^{28-30}$ This unique enzymatic profile ${ }^{25}$ and the fact that citrulline is not metabolised by the liver ${ }^{31}$ account for the fact that the small bowel is the principal source of circulating citrulline. Consequently, the plasma citrull line concentration is highly dependent upon the intestinal cell mass. ${ }^{28}$

We have validated the use of citrullinemia as an assay for radiation-induced small bowel epithelial cell loss in mice following exposure to a single homogeneous dose of whole body irradiation. ${ }^{26}$ The aim of the present study was to confirm our pre-clinical results in patients exposed to a fractionated inhomogeneous dose delivered to the small bowel during abdominal and/or pelvic irradiation. For this purpose, the post-absorptive plasma citrulline concentration has been measured as a marker for radiation-induced small bowel rmucosal atrophy immediately preceding treatment and weekly during treatment. In addition, citrullinemia has been measured at intervals of 2 weeks, 3 and 6 months after completion of radiotherapy to assess subacute radiation effects. Our hypothesis, based on our pre-clinical data, ${ }^{26}$ is that changes in citrullinemia are correlated with small bowel dosimetric and volumetric parameters and with clinical symptoms attributable to acute small bowel radiation toxicity.

\section{Methods and Materials}

Subjects 
This study, carried out between November 2001 and November 2002 , included 23 successive patients receiving abdominal and/or pelvic irradiation (RT) at the Maastricht Radiation Oncology (MAASTRO) Clinic. Patients treated with concomitant chemotherapy or an impaired remal function (GFR according to Cockroft formula $<60 \mathrm{ml} / \mathrm{min}$ ) assessed less than 4 weeks prior to the start of treatment, were excluded. The median age of 9 male and $\mathbb{4} 4$ female patients was 63.1 years (range $28.3-72.6$ years). The primary tumor site, the indications for radiotherapy and the anatomic treatment sites are summarized in Table 1.

\section{Sndied Variables}

In all patients the assessment of clinical toxicity and the acquisition of blood samples for plasma citrulline measurement were performed on the same day.

\section{Cinical Parameters}

Each patient was seen by the responsible physician on a weekly basis during RT and at 2 weeks, at 3 and 6 months following completion of RT in order to assess, where appropriate, treatment related morbidity and tumor response. At each visit clinical symptoms attributable to SB radiation damage were recorded using the RTOG scoring criteria for acute radiation morbidity of the lower GIl tract (Table 2). ${ }^{32}$ In contravention of

the rules for this scoring system we also applied the score at 6 months after RT. For statistical analysis the RTOG scores per time point were used and the percentage of the total RT reatment time that a patient was free of symptoms ( $=\%$ zero score $)$.

Patients were classified according to additional treatment modalities such as hyperthermia and the mode of surgery performed (i.e. extra-peritoneal surgery (I) or intra-peritoneal surgery (II) immediately preceding RT, intra-peritoneal surgery more than 6 months prior to RT (III) of no abdominal surgery (IV)). In addition, patient characteristics such as age, gender, smoking status, length and body mass index, were recorded.

\section{Treatment planning}

A plaming CT scan was performed in supine treatment position with full bladter instruction. Patients were instructed to drink $500 \mathrm{ml}$ oral small bowel (SB) contrast solution 30 min pror to the scan. The entire abdomen was imaged in 22 patients. In 1 patient $(H 5)$ the volume scanned was limited according to the length of the treatment fids. Adjacent $10 \mathrm{~mm}$-thick transwerse images were collected and transfered to a Focus treatment-planning station (CMS). The Large bowel was defined first on each transverse image. The SB was then defined as both opacifed and un-opactied indivitual bowel loops other than large bowel. The small bowel outer contour was delneated on each transverse image enabling calculation of the total small bowel volume (Figure 1). All contouring was done by one of the authors (M.G.) and doublechecked by two others (R.B, L.L) without knowledge of the results of citrulline measurements or dose-volume histograms. This ( T based 3-dimensional dose-volume analysis and treament planning allowed performance of a quantitative tose-woltume histogram (DVH) analysis for each patient. The total RT plan was used in the DVH calculation, ie. both the dose delyered with the primary RT fields and boost RT fields, respectively. The walue of a small bowel DVH is himited due to variations in hminal content and small bowel motility. However, this nethod 
seems appropriate for estimating the proportion of functional small bowel receiving a specified radiation dose. ${ }^{17,33}$

Trable 1 Treatment features.

\begin{tabular}{|c|c|c|c|c|}
\hline $\begin{array}{r}\mathbb{P t} \\
\#\end{array}$ & Malignancy & $\begin{array}{l}\text { Radiotherapy } \\
\text { Indication }\end{array}$ & $\begin{array}{l}\text { Anatomic site } \\
\text { (most upper level field } \\
\text { border) }\end{array}$ & $\begin{array}{l}\text { Treatment } \\
\text { Schedule" }\end{array}$ \\
\hline 9 & Bladder ${ }^{2}$ & Vaginal \& pelvic sidewall & Pelvis / PAO (L2 - L3) & $1.8-61.2$ \\
\hline 2 & Cervix & FIGO & Pelvis (L5 - SI) & $2-46 / \mathrm{BCT}$ \\
\hline 4 & Cervix & FlGO InB, bulky & Pelvis / PAO (L2 - L3) & $2-46 / \mathrm{BCT}$ \\
\hline 6 & Cervix ${ }^{2 \cdot 3}$ & FlGO IB2. pNO. & Pelvis (L5 - S1) & $2-46 / \mathrm{BCT}$ \\
\hline 10 & Cervix ${ }^{2+3}$ & FIGO IB2. pN+ & Pelvis (L5-S1) & $2-48 / \mathrm{BCT}$ \\
\hline 13 & Cervix ${ }^{2 y}$ & FIGO IVA, bulky, pNO & Pelvis (L5 - SI) & $2-50 / \mathrm{BCT}$ \\
\hline 7 & Kidiney & Retro-peritoneal recurrence. & Recurrence $+\mathrm{SM}$ & $3-39$ \\
\hline 3 & Uterus. & Vaginal vault recurrence. & Pelvis (L5 - S1) & $2-70$ \\
\hline 12 & Uterus. & Sarcoma FIGO stage IC. & Pelvis (L5 - S1) & $1.8-45$ \\
\hline 16 & Uterus. & Carcinoma FIGO stage & Pelvis (L5 - SI) & $2-46$ \\
\hline$\llbracket \|$ & Ovary & Chemotherapy resistant & WAR & $0.8-30.4$ \\
\hline 17 & Ovary & Chemotherapy resistant & WAR & $0.8-30.4$ \\
\hline 8 & Prostate & pГ3. Post-operative. & Prostate $^{\alpha}+\mathrm{SM}$ & $2-60$ \\
\hline 14 & Prostate & pT3. Post-operative. & Prostate + SM & $2-60$ \\
\hline 19 & Prostate & pT3. Post-operative. & Prostate + SM & $2-68$ \\
\hline 20 & Prostate & Pelvic sidewall recurrence. & Recurrence + SM & $2-60$ \\
\hline 5 & Rectum & Pelvic recurrence. Pre- & Pelvis (L5 - S甘) & $1.8-45$ \\
\hline 21 & Rectum & Pelvic recutrence. Pre- & Pelvis (L5 - SI) & $1.8-45$ \\
\hline 1 & Testis & Seminoma Staga I. Adjuvant. & $\operatorname{PAO}(\mathrm{T} 10-\mathrm{T} 11)$ & $1.8-25.2$ \\
\hline 15 & Testis & Seminoma Stage I. Adjuvant. & $\mathrm{PAO}(\mathrm{T} 10-\mathrm{T} 11)$ & $1.8-25.2$ \\
\hline 18 & Testis & Seminoma Stage I. Adjuvant. & $\mathrm{PAO}(\mathrm{T} 10-\mathrm{T} 11)$ & $1.8-25.2$ \\
\hline 22 & Testis & Seminoma Stage IIA. & PAO (T10-T11) & $1.8-30.6$ \\
\hline 23 & Vulva & Carcinoma. Groin recurrence. & Pelvis (L5 - S1) & $2-60$ \\
\hline
\end{tabular}

Abbreviations: $B C T=$ Brachytherapy. $P A O=$ Para-aortic lymphnode area. $T, L, S=$ thoracic, lumbar and sacral vertebra, respectively. $\mathrm{SM}=$ safety margin (typically $2 \mathrm{~cm}$ in all directions). WAR $=$ whole abdominal radiation. ${ }^{\circ}$ Prostate: pre-operative prostate bed including seminal vesicles. " Dose per fraction - Total tumor dose. ${ }^{2}$ Treatment combined with pelvic Hyperthermia once weekly during extemal beam irradiation. ${ }^{3}$ Retro-peritoneal lymph node dissection. 
For all patients the small bowel wolume (SBV) receiving a dose between 5 and 55 Gy. recorded at 5-Gy intervals and the SBV receiving at least $50 \%$ of the prescribed radiation dose (SBV $50 \%$ ) was callculated. For statistical analysis volumetric parameters were expressed as the percentage of the total SBV. Thus the SBV30 is the fraction of the total amount of small bowel receiving a dose of at least $30 \mathrm{~Gy}$. Dosimetric parameters used for analysis were the cumulative mean dose delivered to the entire SB during successive treatment weeks and the total mean dose delivered to the SB. Volumetric and dosimetric parameters were conelated with the RTOG toxicity score for acute SB radiation-related morbidity and with the plasma citrulline concentration at corresponding time points.

\section{Table 2}

Lower G.I. Radiation Therapy Oncology Group acute radiation morbidity scoring critera

0 No change

1 Increased frequency or change in quality of bowel habits not requiring medication.

2. Diarrhea requiring parasympatholytic drugs / abdominal pain requiring analgesics.

3 Diarhea requiring parenteral support / abdominal distention (flat plate radiograph demonstrates distended bowel loops).

4 Acute or subacute obstruction, fistula or perforation. GI bleeding requiring transfusion; abdominal pain requiring tube decompression or bowel diversion.

$5 \quad$ Any toxicity which causes death.

\section{Radiation treatment}

All patients were treated with megavoltage equipment (10-MV linear accelerator). Standard SB exclusion techniques were used for treatment planning such as multiple field techniques where appropriate and individual lead shielding. The International Conmission on Radiation Units and Measurement (ICRU) reference point ${ }^{34}$ was chosen at the isocenter and used for dose prescription. Tumor doses prescribed to the ICRU reference point ranged between 25,2 $70 \mathrm{~Gy}$ and are listed in table 1. RT was delivered daily using $1.8-2$ Gy per fraction, 5 times per week. One patient (\# 7) was treated with 3 Gy per fraction, 4 times per week. Two patients (\#11 and 17) were treated with hyperfractionated whole abdominal radiation delivering 0.8 Gy per fraction twice daily, 5 days per week. RT treatment time ranged between 3 - 6 weeks. In 5 patients treated for cervix carcinoma RT was combined with two high-dose-rate brachytherapy applications, prescribing a dose of 8.5 Gy to Manchester point A. Braclyytherapy was delivered on Monday with an interval of 1 week. The first of 2 applications was delivered during the last week of RT or during the $1^{\text {st }}$ week following RT except for patient 2 who received 2 HDR applications during the $2^{\text {nd }}$ and $4^{\text {th }}$ week of RT. On days when intra-cavitary brachytherapy was applied no RT was delivered. In 4 patients RT was combined with pelvic hyperthermia once weekly (up to a total of 5 treatments). 


\section{Figure 1}

Assessment of dose and volume parameters using a $C T$ scan in treatment position and $3 \mathrm{D}$ treatment planning software. Transverse, coronal and sagital plane reconstructed slices are shown, respectively. The organ contour represents the small bowel contour. The relative dose distribution is presented by means of a colour wash with the central dark gray area representing a dose $\geq 50 \%$ of the prescribed tumor dose, i.e. the tissue located actually within the irradiation fields. The upper right panel shows the corresponding small bowel dose-wolume-histogram.

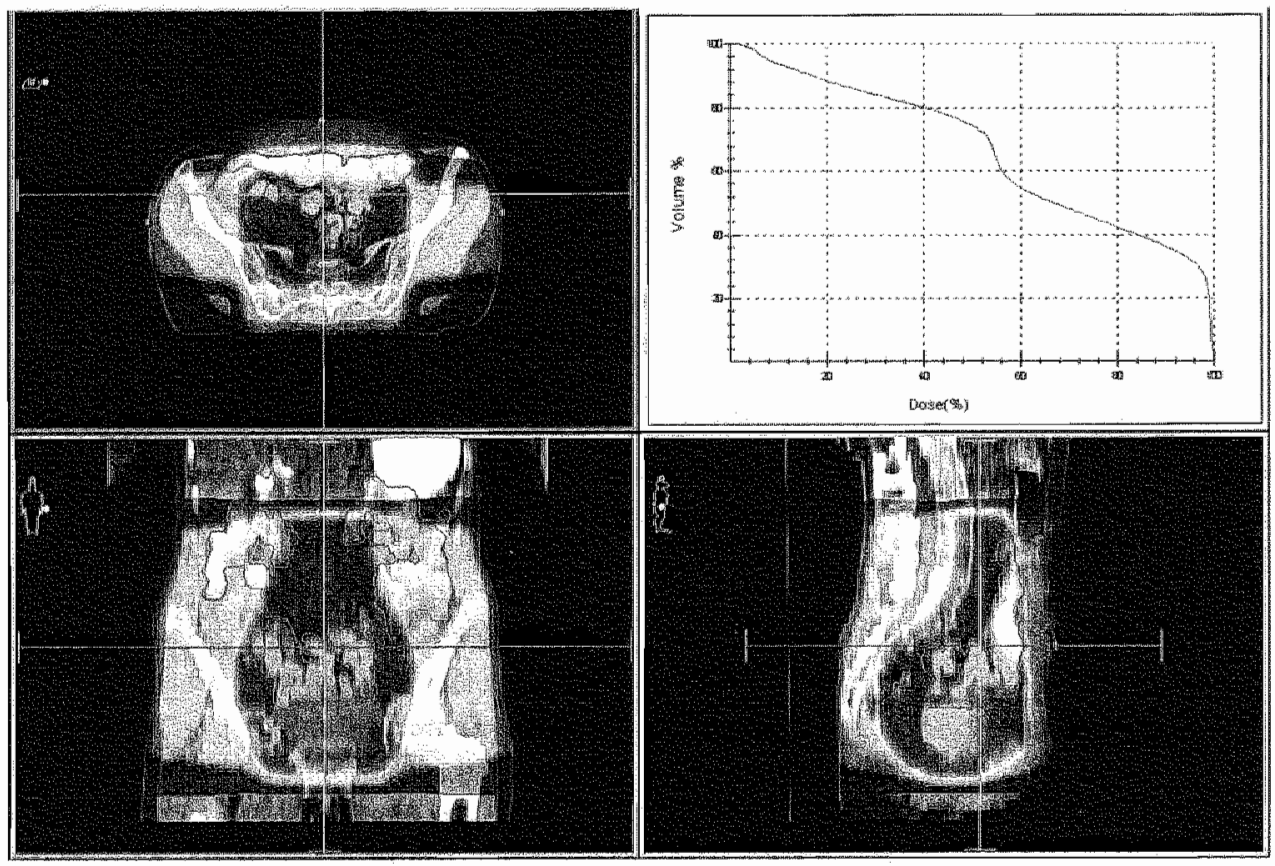

Parient \# 4: Cervix carcinoma. External Radiation treatment delivered by means of 4-field box technique to the primary tumor, pelvic and lower para-aortic lymph nodes. Upper level L2 L3; Daily fraction dose $2 \mathrm{~Gy}$. Total tumor dose prescribed $46 \mathrm{~Gy}$ in $4 \mathrm{k} / 2$ weeks. Mean $\mathrm{SB}$ dose $31 \mathrm{~Gy} . \mathrm{SBV} 50 \%=74 \%$;

Abbreviations: $\mathrm{SB}=$ small bowel; $\mathrm{SBV} 50 \%=\%$ of total $\mathrm{SB}$ volume receiving total prescribed tumor dose.

\section{Plasma citrulline.}

Post-absorptive plasma citrulline concentration was assessed on Tuesdays $15 \mathrm{~min}$ prior to irradiation. Subjects were sampled after an overnight fast and instructed to lie down for 15 min in a hospital bed, avoiding any physical exertion. On Tuesdays irradiation was scheduled between $08: 30$ and 10:00 a.m. An antecubital vein was used for sampling $1.5 \mathrm{ml}$ blood, which 
was collected in a heparinized cup and stored on ice. Plasma was then obtained by whole blood centrifugation at $10000 \times \mathrm{g}$ at $4^{\circ} \mathrm{C}$ for $10 \mathrm{~min}$. For detemination of amino acids, $250 \mu \mathrm{L}$ plasma was deproteinized by adding it to $22 \mathrm{mg}$ dry 5 -sulfosalicylic acid, vortexed, frozen in liquid nitrogen and stored at $-80^{\circ} \mathrm{C}$ until further processing. Plasma citrulline concentration ( $\mu \mathrm{mol} / \mathrm{L}$ ) was measured by using high-performance liquid chromatography." Baseline citrulline level was assessed at day 0 . Subsequently, citrullinemia was measured weekly during RT and at intervals of 2 weeks, 3 and 6 months after RT.

\section{Statistical analysis}

SPSS for windows software (Release 11.0) was used for statistical analysis. All results are expressed as mean \pm SEM. Citrulline levels measured at different time points were compared using a paired-samples $t$ test. For testing correlations between citrulline level, dose-volume and clinical parameters Pearson correlation and one-way andlysis of variance (ANOVA) were used, where appropriate. One-way ANOVA was used to test a dose and volume relationship for serum citrulline and clinical toxicity, respectively. For these tests threshold levels for the mean SB were arbitrarily chosen at 1,10 and $20 \mathrm{~Gy}$, respectively. The choice of threshold levels for citrulline was based on a recently published correlation between citrulline level and the extent and severity of epithelial cell loss in patients with celiac and non-celiac disease, ${ }^{22}$ i.e. 10,20 and $30 \mu \mathrm{mol} / \mathrm{L}$, respectively. A p-value $<0.05$ was considered statistically significant.

\section{Results}

\section{Clinical and Dose Volume Histogram Parameters}

Small bowel dose-volume-histogram parameters are summarized in table 3 . The mean total SBV in 22 patients was $1304 \mathrm{ml}$ (range $482-2117 \mathrm{ml}$ ). Body length was the only patient characteristic that was associated with the total SBV $(\mathrm{p}=0.056)$. None of the dosimetric or volumetric parameters listed in table 3 were associated with patient characteristics or with the type of surgery before RT (data not shown).

\section{Citrulline concentration}

All 23 patients completed RT as planned. Citrulline concentration and toxicity grading were assessed weekly except for the $1^{\text {st }}$ treatment week in 2 patients. At 2 weeks, 3 and 6 months after RT 21,17 and 14 patients were evaluated, respectively.

The average baseline citrulline concentration in 23 patients was $30.9 \mu \mathrm{mol} / \mathrm{L}$ (range $19.1 \mathrm{~m}$ $52.9 \mu \mathrm{mol} / \mathrm{L}$ ). During treatment a significant decline in citrulline concentration was observed at the $2^{\text {nd }}(\mathrm{P}=0,008), 3^{\text {rd }}(\mathrm{P}=0,003)$ and $4^{\text {th }}(\mathrm{P}=0,014)$ treatment week, respectively (Figure 2$)$. The maximum decline was observed during the $3^{\text {rd }}$ week of treatment $(23,6 \pm 2,4 \mu$ mol/L) .

Seventeen of 23 patients displayed a fall in citrulline concentration during RT (mean decrease $43 \%$; range $14-76 \% ; p=0.005$ ) whereas 5 patients ( $\$ 1,6,13,14$ and 19$)$ displayed a rise in citrulline concentration (mean increase $38 \%$; range $19-64 \% ; \mathrm{P}=0.003$ ).

The baseline citrulline concentration was lower in patients displaying an increase of citrulline concentration during treatment as compared to patients with decreasing citrulline concentration 
$(25.2 \pm 1.3 \mu \mathrm{mol} / \mathrm{L}$ and $32.5 \pm 2.5 \mu \mathrm{mol} / \mathrm{L}$, respectively), although not statistically significant $(\mathrm{P}=0.16)$. In 1 patient the citrulline concentration was unchanged throughout RT. None of the patient characteristics or dose-volume histogram parameters were associated with the citrulline pattern, i.e. either a fall or rise in citrulline concentration.

Table 3 Small bowel dose-volume histogram parameters of all 23 patients".

\begin{tabular}{|r|ccc|}
\hline DVH parameter & Mean & range & SEM $^{* *}$ \\
\hline Mean SB dose (Gy) & 11.2 & $0-32.2$ & 2.0 \\
Minimum SB dose (Gy) & 1.1 & $0-20.5$ & 0.9 \\
Maximum SB dose (Gy) & 35.4 & $0-59.7$ & 3.9 \\
Mean SB dlose 2 ${ }^{\text {nd }}$ RT wk (Gy) & 5.0 & $0-17.0$ & 0.9 \\
Total SBV (ml) & 1304 & $482-2117$ & 96 \\
SBV50\% (\%) & 29 & $0-100$ & 6.2 \\
SBV5 (\%) & 37 & $0-100$ & 6.5 \\
SBVI0 (\%) & 34 & $0-100$ & 6.4 \\
SBV15 (\%) & 31 & $0-100$ & 6.3 \\
SBV20 (\%) & 30 & $0-100$ & 6.2 \\
SBV25 (\%) & 24 & $0-94$ & 5.7 \\
SBV30 (\%) & 15 & $0-71$ & 4.2 \\
SBV35 (\%) & 9 & $0-45$ & 3.0 \\
SBV40 (\%) & 7 & $0-39$ & 2.3 \\
SBV45 (\%) & 4 & $0-31$ & 1.6 \\
SBV50 (\%) & $<1$ & $0-5$ & 0.3 \\
SBV55 (\%) & 0 & $0-3$ & 0 \\
\hline
\end{tabular}

Abbreviations: $\quad \mathrm{SB}=$ small bowel. $\mathrm{SBV}=$ small bowel volume; $\mathrm{DVH}=$ dose-volume histogram. SEM $=$ standard error of the mean. SBV50\% = the percentage of total SBV receiving at least $50 \%$ of the dose prescribed to the ICRU reference point; SBV $5=$ the percentage of total SBV receiving a dose of at least 5 Gy. 'Total SBV data available in 22 patients.

Citrulline: dose-response relationship.

The overall change in citrulline concentration during RT significantly correlated with the total mean SB dose (Pearson $r=-0,72 ; p<0.001$ ). Citrulline concentration, categorized according to 
threshold values predictive for the severity and extent of villous atrophy, ${ }^{22}$ i.e. $<10 \mu \mathrm{mol} L$ [1]; $10-20 \mu \mathrm{mol} / \mathrm{L}[2] ; 20-30 \mu \mathrm{mol} / \mathrm{L}[3]$ and $\geq 30 \mu \mathrm{mol} / \mathrm{L}$ [4], respectively, were associated with different mean SB doses: $31.6 \pm 0.6 \mathrm{~Gy} ; 13.1 \pm 2.4 \mathrm{~Gy} ; 9.6 \pm 2.5 \mathrm{~Gy}$ and $2.7 \pm 1.7 \mathrm{~Gy}$ for citrulline category $1,2,3$ and 4 , respectively ( $<<0.001$; Figure 3 ). A similar significant correlation was found during RT between the citrulline concentration and the cumulative mean SB dose: $\mathrm{P}=0.001 ; \mathbb{P}<0.001 ; \mathrm{P}<0.001 ; \mathrm{P}=0.004$ for $\mathrm{RT}$ week $2,3,4$ and 5 , respectively. No correlation was observed at the other time points during and after RT. To further explore a dose-response relationship threshold levels for the mean SB dose of 1,10 and 20 Gy were used and yielded similar results (Figure 4 ).

\section{Figure 2}

Temporal pattern of plasma citrulline concentration $(\mu \mathrm{mol} / \mathrm{L})$ and RTOG toxicity grading relative to radiation treatment. Values for plasma citrulline level (dashed bar) represent mean \pm sem. The dashed line (--) represents the percentage of patients with RTOG score zero, the drawn line ( $\longrightarrow$ ) represents the percentage of patients with RTOG score 2.

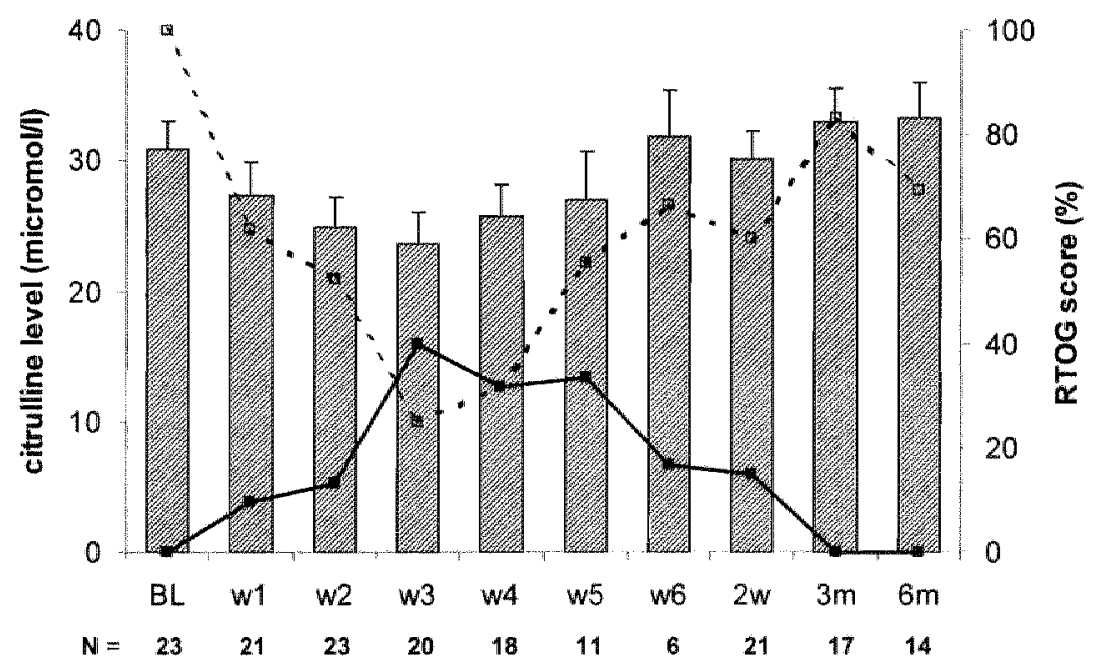

Abbreviations: $\quad B L=$ baseline; $w 1-6=$ radiation treatment week $1-6 ; 2 \mathrm{w}, 3 \mathrm{~m}, 6 \mathrm{~m}=2$ weeks, 3 and 6 months post-radiation. Statistics: 2 -sided two-sample t-test: $* 0=0.008$; ** $\mathrm{p}=0.003 ;{ }^{* * *} \mathrm{p}=0.014$.

Citrulline: volume effect.

The overall change in citrulline concentration during RT ( $\mu \mathrm{mol} / \mathrm{L}$ ) significantly correlated with successive SBV dose levels between $5 \mathrm{~Gy}$ and $35 \mathrm{~Gy}$ at $5 \mathrm{~Gy}$ intervals. The volume effect was further analysed using citrulline threshold levels of 10,20 and $30 \mu \mathrm{mol} / \mathrm{L}$, respectively. A 
significant wolume effect wass observed for the SBV dose levels between 5 Gy and 35 Gy (Figure 5). No volume effect was found for the 2 weeks, 3 and 6 months time points.

\section{Radiation-induced small bowel toxicity ( $R T O G$ score).}

During RT temporal changes in radiation-induced SB toxicity were observed (Figure 2). The maximum acute SB toxicity score was 2 during the total observation time in 23 patients. Weekly assessed toxicity was correlated with the corresponding cumulative mean SB radiation dose. In addition, the fraction of total treatment time that a patient was free from symptoms ( $\%$ zero score) was correlated with the total mean SB dose. For the $4^{\text {th }}$ and $5^{\text {步 }}$ treatment week the cumulative mean radiation dose significantly correlated with clinical toxicity (Pearson $r: 0.50$ and $0.69 ; \mathrm{P}=0.033$ and $\mathrm{P}=0.040$, respectively). No correlation between toxicity and $\mathrm{RT}$ dose was found at any other time point during or after RT. The \% zero score significantly correlated with the total mean $\mathrm{SB}$ dose ( $\mathrm{P}=0.017$ ). No dose-effect relationship was observed using the maximum scored toxicity as parameter (i.e. RTOG score 2).

Weekly assessed toxicity correlated significantly with successive SBV dose levels of 5 - 30 Gy and 5-35 Gy during the $4^{\text {th }}$ and $5^{\text {th }}$ treatment week, respectively. No volume effect was found at earlier time points during RT or at later time points following treatment, respectively. The $\%$ zero score allso correlated significantly with successive SBV dose levels between 5 - 30 Gy.

\section{Figure 3}

Dose effect relationship for plasma citrulline concentration categorized according to threshold values of 10,20 and $30 \mu \mathrm{mol} / \mathrm{L}$, yielding 4 groups, i.e. $<10 \mu \mathrm{mol} / \mathrm{L}(1) ; 10-20 \mu \mathrm{mol} / \mathrm{L}(2) ; 20$ $-30 \mu \mathrm{mol} / \mathrm{L}(3)$ and $\geq 30 \mu \mathrm{mol} / \mathrm{L}$ (4), respectively. For comparison of the mean small bowel dose (Gy) between the respective citrulline categories the one-way ANOVA test with Tukey's post-hoc testing is used. Data represent mean \pm SEM.

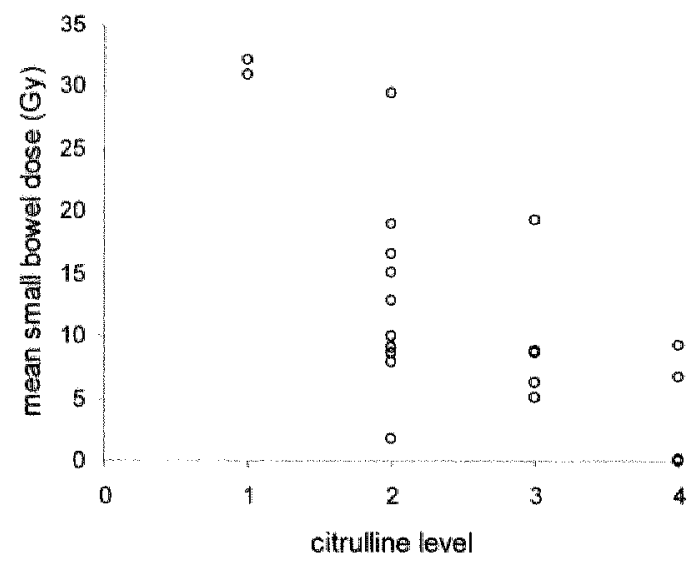

One-way ANOVA: $\quad \mathrm{P}<0.001$. Tukey's post-hoc testing: level I vs level 2 , level 3 and level 4: $\mathrm{P}=0.005$; $\mathrm{P}=0.002$ and $\mathrm{P}<0.001$, respectively. Level 2 ws levell 3 and $4: P=n$.s. and $P=0.020$, respectively. Leve] $3 \mathrm{vs}$ level 4: P=n.s. 


\section{Figure 4}

Dose effect relationship for plasma citrulline concentration at successive time points during RT. The cumulative mean dose delivered to the small bowel at each dose point is cortelated with the plasma citrulline concentration ( $\mathrm{mmol} / \mathrm{L}$ ) at the corresponding time point. Mean small bowel doses are categorized according to 4 threshold levels, i.e. $0-1 \mathrm{~Gy}, \geq 1-10 \mathrm{~Gy}, \geq 10-20$ Gy and $\geq 20 \mathrm{~Gy}$, respectively. For comparison of the mean plasma citrulline concentration between the respective threshold dose categories the one-way ANOVA test is used. Data represent mean $\pm \mathrm{SEM}$.

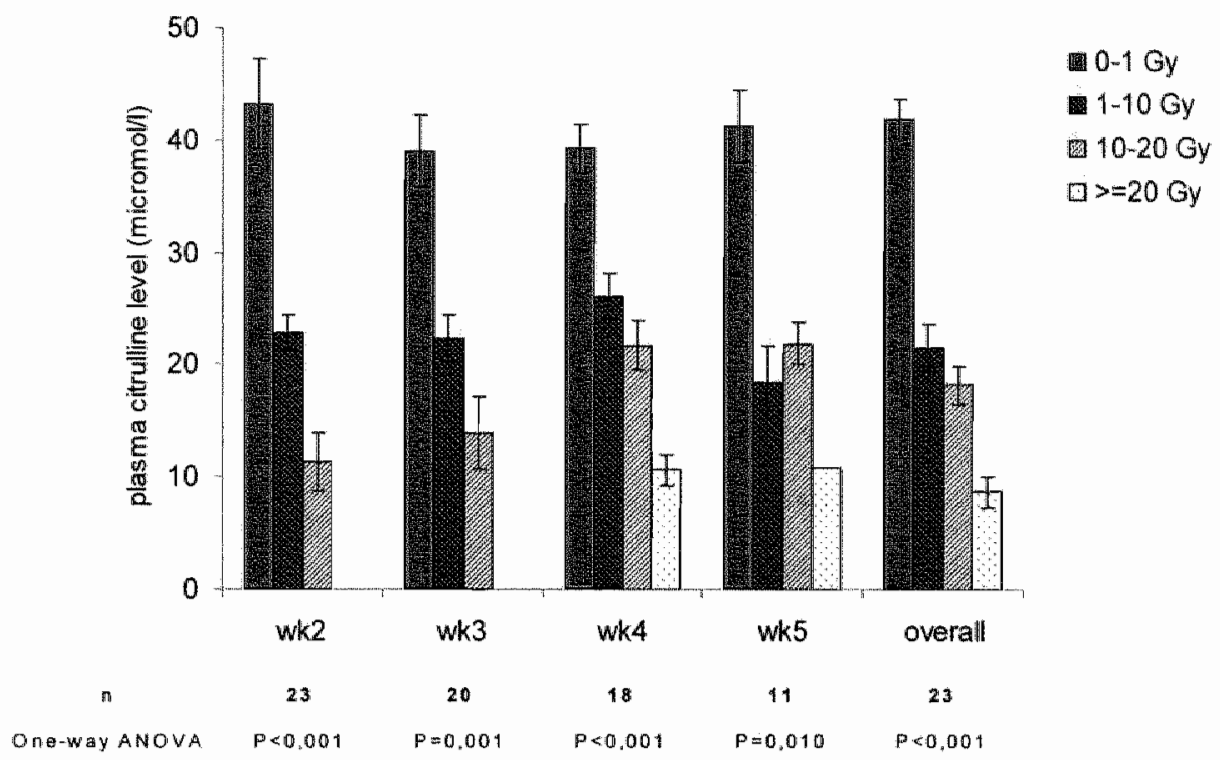

Abbreviation: $W \mathrm{k} 2-5=$ radiation week $2-4$. Overall $=$ the maximum change in plasma citrulline concentration during RT treatment.

Correlation of clinical symptoms with citrulline concentration.

Citrulline concentration was significantly correlated with clinical toxicity during the $4^{\text {th }}$ and $6^{\text {th }}$ treatment week (Pearson $\mathrm{r}$ : -0.62 and $-0.86 ; \mathrm{P}=0.007$ and $\mathrm{P}=0.027$, respectively), whereas a borderline significant correlation was found at the $5^{\text {th }}$ treatment week $(P=0.060)$ (Figure 6). No such relationship was observed during the first 3 weeks or following treatment. The weekly assessed \% zero score significantly correlated with the citrulline concentration during treatment (Spearman's tho 0.93). Similarly, the total \% zero score during treatment significantly correlated with the overall change in plasma citrulline concentration $(P=0.002)$. 
The \% zero score correlated with the 4 groups of citrulline levels categorized according to threshold values of 10,20 and $30 \mu \mathrm{mol} / \mathrm{L}$, i.e. $38 \pm 22 \% ; 41 \pm 7 \% ; 53 \pm 13 \%$ and $82 \pm 12 \%$ for patients with citrulline concentrations $<10 \mu \mathrm{mol} / \mathrm{L} ; 10-20 \mu \mathrm{mol} / \mathrm{L} ; 20-30 \mu \mathrm{mol} / \mathrm{L}$ and $\geq 30$ $\mu \mathrm{mol} / L$, respectively $(\mathrm{P}=0.036$ ). No such relationship was observed for the maximum scored toxicity (i.e. RTOG score 2) and citrulline concentration.

The limited number of patients in this study does not allow a detailed analysis on a threshold level for clinical symptoms. For that reason we used a threshold SBV 15 of $150 \mathrm{ml}$ as recently published by Baglan et al ${ }^{17}$ for acute $S B$ toxicity, although this refers specifically to the situation of combined chemotherapy and radiotherapy in patients with rectal cancer. The $\%$ zero score during RT was $83 \pm 27 \%$ as compared to $44 \pm 24 \%$ for patients with a SBV $15<150$ $\mathrm{ml}$ and $\geq 150 \mathrm{ml}$, respectively $(\mathrm{P}=0.003)$. Corresponding serum citrulline concentrations were $34.2 \pm 13.0 \mu \mathrm{mol} / \mathrm{L}$ and $18.4 \pm 6.9 \mu \mathrm{mol} / \mathrm{L}$, respectively $(\mathrm{P}=0.001)$.

\section{Figure 5}

Volume-effect for serum citrulline concentration. A volume effect is analyzed for SBV dose levels at 5 Gy intervals. Citrulline is categorized into 4 groups using 3 threshold levels, i.e. $<10$ $\mu \mathrm{mol} / \mathrm{L}(1) ; 10-20 \mu \mathrm{mol} / \mathrm{L}(2) ; 20-30 \mu \mathrm{mol} / \mathrm{L}$ (3) and $\geq 30 \mu \mathrm{mol} / \mathrm{L}$ (4), respectively. Data represent means $t \mathrm{SEM}$.

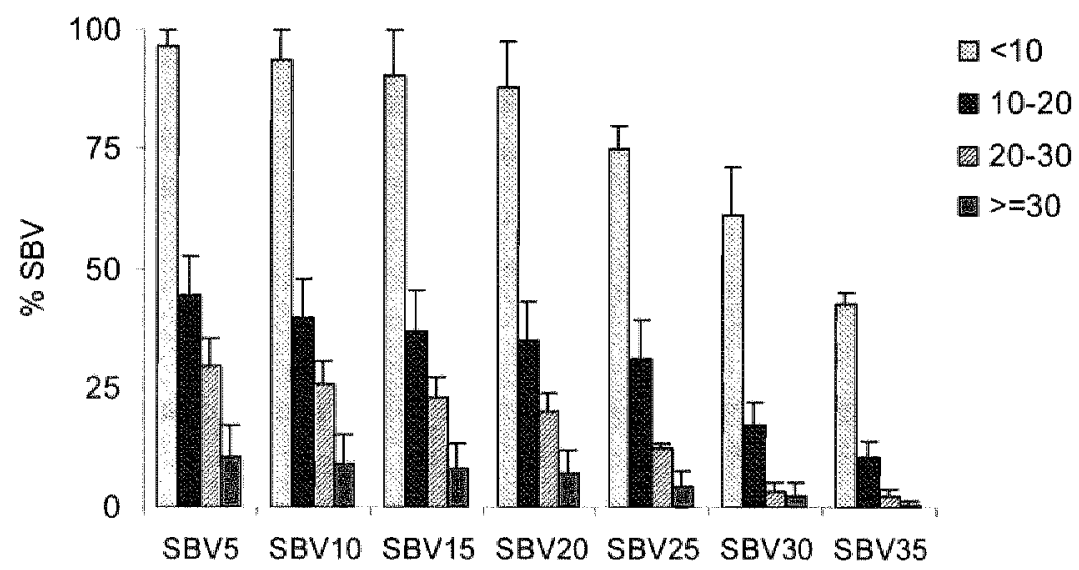

Abbreviation: SBV5 = the percentage of total small bowel volume receiving at least 5 Gy. For statistical analysis the one-way ANOV'A test was used with Tukey's post-hoc testing. Pvalues: $<0.001 ;<0.001 ;<0.001 ;<0.001 ;<0.001 ;<0.001$ and 0.045 for SBV $5-35$, respectively. For SBV $5-15$ the difference between each successive group is significant. For SBV 20 the diffence between category 2 and 3 is not significant. For SBV25-35 only the difference in SBV between category 1 and 2 is significant. 


\section{Figure 6}

Correlation between citrulline concentration and toxicity score during RT treatuant. Data for citrulline concentration $(\mu \mathrm{mol} / \mathrm{L})$ represent means $\pm \mathrm{SEM}$.

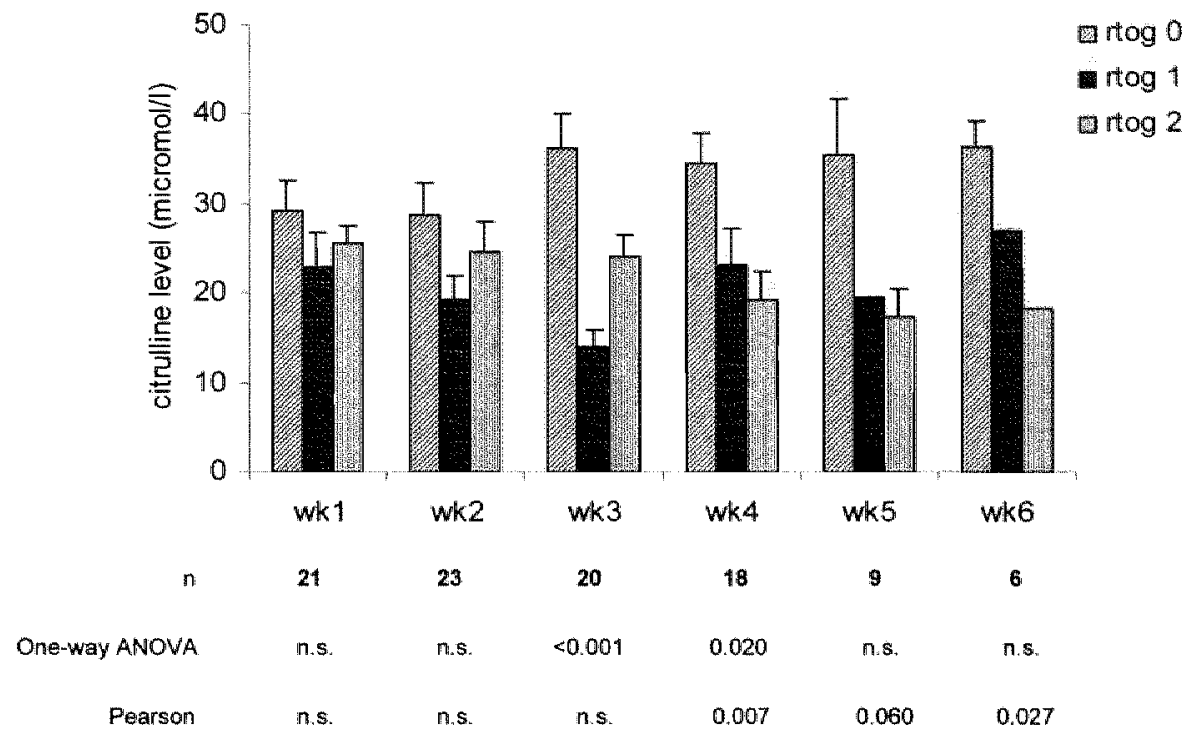

\section{Discussion}

The present study demonstrates that plasma citrulline is a feasible marker in clinical practice to monitor radiation-induced small intestinal mucosal atrophy in patients treated for abdominal and/or pelvic cancers and confirms pre-clinical results in mice following whole body single dose irradiation. ${ }^{26}$ Like surgery, ${ }^{21}$ celiac and non-celiac disease ${ }^{22}$ and acute cellular rejection following small bowel transplantation ${ }^{23,24}$ lonizing irradiation is an additional event associated with reduced small bowel epithelial cell mass that can be monitored by plasma citrulline.

The relationship between plasma citrulline concentration and epithelial cell mass has previously been demonstrated in rodents following surgical resection of small bowel. ${ }^{25,36}$ In an experimental study using mice we suggested plasma citrulline concentration as marker for small bowell epithelial cell mass following a single homogeneous total body irradiation. ${ }^{26}$ Recently, several investigators have suggested plasma citrulline as a specific marker for small bowel functional enterocytes in patients. ${ }^{21} \cdot 24$ This is further substantiated by the present study by adding ionizing irradiation as a mechanism for (temporal) loss of functional enterocytes. 
The pathophysiology of clinical symptoms related to small bowel irradiation is complex with mucosal denudation being one of several events. ${ }^{37-39}$ In rodents the kinetics of radiationinduced small intestininal epithelial changes have been well described. ${ }^{40}$ Radiation damage to the untestinal crypt cell compartment and consequential epithelial denudation is strictly dose dependent. ${ }^{40}$ In patients radiation dose, in addition to the volume of irradiated small bowel, has been demonstrated as determinant for radiation-induced small bowel toxicity. ${ }^{12,36,17}$ Plasma citrulline concentration decreased as a function of small bowel radiation dose (Figure 3 and 4) and volume (Figure 5). Crenn et al ${ }^{22}$ have recently correlated plasma citrulline concentration with histologically graded villous atrophy in 42 patients with celiac and 10 patients with nonceliac villous atrophy disease. These authors identified a threshold value of $10 \mu \mathrm{mol} / \mathrm{L}(25 \%$ of the mean normal baseline value) to be predictive for severe and extensive villous atrophy and $20 \mu \mathrm{mol} / \mathrm{L}$ to be predictive for severe villous atrophy, whatever the extent. Based on these data we used the same threshold lewels for plasma citrulline to analyze radiation-induced effects (Figure 3 and 5). The citrulline categories corresponded with different mean small bowel doses (Figure 3) and volumes treated (Figure 5). Up to a mean small bowel dose of 15 Gy these threshold levels were significantly associated with the volume of small bowel treated. For higher dose Jevels the $10 \mu \mathrm{mol} / \mathrm{L}$ threshold remains a discriminating factor for the volume of small bowel treated.

Radiation-induced small bowel toxicity is associated with the radiation dose and the volume of small bowel treated. ${ }^{12,16,17}$ We found a significant dose and volume effect for radiationinduced toxicity during the $4^{\text {th }}$ and $5^{\text {th }}$ treatment week. In contrast to other authors ${ }^{12,16}$ we did not find such a relationship for late sequelae, i.e. at 6 months. However, the limited number of patients and follow up, respectively, do not permit conclusions on this issue.

Plasma citrulline and the RTOG toxicity score were used as endpoints for radiation-induced small bowel toxicity in this study. A radiation dose and volume effect was observed for both endpoints. However, whereas the dose-response relationship for plasma citrulline was significant at week $2-5$ (Figure 4), this was only true at week 4 and 5 for the toxicity score. Overall, citrullinemia correlates poorly with the severity of clinical symptoms as graded with the RTOG acute toxicity score used in this study, although a correlation was observed with the time that a patient is without symptoms (i.e. the \% zero score). This may in part be explained by the fact that radiation-induced epithelial celll loss, which is typically measured by the plasima citrulline level, is merely one of several pathophysiological mechanisms underlying clinical symptoms. ${ }^{37} \cdot 39$ Also the fact that the clinical toxicity score is a subjective score in contrast to plasma citrulline concentration may further contribute to this poor correlation. The poor contelation between subjective symptons, i.e. complaints and objective endpoints for small bowel radiation injury has been recognized before. ${ }^{5}$ Similar drawbacks exist for the use of sophisticated planning systems to calculate small bowel dose and volume parameters. As reported by others ${ }^{17,33}$ we used a planning CT-scan for computing a small bowel DVH. The $\mathrm{SBV}$ is reconstructed from the $\mathrm{SB}$ contours as delineated on each transverse slice, a parameter that will highly depend on the protocol used for the CT-scan, e.g. whether patients are fasted prior to the scan and if so, for how long? What is the volume of contrast solution administered and what is the time interval between the contrast administration and the CT-scan? A substantial variation exists in the protocols used by different authors with regard to these 
aspects. $^{12,16,17,41}$ Furthermore, without a previous history of abdominal surgery the small bowel is a mobile organ. As a consequence the SBV treated as well as the dose delivered to a particular part of SB will vary daily, not least because of a possible variation in bladder filling. Despite several attempts to standardize registration and consequently publication of treatment rellated toxicity, most authors still use a toxicity scoring system adjusted to their own (historical) chinical practice and or clinical question, 42 as was also done to some extent in this study. Due to this and the fact that toxicity grading systems are being adjusted on a regular basis, an objective marker for normal tissue toxicity such as the plasma creatinine level is for the kidney function, would definitely be of great benefit. Ideally, such a marker should then be easily accessible and independent of medication and metabolic events such as diet and nutritional status. We didn't find a cortelation between baseline citrulline concentrathon and body mass index, surgical status or primary malignancy. Also Crenn et al 22 found normal citrulline concentrations in 10 severely malnourished patients with anorexia mervosa.

In contrast to currently used physical parameters (i.e. radiation dose and volume parameters) biological markers (such as the citrulline concentration) provide information about individual biological variability among patients in terms of intrinsic radiosensitivity. In case of acute reacting tissues like the small intestinal epithelium such information might prove to be useful as a predictive assay and consequently lead to adjustments in the treatment volume and/or total radiation dose.

A rather unexpected finding was the increase of plasma citrulline concentration during RT in a substantial number of patients. The analytical method used by us is highly reproducible (coefficient of variation $3 \%$ ) excluding a large variation in the measured results, ${ }^{35,45}$ No dosimetric or volumetric parameter explained this finding nor did any of the patient characteristics such as age or gender. ${ }^{46}$ A single plasma citrullinemia measurement immediately prior to the start of treatment was considered as representative baseline value in the present study. To the authors knowledge no data exist in the literature about the physiological variation of plasma citrulline concentration in time. However, the mean \pm SEM baseline value in the present study $(30.9 \pm 2.1 \mu \mathrm{M})$ is in complete agreement with previous findings at our lab in healthy volunteers under similar conditions of starvation. ${ }^{47}$ Interestingly, the mode of surgicall treatment was different in patients that displayed an increased plasma citrulline concentration. Thus a rise in plasma citrulline was observed during RT in 5 out of 6 patients $(83 \%)$ who underwent extra-peritoneal surgery prior to RT as compared to 0 of 17 patients with different modes of surgical intervention. An explanation for this can only be speculative. Despite the fact that all patients had normal renal function prior to the start of RT a temporary decline of renal function cannot be ruled out. A reactive proliferation of SB epithelium might be another possibility which would be in agreement with data so far published on citrulline as a marker for functional enterocytes $21 \cdot 26,36$ and the observation that plasma citrulline concentration may change rapidly in response to altered pathophysiological conditions. ${ }^{24}$

In summary, small bowel is an important dose limiting normal tissue when treating abdominal or pelvic cancers with tadiotherapy. Furthermore, combined radiotherapy with chemotherapy is being used more frequently for an increasing number of malignancies originating at abdominal or pelvic sites. ${ }^{4850}$ Since many of the drugs used also affect the proliferative activity 
at the crypts, treatment related bowel toxicity will be enhanced. ${ }^{48}$ Epithelial cell loss has been associated with radiation-induced changes in small bowel function." 9.20 Mainly for practical reasons, currently available tests for $\mathrm{SB}$ radiation damage are not suitable for monitoring purposes during and following fractionated radiation. ${ }^{38} \mathrm{We}$ chose citrullinemia for its methodological simplicity ${ }^{21-26,36}$ and the lack of methodological drawbacks as mentioned before. As a whole, plasma citrulline seems to be a quantitative parameter independent of the underlying cause for epithelial cell loss. ${ }^{28-23}$ Consequently this marker provides an objective parameter to the clinician enabling standardized assessment of treatment related morbidity. In addition to surgery, ${ }^{21}$ celiac and non-celiac disease ${ }^{22}$ and post-transplantation cellular rejection 23,24 the present study provides the proof of principle for the use of plasma citrulline as an assay for radiation-induced small intestinal mucosal atrophy. 


\section{References}

1. Picard C, Wysocki J, Fioramonti J, Griffiths NM. Intestinal and colonic motor alterations associated with irradiation-induced diarhoea in rats. Neurogastroenterol Motil 2001; 13: 19-26.

2. Fraser R, Frisby C, Blackshaw LA, Schimer M, Howarth G, Yeoh E. Small intestinal dysmotility following abdominal irradiation in the rat small intestine. Neurogastroenterol Motil 1998; 10: 413-419.

3. Gunter Smith PJ. Gamma radiation affects active electrolyte transport by rabbit ileum: basal Na and Cl transport. Am J Physiol 1986; 250: G540-545.

4. Lebrun F, Benderitter M, Berroud A, Voisin P, Griffiths NM. Potential role of the membrane in the development of intestinal cellular damage after whole-body gamma irradiation of the rat. Can J Physiol Pharmacol 2002; 80: 686-693.

5. Yeoh E, Horowitz M, Russo A, Muecke T, Ahmad A, Robb T, Chatterton B. A retrospective study of the effects of pelvic irradiation for carcinoma of the cervix on gastrointestinal function. Int J Radiat Oncol Biol Phys $1993 ; 26: 229-237$.

6. Travis $\mathrm{S}$, Menzies $\mathbb{1}$. Intestinal permeability: functional assessment and significance. Clin Sci 1992; 82: 471-488.

7. Craig RM, Atkinson AJ, Jr. D-xylose testing: a review. Gastroenterology 1988; 95 : 223-231.

8. Thomson AB, Cheeseman CI, Walker $\mathrm{K}$. Effect of abdominal irradiation on the kinetic parameters of intestinal uptake of glucose, galactose, leucine, and gly-leucine in the rat. J Lab Clin Med 1983; 102: 813-827.

9. Juby LD, Dixon MF, Axon AT. Abnormal intestinal permeability and jejunal morphometry. J Clin Pathol 1987; 40: 714-718.

10. Thomson $\mathrm{AB}$, Cheeseman $\mathrm{Cl}$, Walker $\mathrm{K}$. Intestinal uptake of bile acids: effect of external abdominal irradiation. Int J Radiat Oncol Biol Phys 1984; 10: 671-685.

11. Petereit DG, Sarkaria JN, Chappell R, Fowler JF, Hartmann TJ, Kinsella TJ, Stitt JA, Thomadsen BR, Buchler DA. The adverse effect of treatment prolongation in cervical carcinoma. Int J Radiat Oncol Biol Phys 1995; 32: 1301-1307.

12. Letschert JG, Lebesque JV, Aleman BM, Bosset JF, Horiot JC, Bartelink H, Cionini L, Hamers JP, Leer JW, van Glabbeke M. The volume effect in radiation-related late small bowel complications: results of a clinical study of the EORTC Radiotherapy Cooperative Group in patients treated for rectal carcinoma. Radiother Oncol 1994; 32: 116-123.

13. Yeoh E, Razali M, O'Brien PC. Radiation therapy for early stage seminoma of the testis. Analysis of survival and gastrointestinal toxicity in patients treated with modern megawoltage techniques over 10 years. Australas Radiol 1993; 37: 367-369.

14. Yeoh E, Horowitz M, Russo A, Muecke T, Robb T, Maddox A, Chatterton B. Effect of pelvic irradiation on gastrointestinal function: a prospective longitudinal study. Am J Med 1993; 95: 397-406. 
15. Yeoh E, Horowitz M, Russo A, Muecke $T$, Robb $T$, Chatterton B. The effects of abdominal irradiation for seminoma of the testis on gastrointestinal function. I Gastroenterol Hepatol 1995; 10: 125-130.

16. Gallagher MJ, Brereton HD, Rostock RA, Zero JM, Zekoski DA, Poyss LF, Richter MP, Kligerman MM. A prospective study of treatment techniques to minimize the volume of pelwic small bowe] with reduction of acute and late effects associated with pelvic irradiation. Int J Radiat Oncol Biol Phys 1986; 12:1565-1573.

17. Baglan KL, Frazier RC, Yan D, Huang RR, Martinez AA, Robertson JM. The dosevolume relationship of acute small bowel toxicity from concurrent 5-FU-based chemotherapy and radiation therapy for rectal cancer. Int J Radiat Oncol Biol Phys 2002; 52:176-183.

18. Overgaard $J$, Matsui $M$. Effect of radiation on glucose absorption in the mouse jejunum in vivo. Radiother Oncol 1990; 18: 71-77.

19. Kirichenko AV, Mason KA, Straume M, Teates CD, Rich TA. Nuclear scintigraphic assessment of radiation-induced intestinal dysfunction. Radiat Res $2000 ; 153$ : 164172.

20. Gunter Smith PJ. Gamma radiation affects active electrolyte transport by rabbit ileum. II. Correlation of alanine and theophylline response with morphology. Radiat Res $1989 ; 117: 419-432$.

21. Crenn P, Coudray Lucas C, Thuillier F, Cynober L, Messing B. Postabsorptive plasma citrulline concentration is a marker of absorptive enterocyte mass and intestinal failure in humans. Gastroenterology 2000; 119:1496-1505.

22. Crenn $P$, Vahedi $K$, Lavergne Slove A, Cynober L, Matuchansky C, Messing $B$. Plasma citrulline: A marker of enterocyte mass in villous atrophy-associated small bowel disease. Gastroenterology $2003 ; 124: 1210-1219$.

23. Gondolesi G, Fishbein T, Chehade M, Tschernia A, Magid M, Kaufman S, Raymond $\mathbb{K}$, Sansaricq $C$, LeLeiko N. Serum citrulline is a potential marker for rejection of intestinal allografts. Transplant Proc 2002; 34: 918-920.

24. Pappas PA, Saudubray JM, Tzakis AG, Rabier D, Carieno MR, Gomez Marin O, Huijing F, Gelman B, Levi DM, Nery JR, Kato T, Mittal N, Nishida S, Thompson JF, Ruiz P. Serum citrulline as a marker of acute cellular rejection for intestinal transplantation. Transplant Proc 2002; 34: 915-917.

25. Wakabayashi $\mathrm{Y}$, Yamada $\mathbb{E}$, Yoshida $T$, Takahashi $N$. Effect of intestinal resection and arginine-free diet on rat physiollogy. Am J Physiol 1995; 269: G313-318.

26. Lutgens LC, Deutz NEP, Gueulette J, Cleutjens JPM, Berger MPF, Wouters BG, von Meyenfeldt MF, Lambin P. Citrulline: a physiological marker enabling quantitation and monitoring of epithelial radiation induced small bowel damage. Int I Radiat Oncol Biol Phys 2003; $57: 1067-1074$.

27. Windmueller HG. Glutamine utilization by the small intestine. Adv Enzymol Relat Areas Mol Biol 1982; 53: 201-237.

28. Wakabayashi Y, Yamada E, Hasegawa T, Yamada R. Enzymological evidence for the indispensability of small intestine in the synthesis of arginine from glutamate. $\mathrm{I}$. Pyrroline-5-carboxylate synthase. Arch Biochem Biophys 1991; $291: 1-8$. 
29. Wakabayashi $\mathrm{Y}$, Yamada E, Yoshida $\mathrm{T}$, Takahashi H. Arginine becomes an essential amino acid after massive resection of rat small intestine. J Biol Chem 1994; 269 : 32667-32671.

30. Wu $G$. Synthesis of citrulline and arginine from proline in enterocytes of postnatal pigs. An I Physiol 1997; 272: G1382-1390.

31. Windmueller HG, Spaeth AE. Source and fate of circulating citrulline. Am J Physiol $1981 ; 241: \mathrm{E} 473-480$.

32. Cox JD, Stetz J, Pajak TF. Toxicity criteria of the Radiation Therapy Oncology Group (RTOG) and the European Organization for Research and Treatment of Cancer (EORTC). Int J Radiat Oncoll Biol Phys 1995; 31 : 1341-1346.

33. Das IJ, Lanciano RM, Mowsas B, Kagawa K, Barnes SJ. Efficacy of a belly board device with $\mathrm{CT}$-simulation in reducing small bowel volume within pelvic irradiation fields. Int J Radiat Oncol Biol Phys 1997; 39:67-76.

34. Intemational Commission on Radiation Units and Measurements (ICRU). Report Number 50 . Prescribing, recording and reporting photon beam therapy. Washington, DC: ICRU, 1993.

35. van Eijk HM, Rooyakkers DR, Deutz NE. Rapid routine determination of amino acids in plasma by high-performance liquid chromatography with a $2-3$ microns Spherisorb ODS II colum. J Chromatogr 1993; 620: $143-148$.

36. Chen K, Nezu R, Sando K, Haque SM, Iiboshi Y, Masunari A, Yoshida H, Kamata $S$, Takagi $\mathrm{Y}$, Okada A. Influence of glutamine-supplemented parenteral nutrition on intestinal amino acid metabolism in rats after small bowel resection. Surg Today $1996 ; 26: 618-623$.

37. Thomson AB, Keelan M, Thiesen A, Clandinin MT, Ropeleski M, Wild GE. Small bowel review: diseases of the small intestine. Dig Dis Sci $2001 ; 46: 2555-2566$.

38. Griffiths NM. The example of gastrointestinal damage induced by ionising radiation: are there accessible markers? Cell Mol Biol 2001; 47: 427-435.

39. MacNaughton WK. Review article: new insights into the pathogenesis of radiationinduced intestinal dysfunction. Aliment Pharmacol Ther 2000; 14: 523-528.

40. Potten CS. Structure, function and proliferative organisation of mammalian gut:: Elsevier Science B.V. Amsterdam.; 1995.

41. Herbert SH, Solin LJ, Hoffman JP, Schultz DJ, Curran WJ, Ji., Lanciano RM, Rosenblum N, Hogan M, Eisenberg B, Hanks GE. Volumetric analysis of small] bowel displacenent from radiation portals with the use of a pelvic tissue expander. Int J Radiat Oncol Biol Phys 1993; 25: 885-893.

42. Miller AR, Martenson JA, Nelson H., Schleck CD, Ilstrup DM, Gunderson LL, Donohue JH. The incidence and clinical consequences of treatment-related bowd injury. Int J Radiat Oncol Biol Phys 1999; 43: 817-825.

43. Miller RC, Sargent DJ, Martenson JA, Macdonald JS, Haller D, Mayer RJ, Gunderson LL, Rich TA, Cha SS, O'Connell M. Acute diarthea during adjuvant therapy for rectal cancer: a detailed analysis from a randomized intergroup trial. Int I Radiat Oncol Biol Phys 2002; 54: 409-413. 


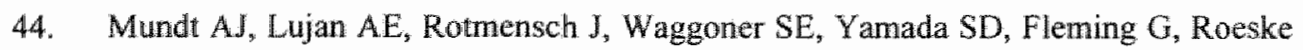
JC. Intensity-modulated whole pelvic radiotherapy in women with gynecologic malignancies. Int J Radiat Oncol Biol Phys 2002; 52: 1330-1337.

45. van Eijk HM, Huinck MP, Rooyakkers DR, Deutz NE. Automated simultaneous isolation and quantitation of labeled amino acid fractions from plasma and tissue by ion-exchange chromatography. J Chromatogr B Biomed Appl 1994; 660: 251-257.

46. van Eijk HM, de Jong CHM, Deutz NEP, Soeters PB. Influence of storage conditions on normal plasma amino-acid concentrations. Clinical Nutrition 1994; 13: 374-380.

47. van Eijk HM, wan der Heijden MA, van Berlo CL, Soeters PB. Fully automated liquid-chromatographic determination of amino acids. Clin Chem 1988; 34; 25l 0 2513.

48. Green JA, Kirwan JM, Tiemey JF, Symonds P, Fresco L, Collingwood M, Williams CJ. Survival and recurtence after concomitant chemotherapy and radiotherapy for cancer of the uterine cervix: a systematic review and meta-analysis. Lancet 2001 ; 358: $781-786$.

49. Han SC, Kim DH, Higgins SA, Carcangiu ML, Kacinski BM. Chemoradiation as primary or adjuvant treatment for locally advanced carcinoma of the vulva. Int $J$ Radiat Oncol Biol Phys 2000; 47: 1235-1244.

50. Pahlman L, Hohenberger W, Gunther K, Fietkau R, Metzger U. Is radiochemotherapy necessary in the treatment of rectal cancer? Eur J Cancer 1998; 34: $438-448$. 


\section{Chapter 10}

GENERAL DISCUSSION AND FUTURE DIRECTIONS 
Research begins with defining valid and representative endpoints. Normal tissue toxicity has been recognized as an important target in pre-clinical and clinical research aimed at improvement of the therapeutic ratio. Moreover, cytotoxic treatment related mucositis, or more specific, gastro-intestinal epithelial treatment related toxicity has become an important dose-limiting factor in curative cancer treatment today. In addition, it has become a major financiall burden. Relevant objective endpoints for small bowel toxicity that can be easily assessed in the routine clinical setting were not available so far. As a consequence, the translation of promising developments obtained in pre-clinical research has frustrated clinical research at this point. Reporting improved cure rates for combined treatment strategies such as chemo-radiation is of utmost importance. The lack, however, of proper data concerning treatment related toxicity often prohibits drawing firm conclusions with respect to the real therapeutic gain.

We have developed an assay for measuring cytotoxic treatment related epithelial small bowel injury that fulfils many expectations of an ideal assay. The plasma citrulline level correllates with relevant morphologic endpoints such as damage to the clonogenic crypt cell compartment and the mucosal surface, a surrogate endpoint for the epithelial cell mass. Under steady state conditions the assay does not suffer from any confounding factor other than analytical circumstances, thus permitting individualized monitoring of cytotoxic damage to the small bowel epithelium for unrestricted clinical conditions. Except the fact that this will ease clinical research during treatment, it enables the application of the assay during follow-up of treatment. The assay is relatively cheap, easily accessible and carries no physical or emotional burden for the patient. Finally, the same assay can be applied in the pre-clinical and clinical setting facilitating translational research.

Plasma citrulline concentration has been identified as a marker for the presence of functional small intestinal enterocytes for various clinical and experimental situations such as small bowel resection, small bowel disease related with mucosal atrophy, small bowel transplantation and monitoring of treatment results. We have identified cytotoxic cancer treatment as another factor associated with alterations in plasma citrulline level. Perhaps one of the most striking observations done by us is the high reproducibility of the results for different patient populations thus underscoring the relative insensitivity of this assay for the experimental circumstances. Another important observation which may somewhat limit its application is the fact that changes in citrulline level require damage to a substantial volume of small bowel. This was obvious in the clinical study including patients subjected to fractionated pelvic and/or abdominal radiotherapy. This implies that despite the high sensitive of the assay, it will not be able to detect small volume effects of radiotherapy, irrespective of the level of damage.

Encouraged by the results obtained in the respective experiments and subsequent clinical observations, plasma citrulline concentration has been introduced by us in daily clinical practice for monitoring prospectively fractionated radiotherapy-related effects on the small bowel. These data will be correlated with prospectively obtained clinical data, indicatiwe for small bowel injury. The small bowel is a mobile organ. In order to minimize the volume of small bowel treated daily, full-bladder instructions are regularly used in clinical practice. As a consequence the dose and volume characteristics for the small bowel may vary greatly on 
a daily base. In contrast to the conventional dosimetric andlysis, which uses fixed parameters usually assessed at a single time point prior to treatment for calculation of the dose-volume-histogram parameters, the plasma cutrulline concentration may be regarded as an individual biological dosimeter. This is supported by another observation done by us. The change in plasma citrulline concentration early after initiating therapy was used to predict the maximum level of damage, as expressed by the citrulline nadir value observed during treatment. The citrulline data of 2 studies were pooled for analysis. Thus the data obtained with the same analytical method, i.e. high-performance liquid chromatography, including the 23 patients from the first clinical study in patients treated with fractionated radiotherapy and the 10 patients included in the pharmacokinetic study treated with myeloablative therapy, were pooled. In 2 patients of the former group the citrulline concentration was not available at the respective time point yielding 31 patients for this analysis. Because no serum was available before the start of treatment in group I and to correct for variations in absolute baseline citrulline concentration, we expressed citrulline level as a percentage of the baseline value. Citrulline levells obtained 1 week after baseline assessment were correlated with the nadir values (\% baseline) observed during the entire treatment period. The mean nadir citrulline value was observed on average during the $3^{\text {rd }}$ treatment week in patients treated with fractionated radiotherapy and at day 5 after the haematopoietic stem cell transplant in patients treated with myeloablative therapy. The results are shown in the figure below. A highly significant correlation was observed suggesting that the rate of citrulline decline early after the start of treatment is predictive for the eventual maximum level of damage. In other words, that the plasma citrulline concentration may be used as a predictive assay.

Figure

Correlation between the citrulline level obtained 1 week after the baseline level and the eventual nadir citrulline level observed during the treatment period. Pearson correlation: $=0.85 ; \mathrm{p}<0.001$.

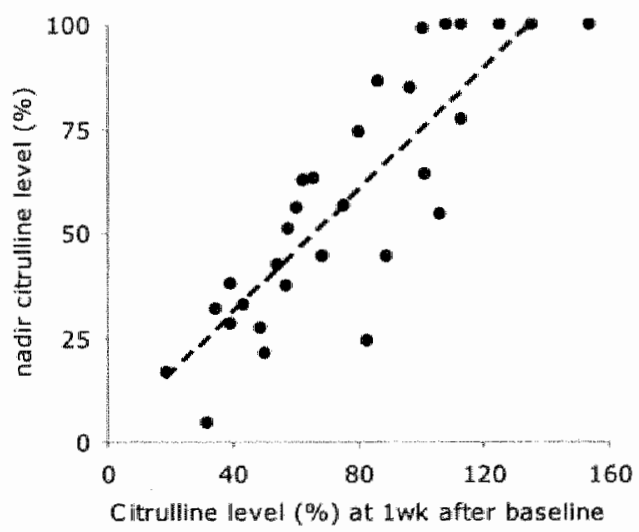


In summary we have demonstrated that plasma citrulline concentration is a radiation dose and volume dependent parameter that correlates with relevant radiation-induced epithelial small bowel morphological endpoints. The assay is easily applicable in clinical practice and the results are highly reproducible. The citrulline assay is more sensitive and more specific for measuring small bowel epithelial cell loss than currently used tests for loss of epithelial gut integrity due to cytotoxic treatment. The ease of assessment and the lack of methodological drawbacks enables monitoring during treatment and during follow up. In addition to surgery, celiac and non-celiac disease and acute cellular rejection following small bowel transplantation, we have identified cytotoxic cancer treatment as another event associated with small bowel epithelial cell loss that can be monitored by plasma citrulline. As a whole, the citrulline concentration seems to be a quantitative parameter independent of the underlying cause for epithelial cell loss. With this objective parameter the clinician will be able to assess treatment related morbidity in a standardized manner. Taken this, the methodological simplicity and the relative low costs, we suggest this assay to be the first choice for measuring and monitoring treatment related epithelial gut damage. 


\section{List of abbreviations}

ANOVA analysis of variance

ASL arginino succinate lyase

ASS arginino succinate synthetase

BM bone marrow

CIT citrulline

CPSI carbamoyl phosphate synthetase I

CY cyclophosphamide

DAO diamine oxidase

DGS daily gut score

DMF dose-modifying factor

DMS daily mucositis score

DVH dose volume hïstogram

EGF epidermal growth factor

ELISA enzyme-linked inmunosorbent assay

$\begin{array}{ll}\text { FCS } & \text { fetal calf serum } \\ \text { FgF7 } & \text { fibroblast growth factor } 7\end{array}$

GFR glomerular filtration rate

GI-tract gastrointestinal tract

GLN glutamine

GVHD host-disease

Gy gray

H\&E hematoxylin and eosin

HSCT haematopoietic stem cell transplantation

KGF keratinocyte growth factor

LAC lactulose

нM micromol/liter

OAR ornithine aminotransferase
OCT ornithine carbamoyltransferase

OMG 3-O-methylglucose

P5CS pyrroline-5-carboxylate synthetase

PAH para-aminohippuric acid

PBS phosphate buffered saline

PDG phosphate dependent glutaminase

PDV portal drained viscera

PN parenteral nutrition

PROox proline oxidase

RBE relative biological effectiveness

RHA thamnose

RT radiation

RTOG radiation therapy oncology group

SB small bowel

SBV small bowel volume

SBV30 percentage of total small bowel volume receiving at least $30 \mathrm{~Gy}$

SCT stem cell transplantation

SEM standard error of the mean

SHWAR shan whole abdominal radiation

SPT sugar permeability test

TCD T-cel depletion

TGF-a transforming growth factor-alfa

TGF- $\beta$ transforming growth factor-beta

TNF-a tumor necrosis factor-alfa

WAR whole abdominal radiation

WBI whole body irradiation

XYL d-xyllose 


\section{Summary}

Ionizing radiation is used in about half of all cancer patients. In case of abdominal malignancies, radiotherapy is applied most frequently for pelvic tumors, less frequently for para-aortic node disease, proximal abdominal disease or whole abdominal disease. As a consequence intestinal side effects are most frequently encountered in case of curative treatment for abdominal and/or pelvic malignancies with radiotherapy. The small bowel is the most radiosensitive part of the intestine and as a result is an important dose-limiting organ with regard to both early and late treatment related morbidity.

Epithelial (or mucosal) injury is an important cause of treatment-induced early intestinal toxicity and may be involved in the development of (consequential) late intestinal toxicity. Combining radiotherapy with other treatment modalities such as surgery and/or chemotherapy is increasingly used as a strategy to improve treatment outcome. This strategy has yielded superior treatment results in a variety of solid tumors, albeit treatment related acute toxicity increased as well. So far no increase in late toxicity has been reported although the relatively short follow-up does not yet allow firm conclusions to be drawn. Thus the reduction of treatment-induced epithelial injury has been recognized as an important target for improving the therapeutic ratio as well as reducing the economic burden associated with these treatment-induced sequellae. Clinical studies addressing this issue, however, are hampered by the fact that specific objective parameters, which enable monitoring of damage in routine clinical practice, are lacking.

The intestinal epithelium provides a barrier and a transport function with respect to luminal contents. In addition to absorbing food, the small bowel plays an important role in the intermediary metabolism of amino acids. Glutamine is an important substrate for small bowel epithelial cells. Citrulline is an endproduct of glutamine metabolism in these cells. Proline is another quantitatively important precursor for citrulline synthesis by these cells. The typical enzymatic profile of small intestinal enterocytes makes that citrulline is not further metabolized by the enterocyte but instead is released into the circulation, i.e. caval vein. The citrulline then passes the liver without being metabolized and reaches the systemic circulation. No other citrulline-releasing organ has been identified so far. Taken together these characteristics make that the plasma citrulline concentration is directly dependent on the production by functional enterocytes and as a result on the functional epithelial cell mass. This relationship has been confirmed in experimental animals following small bowel resection as well as in patients with celiac and non-celiac disease associated mucosal atrophy and following small bowel resections.

Small bowel epithelial atrophy is a well-known and validated endpoint for small intestinal radiation damage. Radiation damage to the intestinal crypt cell compartment and consequential epithelial denudation is strictly dose dependent. Based on this validated radiation effect on small bowel epithelium, the organ-specific metabolic characteristics of citrulline and the correlation between the citrulline level and the functional epithelial cell 
mass, we hypothetized that the plasma citrulline level can be used as a surrogate endpoint for epithelial small bowel radiation damage.

In a series of experiments in mice the effects of a single whole abdominal radiation dose on plasma citrulline level were assessed as a function of the radiation dose and time following radiation. In addition, the citrulline level was correlated with the small bowel epithelial cel:l mass as determined by means of surface line measurements. The results demonstrated a dose- and time dependent effect for the plasma citrulline level following radiation. Furthermore, the citrulline level correlated with the reduction of mucosal surface following radiation.

In another experiment the plasma citrulline level was used as one of several endpoints for measuring chemotherapy plus whole body radiation-induced epithelial small bowel damage. Keratinocyte Growth Factor was tested as a protective agent for the bowel. Plasma citrulline level proved to be a reliable and reproducible parameter for measuring epithelial small bowel injury following this type of treatment and correlated with mucosal surface measurements.

In patients with haematological malignancies who were treated with haematopoietic stem cell transplantation following conditioning with high dose chemotherapy plus fractionated whole body radiation, the course of plasma citrulline level was assessed in response to treatment. In addition, the parameter was correlated with clinical parameters for mucositis and with results obtained with sugar permeability tests as an endpoint for gut mucosal barrier injury. The citrulline level decreased significantly during and shortly following treatment and correlated with the occurrence of mucositis as assessed with validated clinical scores for mucositis. The citrulline assay was more sensitive as compared to the sugar permeability tests for the detection of mucosal injury. The time course of the citrulline level was more in agreement with known kinetics of epithelial cell loss following radiotherapy and chemotherapy. The results therefore suggested a higher specificity for the citrulline assay as compared to the sugar permeability tests.

In 23 patients treated with fractionated external beam radiotherapy for solid pelvic and/or abdominal tumors, the plasma citrulline level was measured prospectively during and following treatment. The irradiated volume of small bowel was assessed by means of a planning-CT scan. Small bowel dose and volume parametters were correlated with clinical parameters for small bowel toxicity and with plasma citrulline levels. The decrease of plasma citrulline levels was dose and volume dependent. The time pattern of the citrulline decrease correlated with the occurrence of and freedom from clinical symptoms.

In conclusion, the plasma citrulline level primarily depends on the functional small bowel epithelial cell mass, which decreases in a dose-dependent fashion following radiation. We demonstrated that the plasma citrulline level can be used as a surrogate endpoint for radiation-induced, and more specifically, cytotoxic treatement-induced, epithelial small bowel injury. Results have proven to be highly reproducible under varying experimental and clinical circumstances. The assay is sensitive and correlates with relevant morphologic and clinical endpoints for epithelial small bowel injury following cytotoxic treatment. Taken together our results and those obtained in patients with functional epithelial cell loss from varying causes, suggest that plasma citrulline level is a reliable parameter for the loss of 
functional small bowel epithelial cells, independent of the underlying cause. The sensitivity, the specificity, the methodological simplicity and the relatively low costs make this assay the first choice for measuring and monitoring cytotoxic treatment-induced epithelial small bowel injury. Its use as a predictive assay for acute and late epithelial small bowel damage is another possible application to be determined. 


\section{Samenvatting}

Ongeveer de helft van alle kankerpatienten zal vroeg of laat tijdens hun ziektebeloop te maken krijgen met radiotherapie. In geval van abdominale maligniteiten wordt radiotherapie het meest frequent toegepast bij de behandeling van tumorlokalisaties in het kleine bekken, minder frequent para-aortaal, proximaal abdominaal of totalal abdominaal. In een curatieve setting bij abdominale en/of pelviene maligniteiten zijn als gevolg bijwerkingen van de tractus digestivus het meest frequent. Dunne darm is het meest stralengevoelige onderdeel en vormt de belangrijkste dosis-beperkende factor zowel voor de vroege als laatijdige bijwerkingen en complicaties.

Epitheelschade is een belangrijke oorzaak van behandelings-gerelateerde acute intestinale toxiciteit en speelt mogelijk ook een oorzakelijke rol bij late intestinale toxiciteit. De laatste jaren vormt gelijktijdige toepassing van radiotherapie met andere behandelingsmodaliteiten zoals chirurgie en/of chemotherapie een belangrijke strategie in een poging de behandelingsresultaten te verbeteren. Deze strategie lijkt succesvol voor wat betreft de genezingskans hoewel ten koste van meer acute toxiciteit. Vooralsnog is er geen toename waargenomen van late toxiciteit hoewel de relatief korte follow-up een definitieve conclusie in deze nog niet toelaat. Reductie van epitheelschade is dan ook onderkend als een belangrijk aangrijpingspunt voor mogelijke verbetering van de therapeutische breedte alsmede een substantiele reductie van behandelingsgerelateerde ziektekosten. Klinisch onderzoek op dit gebied wordt in niet onbelangrijke mate beperkt door het ontbreken van een specifiek en objectief eindpunt voor epitheliale intestinale schade.

Het intestinale epitheel vervult benevens een barrière- en transport functie ook een belangrijke metabole functie. Behalve absorptie bestaat deze ook uit een actief metabolisme van nutrienten. Glutamine is een van de belangrijkste substraten voor dunne darmepitheelcellen. Citrulline is een eindproduct van de glutamine stofwisseling van dunne darm-epitheelcellen. Daarnaast is proline kwantitatief een belangrijke precursor woor de citrulline synthese in dunne darm-epitheelcellen. Het karakteristieke enzym-profiel van deze cellen ligt ten grondslag aan het feit dat citrulline niet verder gemetaboliseerd wordt en in de circulatie terechtkomt, i.c. de vena cava. Het vrijgekomen citrulline wordt ook door de lever onder fysiologische omstandigheden niet gemetaboliseerd en komt als gevolg in de systemische circulatie. Tot dusverre is er geen enkel ander orgaan dan de dunne darm geïdentificeerd als citrulline-releasing orgaan. Dit tezamen maakt dat de plasma citrulline concentratie direct afhankelijk is van de productie door dunne darm epitheelcellen en als gevolg van de totale functionele epitheliale celmassa in de dunne darm. Deze relatie is onder andere bevestigd bij proefdieren na dunne darmresecties en bij patienten met dunne darmepitheel atrofie op basis van coeliakie en andere dunne darm pathologie, alsmede na dunne darmresecties waarbij de plasma citrulline concentratie correleert met de ernst van de atrofie respectievelijk de resterende dunne darmlengte. 
Atrofie van het dunne darmepitheel is een lang bekend en gevalideerd eindpunt van dunne darm stralenschade. Straling veroorzaakt een schade in de epitheliale crypte met als gevolg een epitheliale atrofie welke sterk dosis afhankelijk is. Gebaseerd op dit gevalideerde effect van bestraling op het dunne darm-epitheel, de orgaan-specifieke metabole eigenschappen van citrulline en de correlatie tussen het aantal functionele dunne darm epitheelcellen en de plasma citrulline concentratie werd als hypothese gesteld dat de plasma citrulline concentratie gebruikt kan worden als surtogaat eindpunt voor epitheliale dunne darm bestralingsschade.

In een serie experimenten met muizen werd de verandering in plasma citrulline concentratie na een 1 -malige totale lichaamsbestraling gemeten als functie van de bestralingsdosis en als functie van de tijd. Daarnaast werd de citruline concentratie gerelateerd aan de epitheliale celmassa zoals bepaald aan de hand van oppervlakte-metingen. Uit de resultaten bleek een dosis-effect en een tijds-relatie voor de plasma citrulline concentratie na bestraling. Voorts werd een correlatie gevonden met de mate van stralenschade aan het epitheliale clonogene compartiment van de dunne darm en met de reductie van het darm-epitheel oppervlak.

In een volgend experiment werd de plasma citrulline concentratie gebruikt als één van de eindpunten voor het meten van door chemotherapie plus totale lichaamsbestraling geinduceerde epitheliale dunne darmschade. Keratinocyte growth factor werd in dit proefdiermodel getest als methode om dunne darmschade te reduceren. De plasma citrulline concentratie bleek een betrouwbare en reproduceerbare parameter voor het meten van epitheliale dume darmschade ten gevolge van deze behandelingsmethode en correleerde met het dunne darm-epitheel oppervlak.

Bij patienten met een haematologische maligniteit, behandeld met haematopoietische stamcel transplantatie na conditionerende chemotherapie plus gefractioneerde totale lichaamsbestraling werd het verloop van de citrulline concentratie bepaald in respons op de behandeling. Voorts werd de parameter gecorreleerd met klinische parameters voor mucositis en resultaten van suiker permeabiliteits testen als parameter voor het verlies van de barriere functie van het dunne darm epitheel. De citrulline concentratie daalde significant tijdens en kort na de behandeling en correleerde met het optreden van een mucositis van de tractus digestivus zoals gemeten met daarvoor gevalideerde klinische scores. De citrulline assay bleek sensitiever dan de suiker permeabiliteitstesten voor het detecteren van epitheliale darmschade. Het verloop van de citrulline daling in de tijd was stemde beter overeen met een te verwachten inductie en het herstel van epitheliale schade dan het verloop van de suiker permeabiliteitstesten. Deze resultaten suggereerden een hogere specificiteit van de citrulline assay.

Bij 23 patienten die behandeld werden met gefractioneerde radiotherapie voor soliede tumoren in het kleine bekken en/of abdomen werd in een prospectieve studie het verloop van de citrulline concentratie bepaald tijdens en na de behandeling. Het volume dunne darm in het bestralingsveld werd bepaald aan de hand van een planning-CT scan. Dosis en volume parameters voor dunne darm werden vervolgens vergeleken met klinsche parameters voor dunne darm toxiciteit en met de gemeten plasma citrulline concentratie. De daling van de citrulline concentratie was afhankelijk van de bestralingsdosis en het volume 
bestraalde dunne darm. Het patroon van de citrulline daling in de tija correleerde met het optreden, respectievelijk het ontbreken wan klinische symptomen.

De plasma citrulline concentratie is primair afhankelijk van het aantal functionele dunne darm epitheelcellen. Dit aantal vermindert na bestraling als functie van de bestralingsdosis. Uit ons onderzoek is gebleken dat de plasma citrulline concentratie gebruikt kan worden als surrogaat eindpunt voor bestraling-, en in engere zin cytotoxische therapie, geinduceerde epitheliale darmschade. De resultaten bleken in hoge mate reproduceerbaar onder verschillende experimentele en klinische omstandigheden. De assay is sensitief en correleert met relevante morphologische en klinsche eindpunten voor epitheliale dunne darmschade na cytotoxische behandeling. Onze resultaten en die verkregen bij patienten met andere oorzaken voor verlies van functioneel dunne darm epitheel suggereren dat de plasma citrulline concentratie een betrouwbare parameter is voor het verties van functioneel dume darm epitheel, ongeacht de oorzaak. De sensitiviteit, de specificiteit, de eenvoudige methodologie en de relatief lage kosten maken de citrulline assay de eerste keuze voor het meten en monitoren van cytotoxische behandeling geinduceerde epitheliale dunne darm schade. Het gebruik ervan als een predictieve assay voor acute en late epitheliale dunne darm schade is een mogelijke nader vast te stellen toepasssing. 


\section{Dankwoord / Acknowledgement}

"En, wanneer gaat het lukken?". "December". Een beproefd antwoord gedurende enkele jaren. Menigeen was nu dan ook in dubio over de oprechtheid van "2 December". Ik kan voldaan terugblikken op een mooie reis met vele tempowisselingen en mede daardoor iets langer dan gepland, maar een blijvende uitdaging om te komen op de plaats van bestemming. Velen hebben mij gedurende kortere of langere tijd tijdens deze reis begeleid en bijgedragen aan de volharding deze te voltooien. Wetende dat ik nimmer compleet kan zijn iedereen apart te noemen wil ik via deze weg eenieder bedanken die op enigerlei wijze bijgedragen heeft tot het bereiken van de plaats van mijn bestemming: de aula van de Universiteit Maastricht.

Een aantal van mijn reisgenoten wil ik speciaal bedanken.

Philippe Lambin, mijn eerste promotor. Philippe, jouw analyserend en probleem-oplossende vermogen hebben mijn onderzoek vlot getrokken op een moment dat dit dreigde vast te lopen. Jij bood mij de ruimte en schonk mij het vertrouwen om een herstart te realiseren.

Maarten von Meyenfeldt, mijn andere promotor. Maarten, het is al enige tijd geleden dat je mij overtuigde om toe te treden in de wereld van het metabole onderzoek. De nachtelijke uren bij de laserprinter om een KWF-project in een goed format voor I april afgedrukt en verstuurd te krijgen zullen mij bijblijven.

Mick Deutz, eén van mijn co-promotoren. Mick, jouw wetenschappelijke gedrevenheid was uitermate besmettelijk en voor mij een belangrijke drijfveer om af te maken waar ik aan begonnen was. Jij wist me uiteindelijk te overtuigen om niet één, maar twee keer van proefdiermodel te veranderen.

Brad Wouters, mijn andere co-promotor. Brad, je uitermate kritische beoordelingen van mijn manuscripten waren leerzaam en stimulerend.

Gabrie ten Have. Jouw organisatorische talenten waren voor mij van onmeetbare waarde, niet het minst op die momenten tijdens mijn spreekuur als bleek dat er nog voorbereidingen getroffen moesten worden voor de komende experimenten. Jouw toegewijde zorg voor de proefdieren was mij een groot voorbeeld.

John and Blanche. You were my bedside teacher at the lab. Your incredible scientific devotion and discipline were the insurance for the success of my experiments. I was never able to keep up with the circadian rhythm that both of you exposed during our lengthy experiments.

Jack Cleutjens. Jouw geduld en perfectionisme bij het schrijven van een programma voor de quantimet hebben mij de moed en energie geschonken om al die honderden coupes tot op de micrometer nauwkeurig te meten. 
Regina Beets-Tan. Gaarne wil ik je danken voor je hulp bij het onderscheiden op CT van dunne en dikke darmen.

Hans van Eijck. Jouw scherpe analyse van de opwerking van mijn materialen is behalve een voorbeeld uiteindelijke ook een statistische zegen gebleken.

The members of the promotion committee

Prof. P.Soeters, Prof. M.Hauer-Jensen, Prof. F.Ramaekers, Prof. H.Schouten, and Dr. MC. Vozenin. I would like to thank you for spending your valuable time reading my thesis and for your critical review and stimulating remarks.

Mijn collega's van MAASTRO clinic.

Gaarne wil ik jullie danken voor jullie aanhoudende interesse, voor jullie bijdrage aan mijn klinisch onderzoek en voor de opvang en waarneming van mijn klinische taken ten tijde van mijn laboratorium-avonturen.

Een speciaal woord van dank wil ik richten aan Jos de Jong, mijn opleider en degene die mij stimuleerde om aan deze reis te beginnen.

De "ondersteuning van Maastricht" wil ik bedanken voor hun toewijding bij het inplannen van mijn patienten voor de "Citrulline studie" en voor al jullie invalbeurten bij de afname van bloed, het bezorgen van het benodigde ijs, het bezorgen op het lab en al die andere zaken die ik nu vergeet. Zonder jullie hulp waren mijn curves incompleet geweest.

De "laboranten van Maastricht" wil ik bedanken voor hun bijdrage aan de extra planningen van mijn patienten in de "Citrulline studie" en speciaal Marlies Granzier. Vivian Braeken wil ik bedanken voor de extra uren bestralingstijd.

Hans Beijer. Jouw wil ik danken voor je briljante ideëen bij het vervaardigen van alle jigs voor het bestralen van mijn proefdieren.

Mijn mede-auteurs:

Regina Beets, Martijn Berger, Nicole Blijlevens, Jack Cleutjens, Mick Deutz, Peter Donnelly, Marlies Granzier, John Gueulette, Philippe Lambin, Maarten von Meyenfeldt, Ben de Pauw, Dirk De Ruysscher, Ariane Vanclée en Brad Wouters voor jullie stimulerende bijdrage in het tot stand komen van de manuscripten. 


\section{Mijn patienten.}

Gaarne wil ik mijn patienten danken die bereid waren om wekelijks gedurende de behandeling en bij de controles na de behandeling in alle vroegte, nuchter op mijn spreekuur aanwezig te zijn om na 15 min te hebben gerust, $2 \mathrm{ml}$ bloed af te staan. Jullie motivatie om aan het onderzoek mee te doen was eensluidend: "als" we andere mensen hiermee kunnern helpen...". Nooit eerder werd me zo bewust wat dit betekent.

Mijn ouders en mijn broer voor hun steun en vertrouwen in mij de laatste 45 jaar.

Nicole. Thank you for being my private English teacher.

Yvonne, Maurice en Romy. Jullie zijn, min of meer ongevraagd, samen met mij begonnen aan deze reis. Hoewel jullie vaak alleen verder moesten reizen is telkens op mij gewacht zodat we de reis weer samen voort konden zetten. Vanaf nu gaan we weer altijd samen verder. $\mathbb{k}$ dank jullie voor de onbegrensde krediet en het eindeloze geduld met mij. Ik hou van jullie. 


\section{Curriculum vitae}

Ludovicus Catharma Hubertina Wilhelmus Lutgens werd op 20 maart 1960 geboren te Maastricht.

In 1978 haalde hij zijn Atheneum-diploma aan het St. Maartencollege te Maastricht. Aan de Katholicke Universiteit Nijmegen behalde hij in 1986 zijn artsexamen.

Na een AGNIO-schap radiotherapie in het Radiotherapeutisch Institunt Limburg (RTIL) volgde hij van 1987 tot 1991 in hetzelfde instituut de opleiding tot radiotherapeut-oncoloog, opleider Dr. J.M.A. de Jong.

Na zijn opleiding werkte hij gedurende 1 jaar als radiotherapeut-oncoloog in het Radiotherapeutisch Instituut Friesland (RIF) en vanaf 1992 is hij werkzaam als radiotherapeut-oncoloog in het Radiotherapeutisch Instituut Limburg, tegerwoordig MAASTRO clinic. 